Fitch Eduardus

De hrgoncutarum reditu quaestiones seiectae

BL 820 As F5 


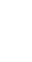
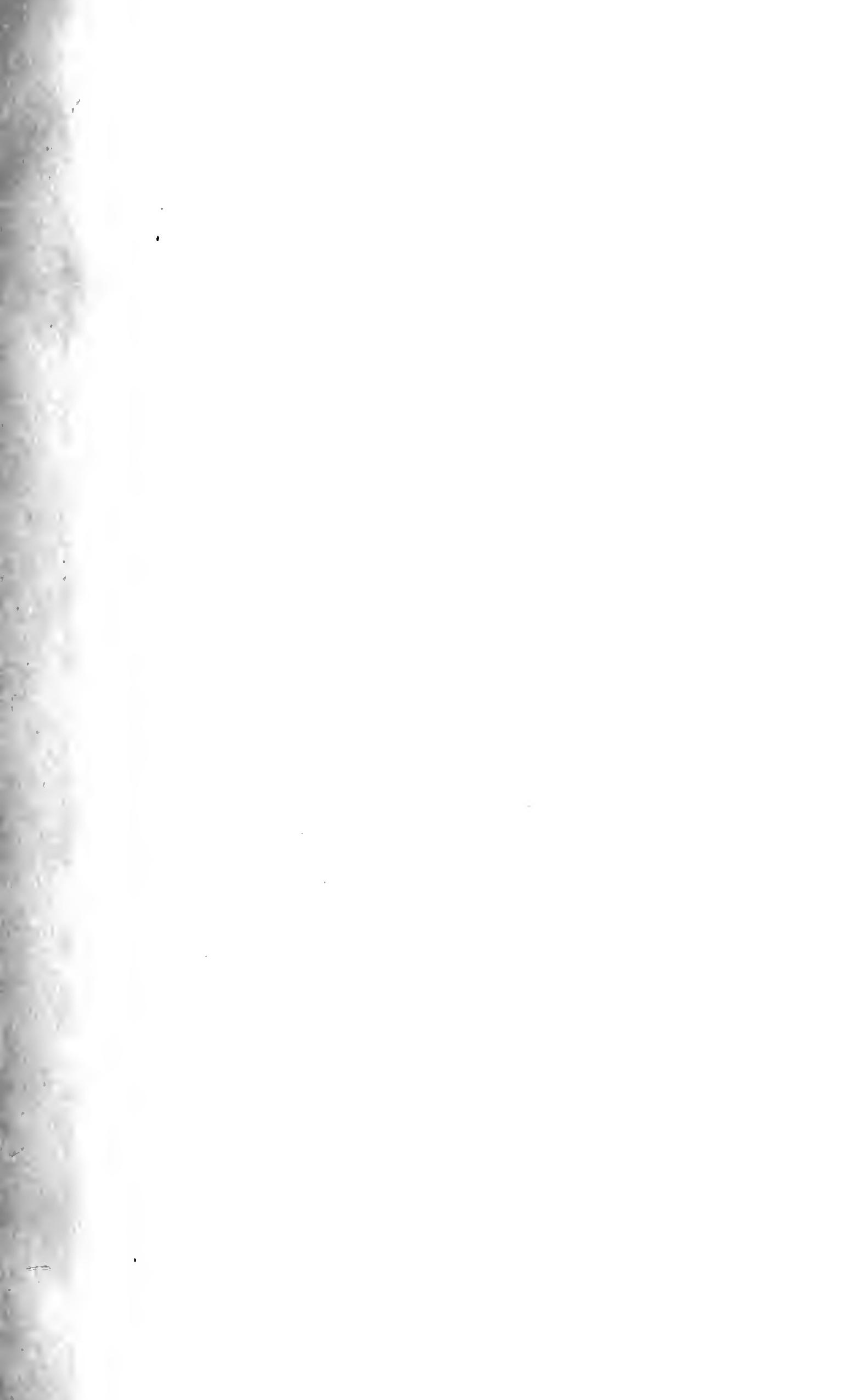
Digitized by the Internet Archive in 2010 with funding from University of Toronto 
DE

\title{
ARGONAVTARVM REDITV
}

QVAESTIONES SELECTAE.

\author{
DISSER'I'ATI0 INAVGVRALIS \\ QVAII
}

AMPLISSIMI PHILOSOPHORVM ORDINIS

CONSENSV ET AVCTORITATE

IN

ACADEMIA GEORGIA AVGVSTA

AD

SVMMOS IN PHILOSOPHIA HONORES

RITE CAPESSENDOS

SCRIPSIT

EDVARDVS FITCH.

GOTTINGAE 1896.

OFFICINA ACADENICA DIETERICHIANA TYPIS EXPRESSIT.

W. FR. KAFSTNLR. 
The discertetione probanda ad ordinem rettulit V. de Wilatnowitz-Moellendorff, Prof.

Examen rigorosum habitum est a. d. III. kal. Iul. a. h. s. XCVI. 


\section{VDALRICO DE WILAMOWIIZ-NOELLLENDORFF}

s. 
1

707697 
De Argonantarum reditu disserturo fabula se offert enins memoria apud reteres iam antiquissimis temporibus cognita fuit. Nihil quidem-apud Homerum de illa expeditione comperimus nisi Imnonis ope salvos eos rediisse ab Aeeta ${ }^{1}$ ). Tum in Hesiodeis ${ }^{2}$ ) exstitit mentio reditus per Phasim et Oceanum facti. Etiam Mimnermus quem propter aetatem cum his principibus consociare licet reditum Iasonis vellusque aureum rednctun cecinit ${ }^{3}$ ). Quae testimonia id potissimum pilam faciunt hanc fabulam vel priscis temporibus et bene notam et sine dubio in poetarum ore versatam esse: quid quod Argo Homero $\pi \tilde{\partial} .5 t$ p.ś2.005\%. appellatur. Iter Iasonis et apud Hesiodum et apud Nimnermun disertis rerbis cum Oceano coninngitur. Oceanus antem, quis et ubi esset, pront quisque inter veteres notitiam orbis terrarum latiorem artioremve possideret, aliter intellegebatur. Quare mirum non est, crm poetac primis temporibus domum Aeetae, prope Oceanum sitam, ab Iasone petitam reditumque inde factum esse finxerint, ea quoque quae de reditu ab Oceano narrabantur in cadem inconstantia versari. Quae tam varia per multa saecula scriptores ant versibus ant solnta oratione de illo reditu protulerunt, ea nondum omnia percensebo. Id tartum praemonendum est non solum de fabula Graeca agi, sed etiam de terrarum mariumque sensim aucta cognitione.

1) Od. ข. $69-72$.

2) In scholiis Apollon. IV 259. 284.

3) Frag. 10. 
Aredit quod practer Pindari Pythicum IV. nullum ipsi manilus tenemus carmen quod saeculo tertio antiquius est. Habrous antem carmen Apollonii Rhodii epieum, cuius fliartus liber reditum Argonautarum multis enarrat. 'Tum scholiorum eratia etiam operae atque diligentiae fructibus utimur ynam grammatici reteres in fontibus Apollonii exploramlis collocaverunt, unde quac ratio inter Apollonium et seriptores priores intercesserit, multis in rebus statui potest. Recentiores quicumqne Argonautarum res celebrant phurima Apollonio debent. Quam ob rem in hoc carmine. yuod ad nos attinet, summa totius memoriae continetur. (Quae cum ita sint, ipsa rei natura ah Apollonio initium cilpi iubet. et tali ratione totam quaestionem de Arconaturum reditn tractare mihi aliquamdin propositum erat. (Quod cum nune quidem ita ut faciendun esse intellego al finem perducere nondum valeam, haec capita quasi initia operis integri promere constitui.

Primum igitur via qua Argonantae secundum Apollonium redeunt eximinanda est. Ac totam quidem narrationem tribus ex partibus constare, quae potissimum ad tres regiones pertinent, mihi certum videtur. Finxit enim poeta heroes Ponto relicto per Histrum fluvium usque ad Cauliacum montem navigantes, inde per alteram Histri partem, qui illic dividatur, in mare Adriaticum derenisse. Sic conficitur pars prima itineris.

Dei propter Apsyrtum interfectum irati Argonautas, viam in Thessaliam iam ingressos, quo volebant statim pervenire retant. Tempestatibus depulsi retro in Eridani ustium vebuntur. Hinc contra aquam cursum tenent usque ad Rhodanum fluvium, per quem descendentes in mare quod est ad vecasum ab Italia versum evadunt. Secundum Italiae uram et praeter Thrinaciam insulam (i. e. Siciliam) navigantes denique ad Phaeaciam (i. e. Corcyram) appellunt. Unde pars itineris tertia initium capit, namque denuo procellae reditum in Thessaliam interpellant. Profecti enim ex insula Phaeacum aliquamdin prospere procedunt: brevi rero a tempestate ingenti ad Syrtes et oram 
Libycam deferuntur, unde nave umeris sullata ad mare Tritoniacum pedibus perveniunt. Inde Tritunis dei ope via per Creticum et Aegaeum mare facile et sine erroribus conficitur.

Hano mirabilem reditus rationem cum in universum inspiciamns, nulla ratione singularum rerum lialbita, facile apparet quam viam Apollonius in narratione sua instruenda ingressus sit. Tres regiones, quae inter se late distant neque quidquam eommune habent, violenter in unam reditus rationem complectitur et conglutinat. Si enim iter per Histrum et Adriam fit, nihil est cur Argonantae ad mare Tyrrhenum perveniant. Rursus eisdem per mare Tyrrhenum redcuntibus nulla est ratio cur in intimum Adriae sinum penetrent. Porro fabulosus ille ad mare Tritoniacum aditus ad rationem reditus respicit quae nequaquam cum via altera utra circa Italiam facta conspirat. Itaque narratio Apolloniana ita intellegi non potest ut quaeramus quomodo res ant verisimiliter ant simpliciter aut eleganter exponi potuerit.

Iam primum monendum est, id quod satis superque notum est, Argonautica Apolloniana ea aetate orta esse, cum carmen epicum non amplius ex copia ubertateque ingenii poetici profluebat, atque cum Vergilio potins quam cum Homero Apollonium componendum esse. Sed haud scio an poeta Rhodius per hane comparationem nimis lindetur. Nam cum opus esset utrumque multa quile sibi deessent per doctrinam supplere, Romanus poeta doctrinam (ut ita dicam) perdonuit et suis usibus facile obsequentem reddidit, Graceus autem multa ac diversa coacervavit ${ }^{1}$ ) et maxime in rebus geographicis importunum omnia in nnum complectendi, res diversas ad concentum consensumpue redigendi studium ostendit. Nam cum poeta doctus materiam ingentem ante oculos haberet atque de iisdem rebus

1) In universum sententiam tuli. Sane librum III. Argonauticarum haud recte ita depresseris: item Vergilius in libro Aencidos III. ad peiora delapsus est. 
Jarratimenlas inter se vehemented repugnantes pari auctmitatresse anmadrerteret, satis non habuit — id quod veri guetare ast - optinis selectis imaginem mam atque intergan depingere. Inmo vero ubique patet studium fabularmm contaminamlarum, guod dissimmlare poetae non contigit. forrtasse etiam curae non fuit $\left.{ }^{1}\right)$.

Potissimum ex Argonautarum reditu exempla huius stmdii peti possunt. Supra enim momi tres esse regiones ${ }^{2}$ ) quate in mins reditus fines coartatae smont. (Qnod ad Librim attinet, mirum esset si hase filmlac pars silentio prictermitteretur quate iam saceulo ante Christum quinto, testihs: Herodute et Pindaro, pervulgata, etiam sacenlo sepitime, ut ducet illa de ('rrenis conditis memoria, nota fuit. 'Tum rersus illi () droseae ${ }^{3}$ ) effecerunt ut seriptores recentiores, verilupuiorum rerumque nirabilinm studiosi, multa Argonantarum restigia in mari Tyrrheno invenirent. 'I'estimonia tam fracelara Argonatas vel Adriam adiisse sane desunt: scel tamen inonumenta ae memoriam luiusmodi in his regionilus exstitisse in dubium vocari non potest ${ }^{4}$ ). Sed de his mox, cum de Callimacho agam, dicendum erit.

Quas tres reditus species in unum redigere, quam ardum fuerit. preta ipse semel discrte profitetur. Postquam enim Argemantac in Adriam venerunt, iam itinere uscue ad insulam Hyllensium prospere confecto exclamat ]rocta $\left.{ }^{5}\right)$ :

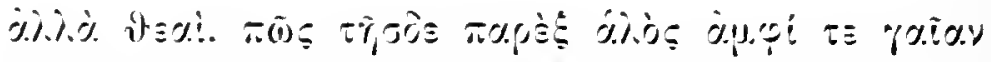

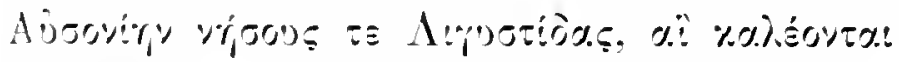

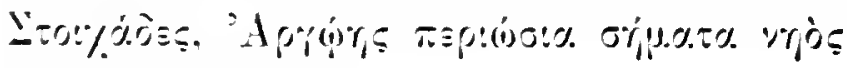

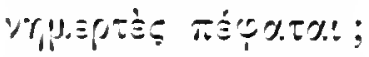

Manifeste confitetur poeta quae sit ratio sna carminis in-

1) Verbi gratia in $1 \mathrm{~V}, 610$ serrl.

2) Libyam, maria Tyrrhenum, Adriaticum.

3) y. $69-72$.

4) Quae memoria unde nata sit exposuit O. Müllerus Orchomenos 1. 292 .

5) $1 \mathrm{~V}, 552 \mathrm{seq}$. 
struendi: suo enim iudicio non licitum csse insignia Argonautarum restigia quae sint in mari Italico silentio practermittere. Vides igitur his in versibus suturam (ut ita dicam) quae aperte monstret ubi et quomodo duae res diversae et inter se discrepantes commissae sint. Hie quoque, ut supra factum est, conclusionem ex ipso carmine efficimus, etiam si non inquirimus quae vel Callimachus vel Timaens vel alius quispiam de Argonantarum reditu scripserint. Primum igitur Apollonius unus audiendus est, atque hic ipse satis docere videtur a versu 552 aliquid novi incipere. Quae cum ita sint, primum est in carmine interpretando eam partem examinare quac iter a Ponto usque ad Adriam factum enarrat, tum de fontibus, unde poeta hauserit, disserere. Sic etiam apparebit utrum conclusiones, quae ex carmine in universum inspecto effectae sint, confirmentur an redarguantur.

\section{I.}

\section{DE REDITV PER HISTRVM SECVNDVM APOLLONIVM.}

Initium carminis interpretandi a versu libri quarti 254 capiamus, ubi Iaso ea quae Phineus de alio reditu vaticinatus erat repente in memoriam sociorum revocat. Heroes enim a Colchis fugientes, itinere trium dierum iam confecto, ad litora Paphlagonum appulerunt. Iaso autem, qui verborum Phinei memor est, haec alia navigatio quomodo instituenda sit nequaquam scit. Statim suadet Argus, Phrixi filius, ut per Histrum egressus petatur, exponens quae sit viae natura ${ }^{1}$ ). Faustum omen consilium Argi corroborat et riam ad Histri ostium monstrat ${ }^{2}$ ). Sequitur descriptio itineris a Ponto per Histrum usque in Adriam facti ${ }^{3}$ ).

1) $257-293$

2) $294-302$.

3) $303-337$. 
Itaque res duas uno sermonis contextu compreliensas tenemus, dico viam quam Argus exponit et viam quam Argonatitice revera conficiunt. Licet igitur exspectare has duas inter se concinere, propterea quod poeta fingere videtur Argonaintas il quod Argus suasit perfecisse. Nihilominus inest in verbis, sicut tradita sunt, discrepantia, in eo quidem quod Argus rem aliter atque exspectes exposuit. Quze cum ita sint, eam narrationis partem ${ }^{1}$ ), de yua mulla fée dubitatio est, examinabo, tum ad illam Argi orationem interpretandam aggrediar.

Ac prinum quidem et Argonintae et Colchi qui eos persecuntur ad Histrum cursum tenent. Hister antem, qui insulan triangularem cireumfluit, per duo ostia ayuam in milre mittit. Illud ostium quod est sub imam insulae partem duce Apsirto Colchi intrant et prius quam Argonautae usifue ad intimum sinum maris Ionii perveniunt ${ }^{2}$ ). Ubi sit mare illud, ex rersihns $32 \bar{r}$ seqq. satis apparet.

Ego quidem non intellego qua ratione interpretandi (ierhindus ${ }^{3}$ ) et Merkelius ${ }^{4}$ ) usi sint, qui de parte oecidentali Ponti Euxini lie agi putant. Seholia enim ad versum $30 \mathrm{~s}$ adscripta niliil afferunt quod huie opinioni faveat 5 ). Neque apud reteres opinio ista pervulgata erat, id quod panlo infra demonstrare conabor. Sed redeamus ad ipsam narrationem.

Argonantae per alterum Histri ostium, a septemtrione Pences insulate situm, riam tenent. Thracum Scytharum Sigrnnorum terram, Angurum montem praetervecti, ad scopulum Cauliacum perveniunt, ulji Hister in duas partes scinditur: tum campo Laurio praeternarigato mox a Colchis obsidentur qui in mare Saturnium egressi sunt. Unde hic egressus factus sit, e rersibus $307-308$ colligi potest, ulbi dicitur Colchos cervice terrae traieeta usque ad in-
1) $302-33 \%$
2) $30 \mathrm{~s}$.
3) Rem tractavit Gerhardus in Lectionibus Apollonianis pag. 81 .
4) ad Apollonii B 745 .
5) cf. etiam Schol. Eurip. in Hippol. 786. 
timum Ionii maris sinum penetrasse, Argonautas pracrenientes. Poeta igitur rem sic excogitavit quasi pars intima sinus Ionii, quem in locum Colchi iam pridem penetraverant, illud mare quod est $\mathrm{K}_{\text {povin }} \not \lambda \varsigma^{1}$ ) attingeret. Itaque dicit Colchos in mare Saturnium ingressos exitum Argonautarum, qui iam flurium descendant, praecidisse, appulisse autem hos ad dnas Dianae insulas quae solae nondum a Colchis occupatae essent.

Sic rem enarrat Apollonius neque dubium esse potest quid voluerit. Recte explanat scholiasta ${ }^{2}$ ), sic dicens:

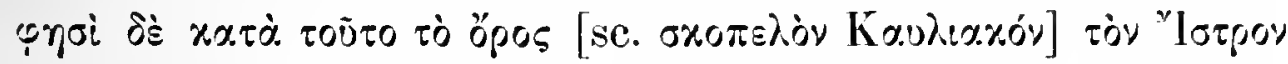

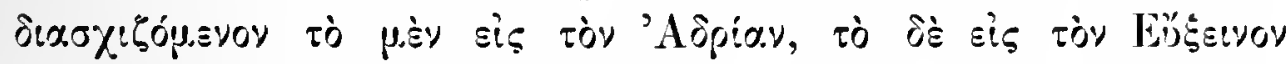

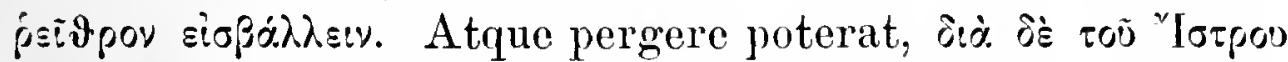

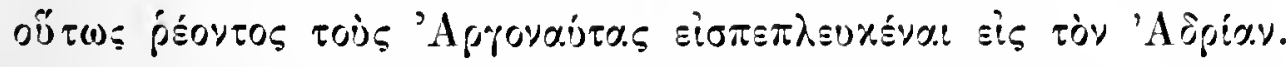
Iam ratione satis certa effici potest unde Apollonius suam locorum notitiam sumpserit. Nam de Anguro monte scho-

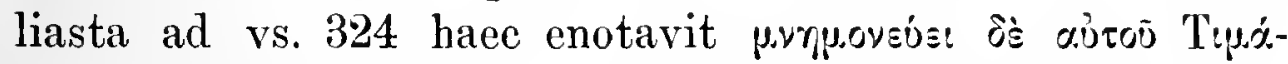

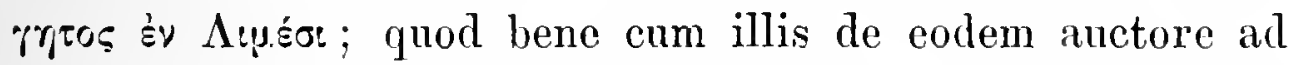
vss. $259,284,306$ adscriptis consentit. Tum Hellanicus gentis Sindorum mentionem fecit ${ }^{3}$ ). Unde concluseris scriptores rerum geographicarum plurima de his regionibus contulisse. Exstat autem in his unum singulare quod etiam naturae Apollonii maxime consentaneum est. Nam in versu 327 de mari Saturni agitur, quod suspicari licet illam maris partem esse quac Histri ostio proxima est. In sequentibus antem rem panlo aliter depinxit. Mentio enim Hylli fit ") qui coloniam Phaeacnm in mare Saturnium deduxerit et nomen genti Hyllensium insulas prope Illyriam habitanti dederit. Sed quoniam Hyllenses partem maris

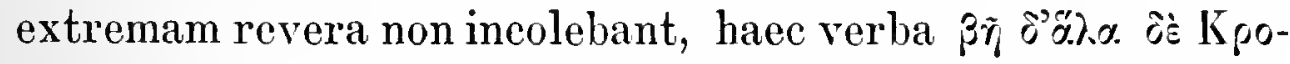
ving potius in universum accipias et totum mare quod Corcyraeis ad septemtriones versum iacebat intellegas. Itaque mare Saturnium mari Ionio aequiperare licet. Nunc in
1) 327 .
2) ad IV, 324.
$3)$ in' schol. ad IV, 321.
4) 548 . 
mentem renit poetam, qui rerum maxime reconditarum studiosissimus est, etiam hic appellationem raram et fere ublivioni datam retinnisse. Quae opinio scholiorum testimonio confirmatur. Vide argumenti libro IV. praefixi ini-

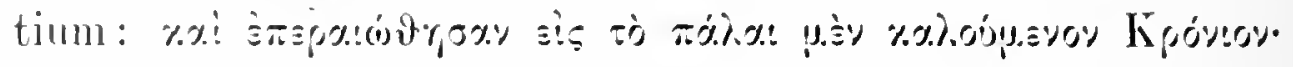
Haud levis momenti est quod Aeschỵus ${ }^{1}$ ) idem mare peśra.

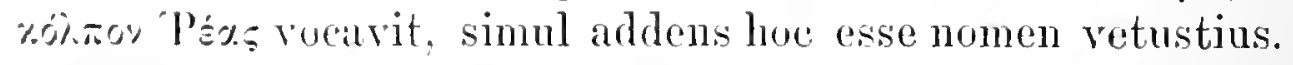
Exstabant igitur priscis temporibus appellationes huius maris a nomine ra] Saturni vel eius coniugis ductae. Qno spectent talia indieant testes aliquot ut recentes ita hand spernendi.

Ac prinum Plinins ${ }^{2}$ ) de mari septentrionali remotissimo disserens halec dicit: A Tyle unius diei navigatione mare concretum a nommellis Cronium appellatur. Tum simili ratione in Orphicis 1085 mare Cronium hand procul ab Hrperboreis situm commemoratur. Denique eandem memoriam apud Iionysium, quem Periegeten rocamns, in rs. 32 et in seholiis ad h. r. invenies. In his quidem mihi videor priscam rim ac sententiam eius nominis cogmoscere quod ibi mari Ionio inditum est. Nam mare Cronium erat sine dubio illud ignotum ae inexploratum quod lomines adire non solebant. Qnae appellatio quomodo ad mare Adriaticum pertinere possit. magis apparebit. si speciem orbis terrarum quam Homeri aetate homines sibi fingehant animo cogitareris. Nam de terra continenti, cuius Graccia et Italia et Iberia partes essent, nulla omnino fama cireumferebatur. Erant hae quasi insulae quas maria ingentia circumfluerent ${ }^{3}$ ). Atque Herodoto teste I 163 Phocaei primi Adriam exploraverunt. Unde percipis priscis temporilus has regiones inexploratas esse ac din intentatas. Ad hane pristinam aetatem, qua intimus Adriae sinus remotissimus erat et quasi tenebris involutus, hand dubie referenda est hace appellatio quae gradatim propter auc-

1) Prom. Vinct. 837 .

2) N. H. IV, 104. cf. etiam IV, 84 seq.

3) Vide Bergeri disputationem in libro Geschichte der Wiss. Erd. kunde der Griechen, pp. 22 serq. 
tam orbis terrarum cognitionem in mare ultra 'Thulen removebatur. -

Iam ad illam Argi vaticinationem aggrediamur. Eo quidem non offendimus quod poeta epieus Argum viam exponentem introduxit. Habebat enim ante ocnlos exemplum Homeri praeclarum qui iter Ulixis ad inferos factum ita narrat ut prius Circe omnia quae sint facienda describat. Hic autem de singulis eius itineris quod Argus profert partibus diligentius inquirendum est: multa enim quae arto nexu vincta non sunt in unum poeta comprehendit.

Ac primum quidem animadvertimus haec verba Argo, Plirixi et Chalciopes filio, attribui, qui inde a puero apud Colchos educatus, quam scientiam e tabulis quibusdam illic servatis desumpserit, nunc Argonautis enmitiat. Quamobrem sic de Graecis et Graecia loquitur ut in vs. 257 öp.s, 292

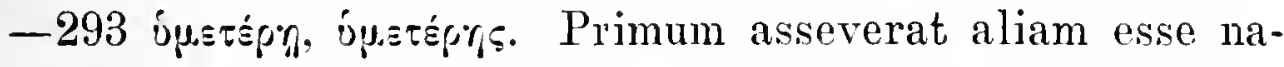
vigationem, quam sacerdotes Thebarum Aegyptiarum monstrassent. Tum rem ipsam non statim explicat sed permultis verbis antiquitatem Aegypti extollit. Deinde declarat quomodo factum sit ut sapientia sacerdotum inter Colchos pervulgaretur : regem enim Aegyptiorum ${ }^{1}$ ) fuisse qui exercitu magno totam Europam Asiamque emensus sit multasque urbes condiderit: quarum in numero Aeam esse: filios illorum priscorum (i. e. Colchos) tabellas scriptas servasse in quibus omnes vias terrae marisque inessent, in quas rex ille pervenisset. Iam demum Argus, his omnibus praemissis,

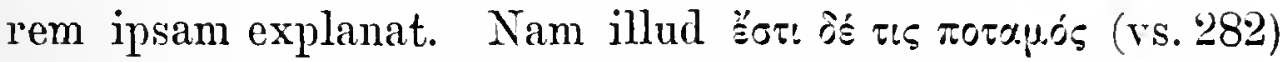

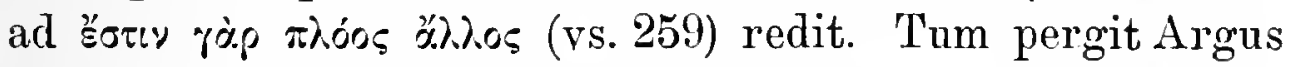
in fluvio describendo: primum eum esse cornu Oceani, et latum et profundum; nomen eins Histrum, fontes ultra Boreae flatum in montibus Rhipaeis esse: aliquamdiu uno alveo profluentem terram immensam secare, quando autem ad

1) Herodotus primus (II 102) haec narravit. Quae Eustathius ad Dion. Per. I p. 80 de tabellis profert, ad Apollonium referenda sunt. Praeter haec nulla harum tabularum memoria exstat neque dubium essc videtur quin ipse Apollonius e sua potius quam ex heroic a consuetudine ea commentus sit. 
fincs Thracum Scytharumque appropinquarit in duas partes dividi. Sed priuspuam an difficiliora aceedamus, in his panlisper insistamus.

Qua quidem de causa poeta hace de Aegyptis et Colrhis congesscrit, nisi sic de Colchorum origine nos certiores ficere studeret (qua de re adhue tacnerat), haud perspicio. 'Tum vides colore quam prisco ac vetusto totam orationem affecerit. Nam mentio montium Rhipaeorum, qui ultra Boream siti sint, ad opinionem locorum spectat quae vel Herodoti aetate sublata erat. Deinde quod Hister cornu Oceani vocatur, satis mirum est. Primo enim obtutu cogites poetam indicare flumen ex Oceano derivatum esse. Nam \%śpr.s saepius de fluvio vel fluvii ostio dicitur. Vide quaeso Pindari frag. 201, Thue. I 110. Fieri igitur potest ut seriptor aliquis, sicut nomnulli Nilum ${ }^{1}$ ) et Phasim, etiam Histrum Uceani cornu esse opinatus sit, per quod iter feeissent Argonantae. Sive enim per Histrum sive per Tanaim sive per Phasim via petitur, una eademque est ratio geographica. Nam apud veteres opinio fluvios ingentes eum Oceano iunctos esse omnino non ignota erat. Sed cum in sequentibus fontes Histri in montibus positos esse invenias, patet poetam opinionem istam de Histro non amplius respexisse sed satis habuisse ornamenti causa vestigia memoriae fere oblivioni datae servare.

Iam ad difficiliora nos accingamus, nam versus 289293 dudum crux interpretum sunt. Haeremus enim in hae perobscura imperfectaque descriptione. Nam nulla mentione brachii Pontum petentis facta primum de mari Ionio, tum de aliquo Trinacrii maris sinu audimus. Quare Ger-

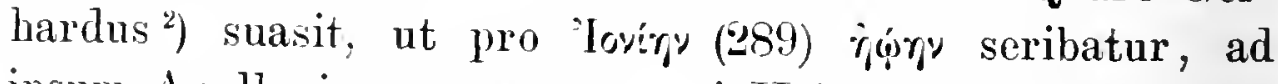
ipsum Apollonium provoeans, qui II 745 sic:

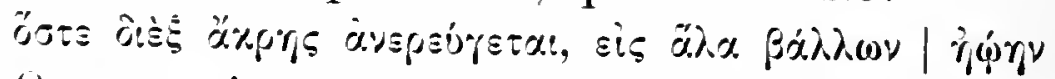

Quam coniecturam etiam Waltherus ${ }^{3}$ ) nuper probavit. Sed ne hoe quidem concesserim, quod rir doctus ille ex

1) cf. Herod. II 73 : Diod. Sic. I 37.

2) In Lect. Apoll. pp. 80-81.

3) De Ayollonii Rhodii Argonaut. velus geograpleicis : pp. 61, 83 seqq. 
isto versu certa ratione collegisse sibi visus est. Sic enim versus intellegendus est ut vox rigry praedicativa sit. Inter se differunt mare arientale et mare ad orientem spectans. Accedit quod scholiasta ${ }^{1}$ ) sic sensum verborum exprimit:

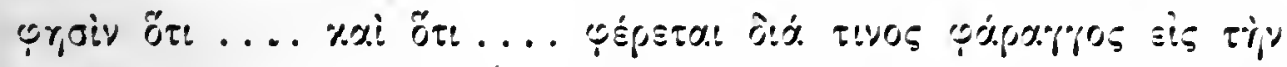

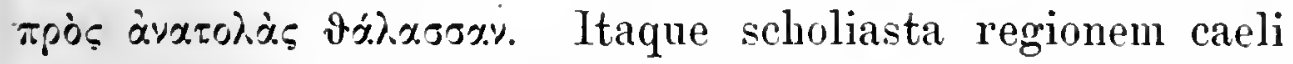
potius quam nomen maris proprium intellexit. Idem loquendi genus Herodotus usurpavit (IV 100), ubi de Scy-

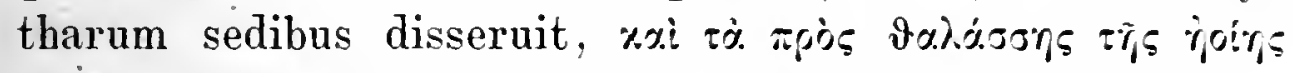
vépovrx.. Quae verba ad totum mare Ponticum (sicut nonnulli commentatores autumant) pertinere non possunt. Nani Herodotus inde ab Histri ostio incipiens (capp. 99-100) oram maris usque ad Tanaim depingit. Primum de parte inter Histrum et Carcinitin, tum de paeninsula cuius partem infimam Tauri incolunt, deinde de locis supra Tauros sitis usque ad Bosporum Cimmerium, denique de regionibus ab occidente Bospori paludisque Maeoticae nsque ad Tanaim

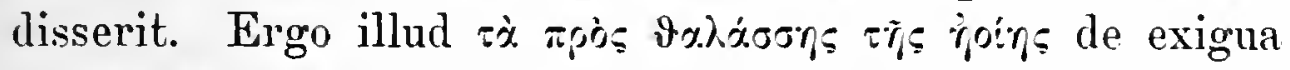
Ponti parte ad orientem spectante dicitur, neque de nomine Ponti proprio hic agitur ${ }^{2}$ ). Mittamus igitur illam Gerhardi coniecturam.

Iam aliam viam alii monstrant, qui dicant Ionium mare partem occidentalem Ponti Euxini nuncupatum esse ${ }^{3}$ ). Quae via difficultatibus non caret, ea potissimum causa quod ceteroquin apud Apollonium sicut apud ceteros 'Iovin

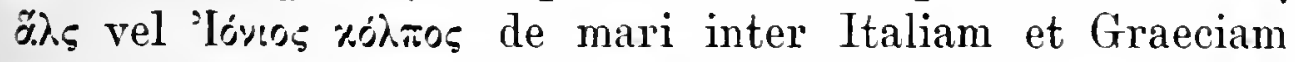
intellegitur. Duo alii loci sunt, IV 308. 632. De hoc (IV 632), qui in dubium rocari non potest, primum aganius. Poeta dicit Eridanum fluvium in mare Ionium effluere, ubi

1) ad II 743.

2) A re non alienum erit etiam alios Herodoti locos conferre, IY 13

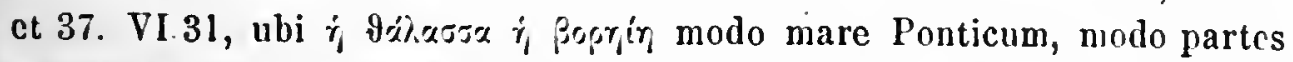
maris Aegaei, $\dot{\gamma}$ vozin $9 \dot{\lambda} \lambda .25 s x$ autem modo mare Indicum, tum partes Aegei, denique etiam marc Ponticum significant. Quae sit ratio grammatica, facile perspicies.

I p. 7.

3) Scil. Merkelius ad Ap. Rh. Il 745. Wilamowitzius Herakles ${ }^{2}$ 


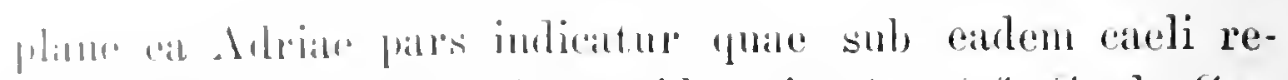
minme atque imsular Apsirtides ialeet. (ef. Sicyl. Car. Peripl. 1!1.201). De altero loce qui est IV 308 iam supra mer. Accolit quonl Merkelius testinonium Ammiani Marallini XXII S, l: atlort: Sirtremitates antem arcus utrimque Innes lho caprimunt Bospori e regione sibi oppositi Thlera-

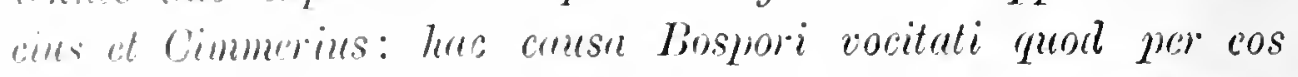
ynonlam Inachi filia mutrete, ut poctac locuntui, in bovem ad mure Ioninu permavit. Rom tamen haec verba omnino nun tangunt. Sime si Ammianus ar Bosporum Thracium respiciens sic seripsisset hac causa Bospurus vocitatus quod wer enen qrondam Inachi filie ad mare Ionium permeavit, testimonium eius reicere non liceret. Revera autem de mari quodam cogitat ad quod Io pervenerit Bosporo utroque iam traiecto. Ergo mare Ionium voluit ille non inter duos Busporos, sed ultra utrumque iacere. Nibil igitur de rebus geographicis ex his colligi potest. Quid autem ille voluerit statim apparebit, si fabulam de Io in menoriam revocaveris. Nonsolum illud rocabulum Bosporus sed etiam agnomen maris Adriatici 'lows per veriloquium ad To eiusque errores referebatur ${ }^{1}$ ). Sic aceidit ut Ammianus has regiones, nulla ratione reri situs locorum habita, continua narratione coniungeret.

Denique paucis tangam scholium in Verg. bucol. VI 43 : Hylas puer. Thiodamantis filius, ob specicm Herculi fuit carissimms, quem secutus navigantem cum Argonantis, in finitus Ionii inxta Mnesiam amud fontem Calci ammis cum aquatum issct. a nymmis riptes est. Primo obtutu eam regionem, ubi Hrlas raptus est. quae haud procul a Ponto Euxino est prope Ionium (i. e. mare Ionium) sitam esse diei concludas. At verba in funibns Ioniz sic expleri ut in finitus Ionii mar.is intellegatur retat testimonium Servii ibidem, qui haee habet: quem perdidit in finibus Ioniis iuxta Mysiam. Quam memoriam meliorem esse etiam illud Mysiam pro Moesiam

1) cf. Schol. Ap. Rh. IV 303. Acsch. Prom. 840 et scholia. Schol. in Eurip. Hipl. $7: 33$. 
declarat. Cum igitur vera lectio in finibus Ioniis iuxta Mysiam sit, adiectivum non a mari ad septemtrionales versus iacente, sed potius ab ea regione Asiac Minoris quae est Ionia ducendum est. Atque scholiasta, quod ad res geographicas attinet, omnino confuse loquitur. Nam verba Calci amnis (sic Leid.) vel Caici (sic Vossius) ad bene notam de Hyla fabulam non quadrant.

Quae cum ita sint, vox 'Jovinv (IV 289) si revera de

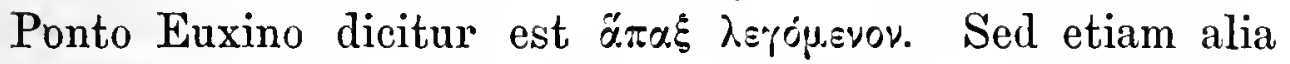
ratio rei temptandae exstat. Ex scholiis enim apparet vel apnd veteres interpretationes diver'sas circumlatas esse. Et primum una via explanandi sub finem scholii in IV 284

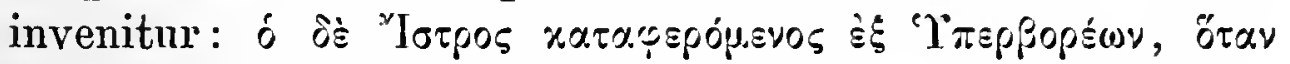

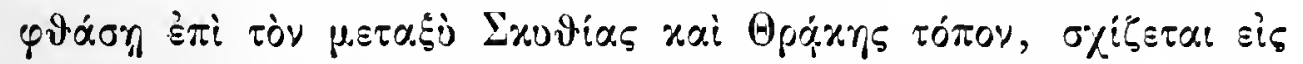

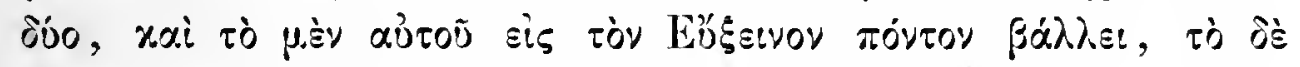

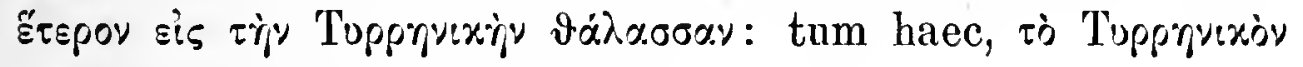

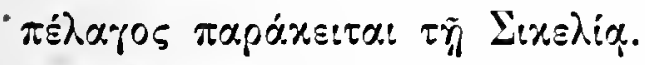

Explicationem ab hac plane distantem initio eiusdem

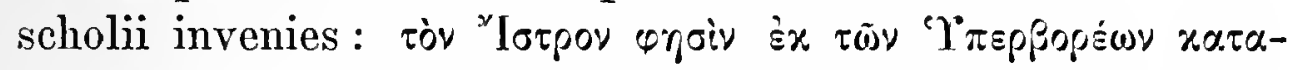

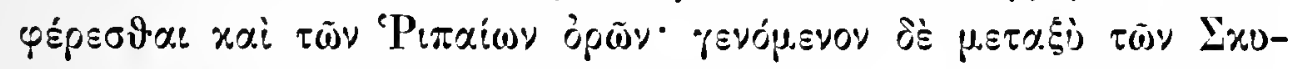

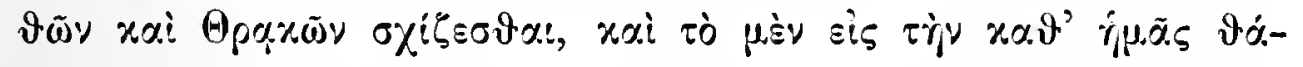

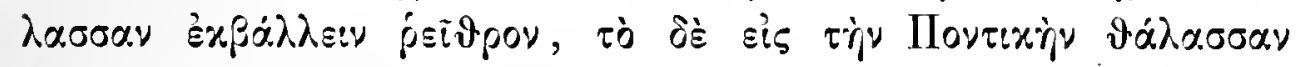

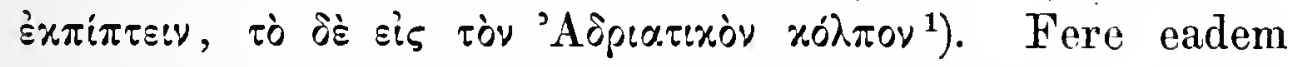
interpretatio in scholiis Flor. et Paris. ad vs. 291 ad-

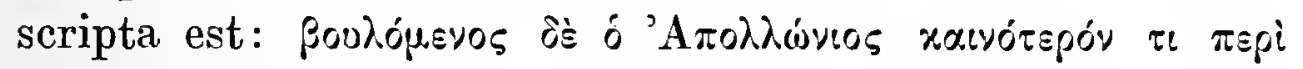

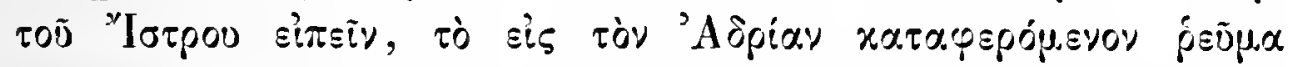

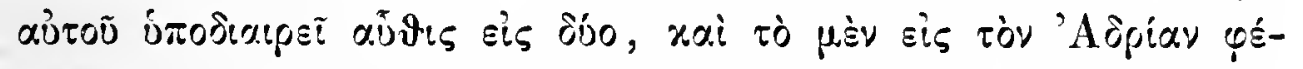

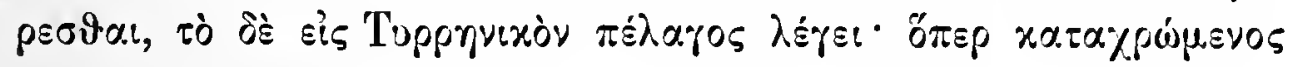
Tptráxpiov sins.

Vides quo nisus sit interpres. Nam illud oxi६óp.\&vos, quod cum है tares, alteri enuntiationis membro insertum est. Hanc quidem explicationem etiam novelli aliquot defendere stu-

1) Omisi illud Aeschyleum quod in continua oratione quasi intercalatum est. 
(unerunt), sed frustra. Nam si haee vis ae sententia in cratime contincretur, scriptum esset žm autum 访 igitur nom subsistamus. Gaudeo quidem quod insigni benignitate priseceptoris mei Wilamowitzii usus hane rei medelam atferre possum:

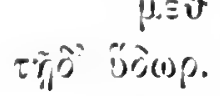

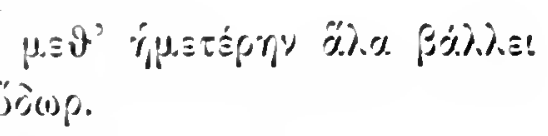

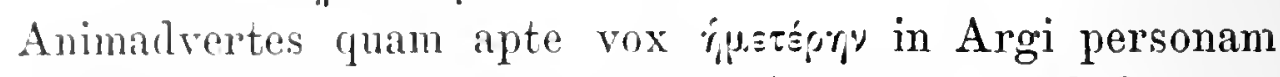
collata sit, qui quidem pronomen jpeśrspos bis ad Graecos apposuit. Cum igitur per totam orationem ille partes Colchorum egerit, appositum mare nostrum in eius ore facillime pro Ponto Euxino aceipi potest. Tum scholium ad IV 284 quomodo exstiterit facilius intellegitur, euius

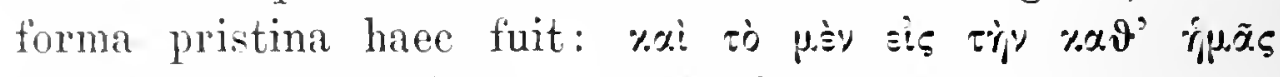

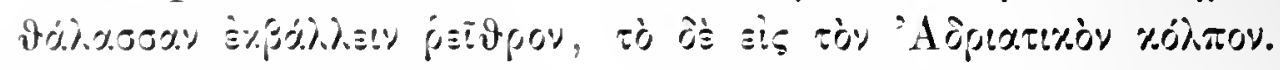
Quae explieatio cum non amplins sensum praebere vide-

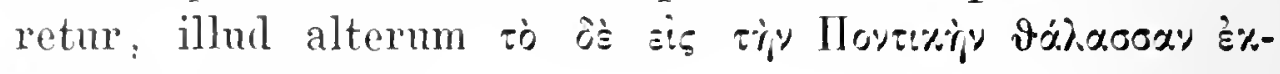
$\pi i \pi \tau: ! y$ additum est.

\section{II.}

\section{DE TIMAGETO ET CALLINIACHO.}

Eis quae Apollonius ipse narravit ita pertractatis opportmum est accuratius inquirere quo consilio quibusque fontibus usus rem sic instituerit. Ac primum quidem redeamus ad illam opinionem supra prolatam, quae versilus 5̆็2-5̆6 suseitata est. Conclusi enim, cum poeta ipse nobis ostenderit aliquid novi ineipere, hane narrationis partem quae est de via ex Ponto usque ad Adriam per se traçtandam, neque seriptorem quemquam requirendum esse qui illam de Eridano fabulam cum hae de Histro iam coniunxerit.

1) Zsishmannus, Die Isterfahrt im griechischen Sagenkreise. Tergeste 1852. Ukertus, Geographie der Giviechen mo Römer II 2, 45. 
Inquiramus igitur cuius anctoritatem amplexus sit Apollonius cum Argonantas per Histrum redeuntes faceret. Ac primum ad seholium in IV 284 nos conferamus: oijosis

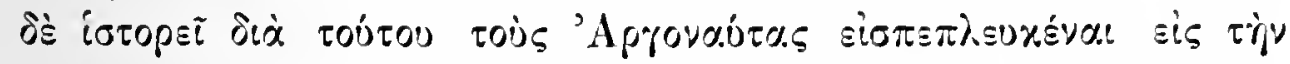

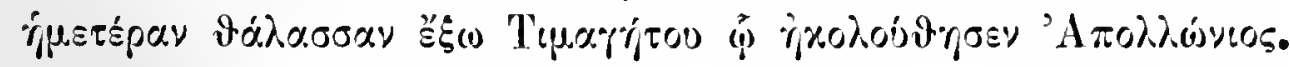
Tum in scholio ad IV 259 ratio reditus secundum Tima-

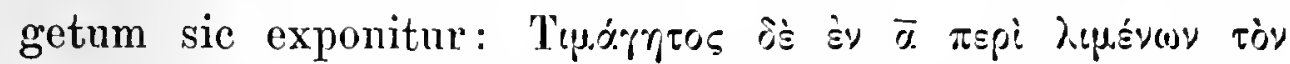

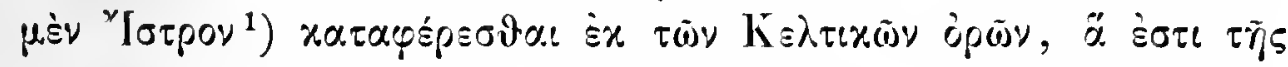

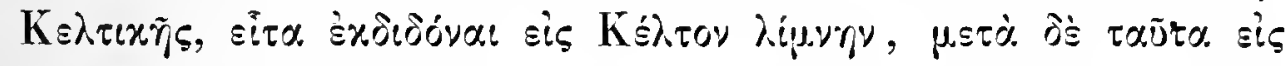

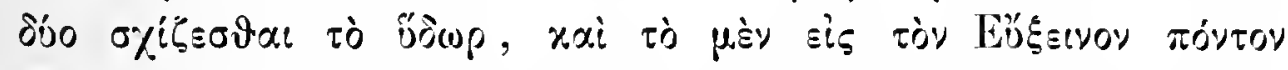

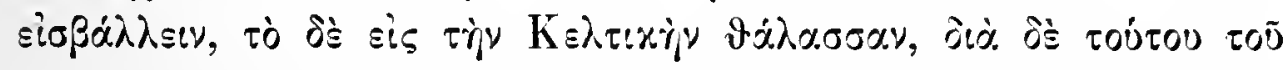

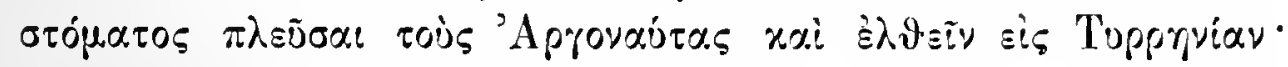

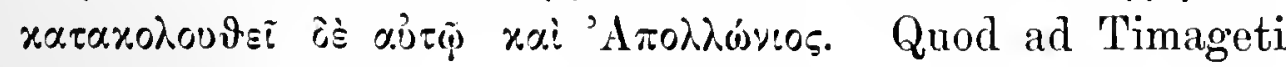
sententiam attinet, si una verba tradita audimus, docet scholiasta Histrum secundum Timagetum a lacu Celtico (nimirum prope fontes) se dividentem in Pontum Euxinum et in mare Celticum defluere. Quid sit mare Celticum, mon-

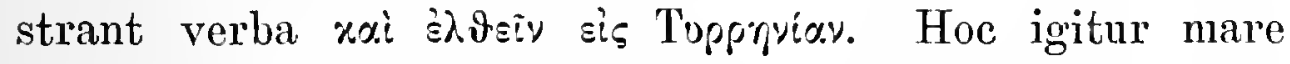
nihil est. nisi sinus maris interni prope Massiliam, quem

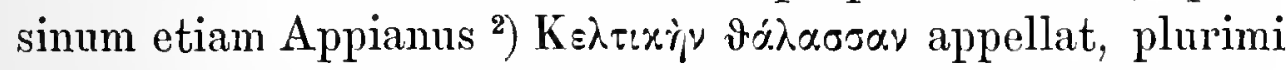

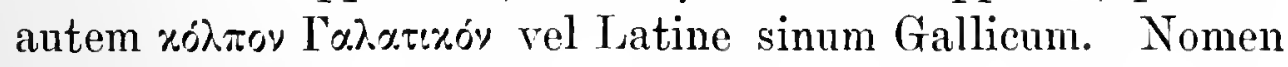
Celtorum ab incolis huins regionis ortum et dehine universis Gallis inditum esse tradidit Strabo III 189. cf. etiam Plin. N. H. III 74. Dionys. Perieg. 74 et scholia.

Huic interpretationi verborum obstare videtur illa

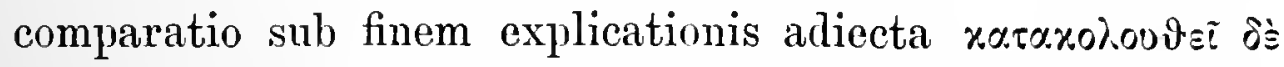

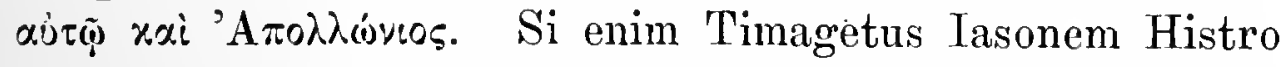
relicto in mare Tyrrhenum, Apollonius autem in Adriam descendisse tradidit, qui tandem dici potest Timagetum Apollonii ducem fuisse? Quam difficultatem Muellenhoffius ${ }^{3}$ ) respiciens alteram viam ingressus est, cum nomina Kśs zov $\mathrm{K} \Sigma \lambda \tau i x$ inv pro corruptelis damnaret. Credo tamen hoc cum illo non ita pugnare ut alterum utrum abiciendum sit. Primum enim observes quaeso in scholio ad IV 284 nihil

1) sic Flor.: Фйбเ Laur.

2) Mithr. 95.

3) Deutsche Altertumskunde I 431. 
de his anchorihus dici nisi quod apud utrumque Argonatae per Histrun in mane internum pervenerint. De Adria mminu num agitur. Usu loquendi per duas adnotationes

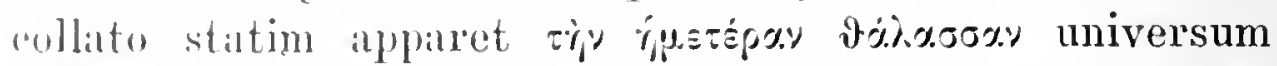
minre internum significare. In opinione Seymni exprimenda

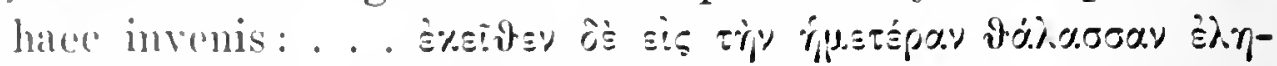

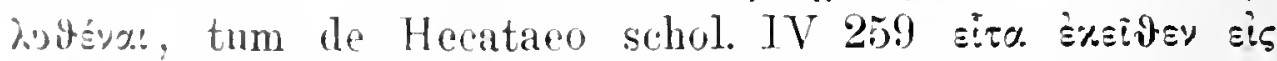

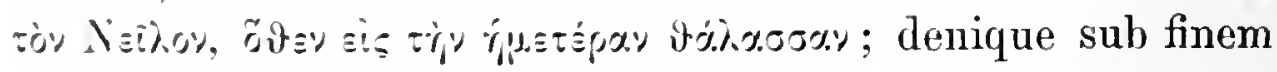

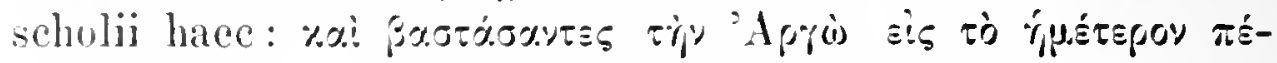

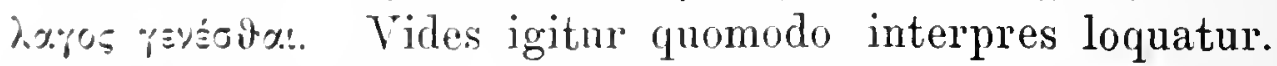
Diversas vias inter Pontum Euxinum et mare internum tractat, ita quidem ut viam per Propontidem, tum per Phasim ()ceanum Nihum vel trans Libyam, deinde per Tanaim Oceanum septemtrionalem, denique per Histrum respiciat. Qnoniam et Timagetus et Apollonius reditum in Histrum collocant, non iniuria dicit scholiographus illnm huic in fabula narranda praeivisse. Consentiunt enim in eo quod per Histrum, non per Phasim vel Propontidem vel Tanaim reditus in mare internum fit.

Qui Timagetus fuerit quandoque vixerit, diserte traditum non est. Nemo praeter scholia Apolloniana de hoc scriptore certiores nos fecit ${ }^{1}$ ). Apparet autem ex his inter se comparatis Timagetum libros certe duos de Portubus scripsisse, in quibus de fontibus cursuque Histri egit atque de lacn Celtico qui aquam et in Pontum Euxinum et in sinum Ligusticum emitteret. Famam aliquam de lacubus Brigantino et Lemanno per quos flumen magnum cursum teneret, Timagetus sic accepisse videtur quasi ex eodem lacu et Hister et Rhodanus fluerent ${ }^{2}$ ). Tum de

1) Schol. ad II 1031. IV 259, 284, 306, 324.

2) Th. Bergkius (17ilol. 30, 679. Opusc. Philol. II 754) contendit Timagetum, teste schol. ad IV 259, Rhenum et lacum Brigantinum commemorasse. Ipsa rerba describam: Der lieltischc See ist natïrlich der Bodensce; nachher teilt sich der Strom, der eine Arm fliesst ins keltische Meer (l.h. der Rhcin), der andere (d.h.eder Ister) in das schwarze Neer. At illud alterum flumen quod a lacu Celtico manat pro Rheno

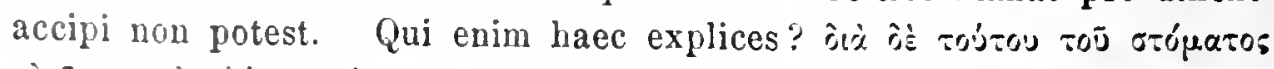

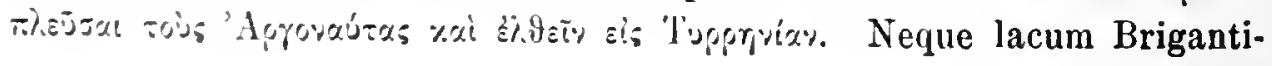


monte Anguro prope Histrum sito, de Histri ostio Pontico, de Martis insula quae haud procul a Colchide sita est, deque avibus illic repertis narravit Timagetus. Comperimus igitur ex his paucis Timagetun fuisse scriptorem rerum geographicarum, haud dubic pedestri sermone usum, et fabulam Argonauticam dedita opera tractasse.

Nomen Timagetus nusquam alibi in monumentis litterarum invenitur nisi apud Theocritum in carmine cuius est titulus Pharmaceutriae, vss. 8, 97. Non solum ab hac parte nomen esse Dorica stirpe cognoscas, sed maxime ope exemplorum quae Fickius et Bechtelius (Die Griechischen Personennamen pag. 42) congesserunt. Nam - áryos et 'Ay Dorienses reperiuntur.

Quibus temporibus Timagetus scripserit fere definiri potest. Primum enim Apollonio superior fuit, sed haud magno intervallo. Mirum enim est quod famam lacuum Helveticorum acceperat, quos Aristotelis temporibus nondum notos fuisse, descriptio cursus Histri (Meteorol. I 13) indicare videtur. Timagetus igitur qui harum regionum cognitione Aristotelem superarit, ab Apollonio victus est, temporibus mediis vixisse videtur.

Scholiasta teste Apollonius cum egressum ex Ponto Euxino per Histrum factum esse statueret auctoritatem Timageti amplexus est. Quem vero secutus poeta exitum in Adriam per alterum Histri bracchium finxerit, non comperimus. Etiamsi nullum nomen traditum est, tamen quam facile rel Apollonius vel alius quispiam rem ita novare potuerit, mox apparebit ${ }^{1}$ ).

Iam scholiis quibus potissimum nituntur hae conclnsiones fidem denegat 0 . Schneiderus ${ }^{2}$ ). Nam contendit ille vir doctas etiam apud Callimachum Argonautas per

num Timageto ita notum fuisse ut rult Bergkius dicas. Iste enim lacus Celticus et Brigantinum et Lemannum comprehendit, aui propter ignorantiam locorum pro uno eodemque habebantur.

1) cf. pagg. 46 seqq.)

2) Callimachea II 81 . 
Mistrum Adriam petivisse; docere etiam locos a Becknllanm an Aristot. Ar mir. anse. collectos seholiastam valde

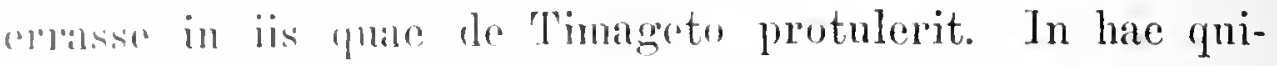
drum opinimo do batione quac inter Callimachum et Apol-

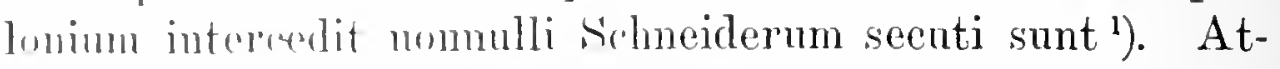
(pur lissonius") qui maximam partem se ab hae opinione liheravit, tamen nondum omnia meo indicio recte statuit.

Mihi quidem persuasissimum est totam Sehneideri sententiam fundamento carere. Quare cum apud eos qui his de rebus egerunt anctoritas hnius viri doeti multum valnerit et nume valeat, opportunum est totam rem denuo perserutari. (2ua in re minime eonvenit sie proeedere ut singula argumenta aut Schneideri ant eorum qui ei assensi sunt tractem. Immo quaestio multo facilior est. Nam de carminilus Callimacheis interpretandis hic non agitur, propterea yuod ipsa carmina interierunt. Fragmenta tantum et parea et hrevia habemus, unde conclusiones efficiendae sunt.

Ac primum quidem ordiamur a seholiis in Euripidis Medeam 1334; est apud Schneiderum Frag. 411. Ad haec verba Euripidea

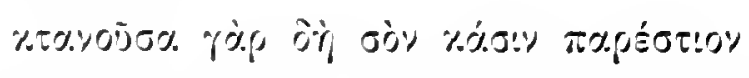

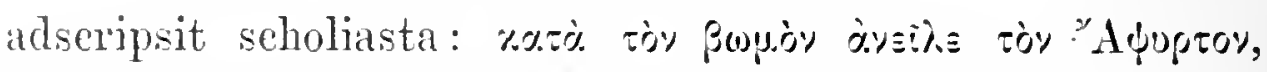

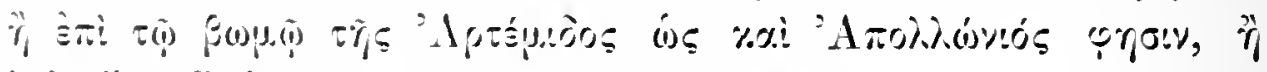

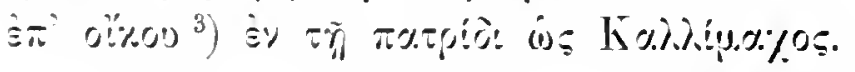

Itaque Callimachus fratrem Medeae in Colchide interfectum esse tradidit. Quac est fabula inter auetores prio-

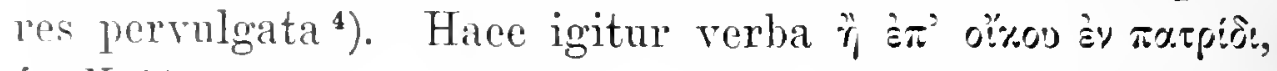

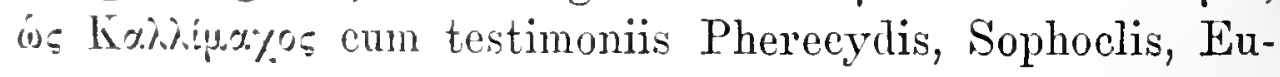

1) Geffckenius, Timaios' Georraphie des Westens, pag. 93. Seeliger, Roscheri Myth. Ler. 537. Groegerus, De Argon. Fab. Historia pag. 45. Kennerknecht, Zur Argonautensage, p]). 54-55.

2) cf. Pauly et Wissowa, Real-Enc. II $769,11$.

3) Sic Schwartzius: libri

4) Sic Sophocles ap. Schol. Ap. Rh. IV 228: Eurip. Medea 1334. Pherecyd. in Schol. Ap. Rh. IV 223, 228. 
ripidis collata, sine ulla dubitatione Callimachum fabulae formam vetustiorem retinuisse docent. Si contra in mentem revocamus quam diversas res Apollonius de Apsyrto protulerit, statim apparet lae quidem in re nihil omnino commune esse inter hos duos auctores. Hie enim Apsyrtus aduleseens alaecr ad pugnandum primum locum in Argonautis persequendis obtinet et itinere per Histrum facto, in insula Adriae interfieitur. Illic autem nihil huius generis fuisse potest. Nam seholiasta diserte testatur Apsyrtum domi oecisum esse.

Alterum fragmentum scholia Apolloniana in IV 284 praebent: est apud Schneiderum 377. Traditum est in

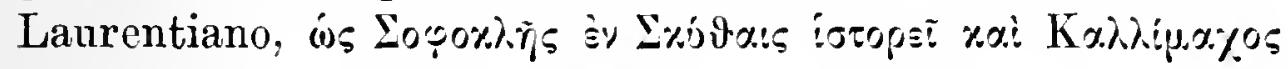

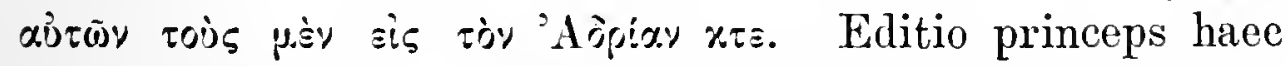

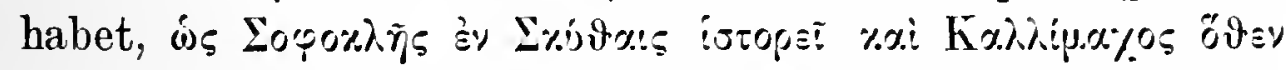

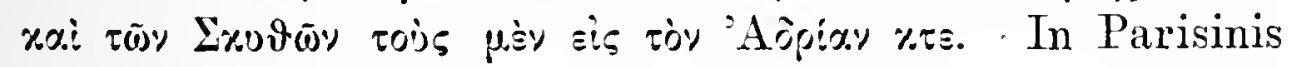
scholium tam inseite contractum est nt nihil inde effici possit. Quaestionem primam quae in verbis recensendis versatur, nondum attingam, praesertim cum res alia ratione diudicari possit. Nam potissimum de verbis distinguendis agitur. Editores enim qui Keilium antecedebant

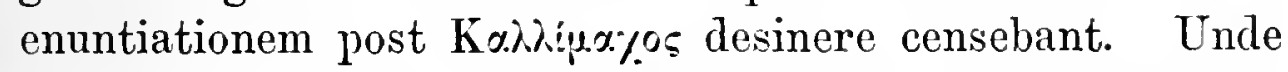
efficiebatur ut apud Callimachum sicnt apud Sophoclem cum aditus in Pontum tum reditus in Thessaliam per Hellespontum fierent. Keilius autem post ioropsĩ pedem sistens,

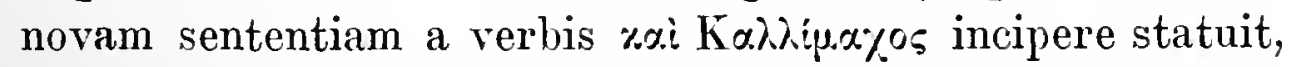
quae sententia statim per lacunam interpellatur. Quamquam Keilius suas rationes nusquam quantum scio exposuit, licet tamen concludere eum, verbis quae secnntur

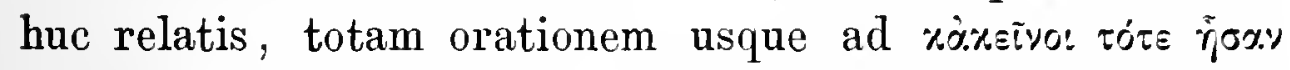
Callimacho tribuere velle. Quae conclusio reapse a Schneidero et facta et defensa est.

Ego quidem vix credo quemquam talibus argumentis fidem tribuere posse. Cum rero haee Callimachea ordine tractem, etiam hoc praetermittere non licet. Itaque contendo scripturam editorum illorum restituendam esse qui 


\section{$-24-$}

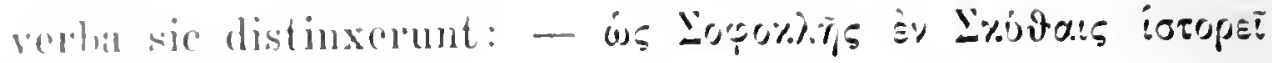

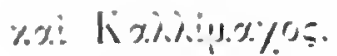

Primum enim in rerbis ita distinguendis viam monstrat ratio gralnmatica. Xiam jer totam paragraphum scholiasta diversas scripturum opiniones de iisdem rebus affert: sic antem procedit ut noram sententiam introducens particulim ḋ̀ addat. Neque usus loquendi sententiam novam quae rriori opponatur per coniunctionem r.s! adnecti to-

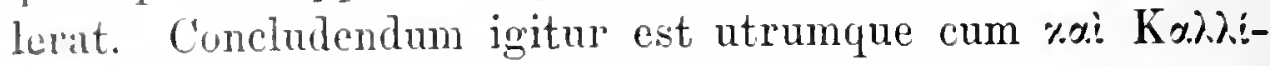

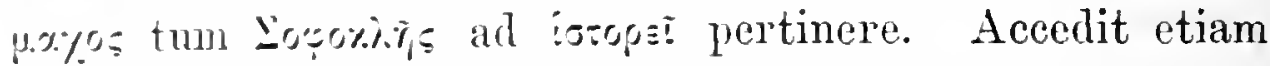
argumentrm quod ex tota scholiorum paragrapho peti potest. Ex dualms enim partibus constant ea quae ad rs. 2st adscribuntur. Prima enim sententia nihil est nisi paraphrasis earminis ipsius illa comparatione inter Aeschylum et Apolloninm interiecta. Tum pergit scholiasta in

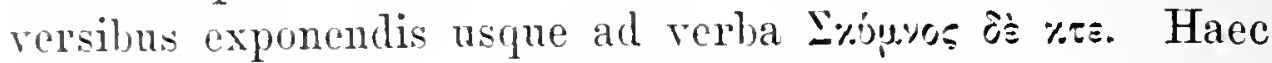
excipiunt opiniones multae multorum scriptorum de via qua redierint Argonautae. Nemo quidem dubitet quin ultima sententia o ò Atque etiam rerba quac \% s: Kovip.x\%s secuntur meo iudicio sic accipienda sunt. Schneidero enim his in verbis genuinum fragmentum Callimacheum latere opinato indicia omnia obstant. Primum enim verba in universum cum Apollonio consentiunt. Praecipue autem paragraphus Apolludori Bibliothecae I 137 (Wagn.) momentum facit. Optime consentiunt haec duo in his potissimum rerbis: sch.

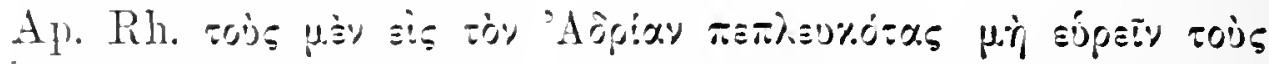

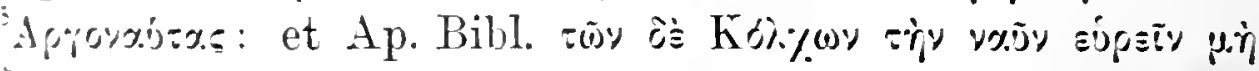

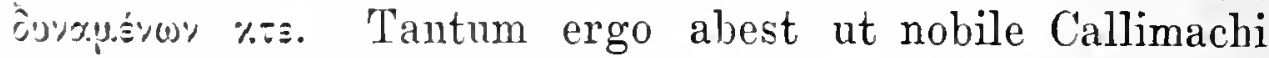
fragmentum nobis offerri statuamus, ut grammatici cuiusdam doctrinam haec verba olere pateat. Non licet igitur Schneidero assentiri dicenti Argonautas apud Callimachum per Histrum flurium Adriam petivisse.

Tertio loco de scholio Apolloniano in vs. IV 303, quod est apud Schneiderum Frag. j63, disserendum est. Adnotatio scholiastae quamquam brevis est, tamen non statim intellegitur. Quare mirum mihi videtur quod viri docti 
qui his fragmentis Callimacheis operam dederunt, difficultatem ne leviter quidem tetigerunt ${ }^{1}$ ). Sed ad rem ipsam procedamus.

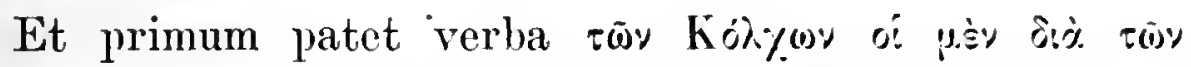

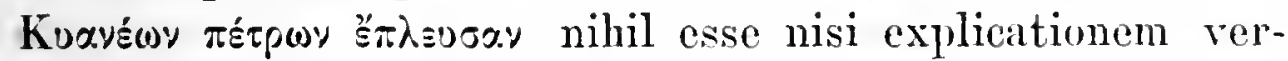

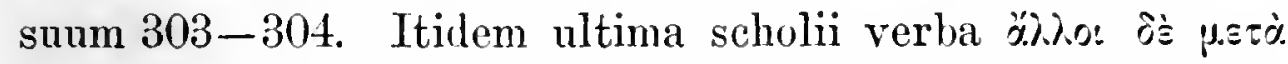

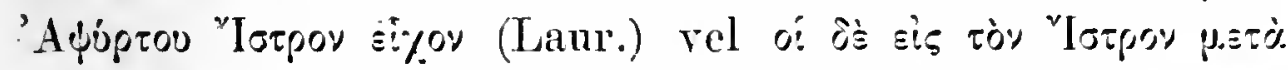

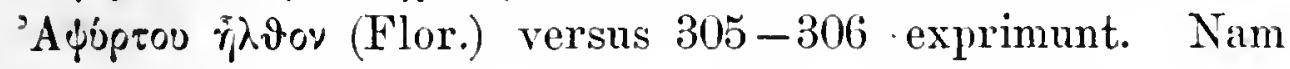
ea potissimum quae de Apsyrto dicta sunt ut narrationi Apollonianae accurate respondent, ita Callimacheis supra tractatis repugnant. Sed aliam partem addidit scholiasta

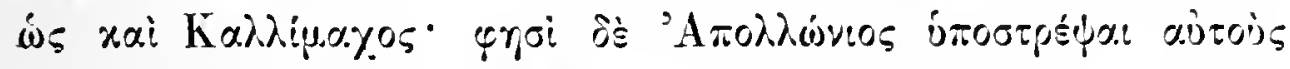

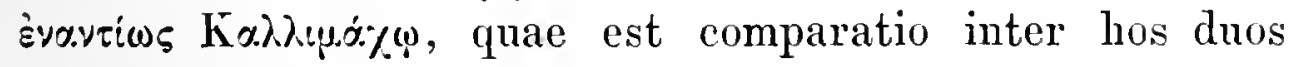
auctores instituta ${ }^{2}$ ). Iam in his quae sunt de Colchis Argonautas extra Pontum persequentibus, Callimachum aliquatenus Apollonii ducem fuisse, versus illi Callimachei apud Strabonem I 46 docent. Quare mirum non est scholiastam hos duos poetas comparasse. Nunc autem accuratius quaerendum est, qualis fuerit narratio Callimachi ac praecipue quidem utrum Colchos in duas manus discessisse ${ }^{3}$ ) tradiderit necne.

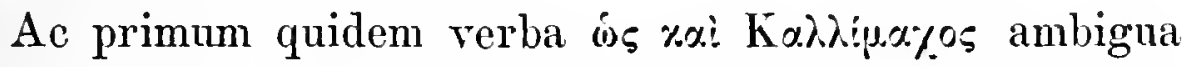
esse existimo. Duo enim intellegi possunt, aut "Colchorum alii per Cyaneas iter fecerunt sicut Callimachus partem unam Colchorum bane viam ingressam esse dicit", aut "Colchorum alii per Cyaneas iter fecerunt, quam viam, etiam Callimacho teste, Colchi ingressi sunt". Itaque scholiasta comparationem instituit quae aut ad Colchos se in duas manus dividentes aut ad viam tantum a Colchis omnibus initam pertinere potest. Si autem supra de scholiorum

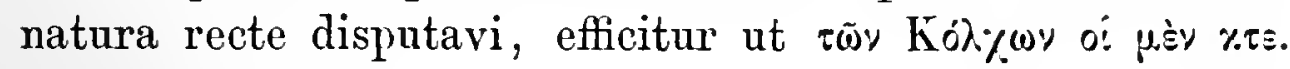

1) Schneiderus. Heckerus, Com. Callim. pag. 44.

2) Simili ratione infra (ad IV 306) inter haec genera distinguendum

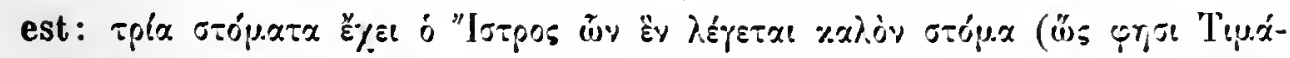

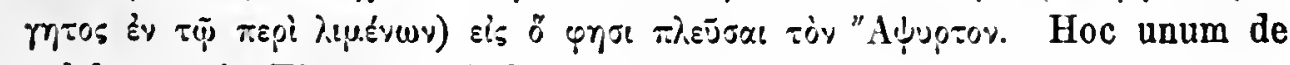
pulchro ostio Timagetus habuit, reliqua sunt Apolloniana.

3) Sic Iessenius II 769. 


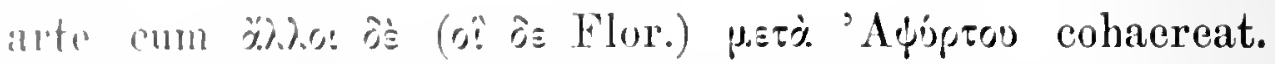

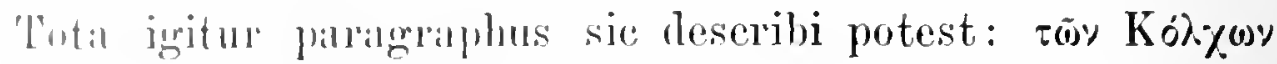

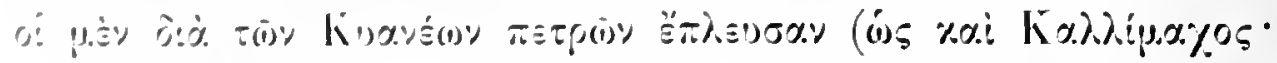

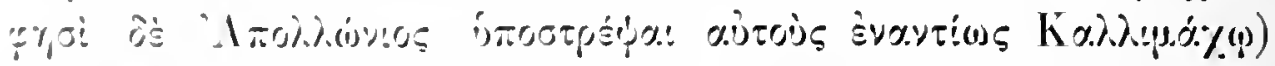

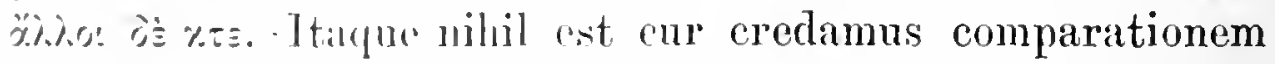

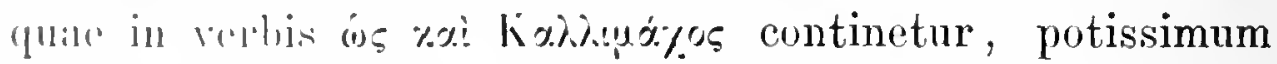

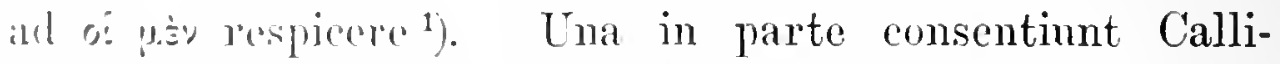
mischus ot Apollonius yuod apud utrumque per Cyaneas colchi iter faciunt.

Sed pergit scholiasta una in re illos dissentire expo-

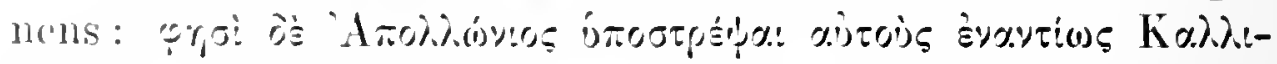
y. \% \% (Quile sentential sicut tradita est, non facile intellenitur. Primo aspectu sic interpretamur ut Evavrios ad "rovi referatur: Apollomius autem aliter ac Callimachus dirit cos rediisse ${ }^{2}$ ). Quod minime verum esset. Nam Apollonins dicit Colchos omnino non rediise sed in oris Adriae sedes collocasse ${ }^{3}$ ). Neque particulam ó supplendam esse coniricere liceret (çro' j̀̀ 'A 's:), quoniam ('allimachus quoque, Strabone I 46 teste, Colehos propter metum Aeetae domum non repetisse dixit. Erogo si quaeris qua in re Apollonins et Callimachus dissentiant. de Colchis domum redeuntibus omnino non agi concedendum est.

Restat ut rem aliunde aggrediamur. Cum enim Apollonius aliam rationem rerum depingendarum atque Callimachus ingressus sit, facilis est coniectura discrepantiam eam esse ruod Colchi se in duas manus diviserint. Seimus enim ex iis quae de scholio in IV 284 disputata sunt, Argonautas apud Callimachum per Cyaneas iter fe-

1) Nihil aliud intellegi posse Iessenius putat. Ego autem demonstrare studeo illud alterum non solum fieri posse, sed veri etiam simile esse.

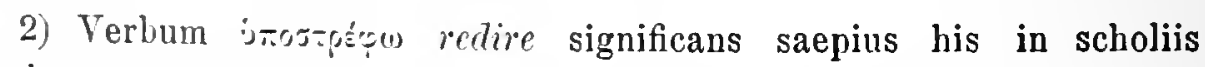
invenitur: vile ad II 854,904 . III 260. IV 228. Rem igitur ab hac parte non temptari.

3) IV 507 seqq. 1206 seqq. 
cisse. Quae cum ita sint, minime verisimile est Callimachum eadem atque Apollonium de itinere Colchorum per Histrum facto protulisse. In iis quidem quae de Apsyrto et Argonautarum reditu sunt, diserte traditum est eum cum Sophocle consensisse, id est cum retustiore huius fabulae memoria. Cur igitur credamus Callimachum sine causa hane de Colchis per Histrum navigantibus narratiunculam intulisse? Ut tale quid concludamus, scholium in IV 303 nos nequaquam cogere paulo ante demonstrare studui. Quamobrem aptum esset, si pro inoorfósul: vocem quampiam poneremus quae significet se in duc partes dividere $^{1}$ ). Sed quamquam mihi videor sensum bomum inferre posse, tamen verba emendare nequeo.

Itaque alia via ${ }^{2}$ ) rem absolvere temptabo. Si enim aijroós non de Colchis sed de Argonantis intellegitur, tum sententia omni parte cum scholio in IV 284 concinit; "Apollonius redisse Argonautas aliter dicit ac Callimachus", id est per Histrum, non per Hellespontum. Fieri potest ut nonnulla interciderint unde perpetuitatem orationis tali modo turbatam explices. Atque proxime antecedit schol.

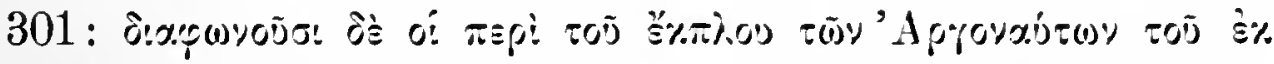

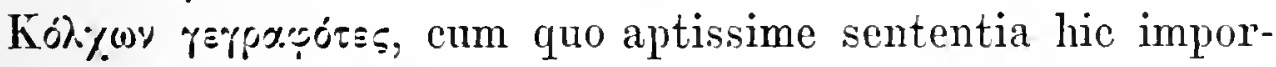

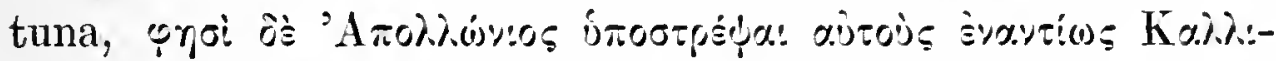
$\mu \dot{\gamma} \%$, coniungi posse apparet. Sed haec hactenus. Satis habeo si propter hanc disputationem verba scholiastae

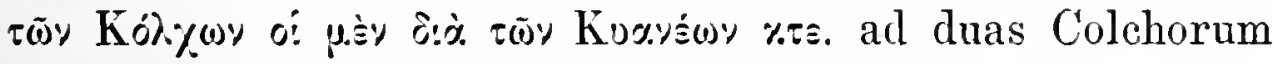
manus non pertinere, mihi concedes.

Nunc ad fragmenta quorum sedes apud Strabonem est procedamus. Per totum locum de expeditione Argonautarum in Phasin suscepta deque reditu agitur. Contendit Strabo et expeditionem Iasonis et errores eius prorsus non repudiandos esse tamquam fabulas a poetis confictas; immo etiamsi res aliquatenus a poetis exornatae sint, tamen in

1) Quae sententia vix per unum vocabulum exprimi posset. Cf. Schol. Laur. IV 291 isoìtx!feĩ als j̀óo.

2) Quam viam Wilamowitzius mihi benerolenter monstravit. 
universum rerum fundamentum rerum gestarum suppeditalle, sicut testimoniis poetarum de Menelai et Ulixis ermribus fiden habemus; non solum enim in mari Pontico "t Acoileo, sed etiam remotis locis, cum ad solem orientem tum and occilentem circa Italiam, monumenta Iasonis of ('olohnlum enm persequentium inventa esse. Tum pergit

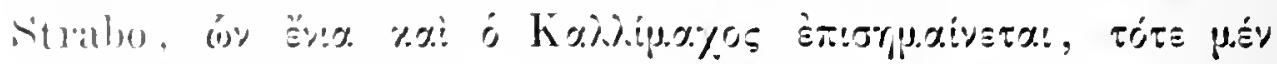

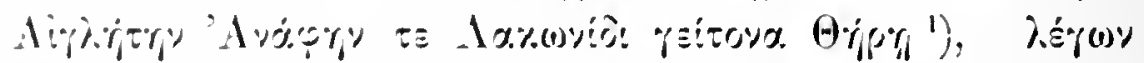
${ }^{2}$ \p

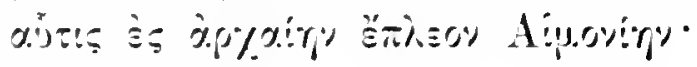

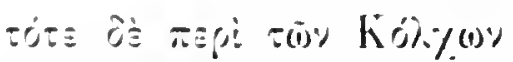

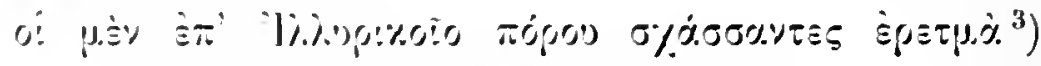

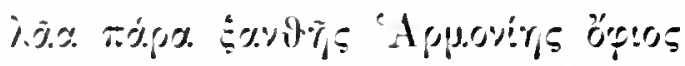

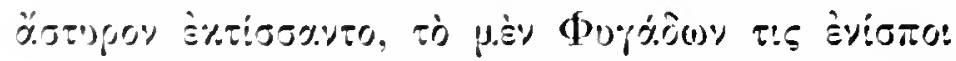

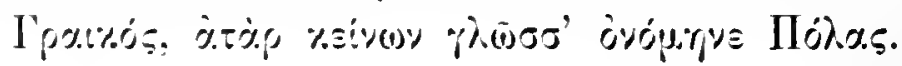

Iam illum versum de Anaple Strabo in insulis maris Aegaci enumerandis (X 481), iterum affert. Verba sic vertuntur: Aegleten et Anaphen quae est Spartanae Therae mroxima. Primum Aegleten esse Apollinis appositum qui ab incolis Anaphes hoe nomine colebatur, eum Apollonius Rhodius ${ }^{4}$ ), Cono ${ }^{5}$ ), Apollodori Bibliotheca ${ }^{6}$ ), tum tituli nomulli testantur. Iidem scriptores etiam causam nominis Anaphes et cognominis Aegletae, quomodo ad Iasonis reditum pertineant, exponunt. Sed poeta $\mathrm{Cy}$ renaeus sui propria narrasse videtur. Nam cum duo no-

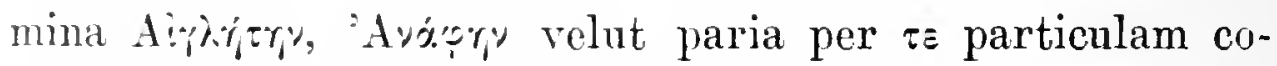
pulentur; etiam 'Avýrry' quasi personae nomen accipiendam esse suspiceris. Quocum bene congruit haec mentio Spartanae Therae, quae etiam (Frag. 112) mater Cyrenarum appellatur. Tum animadverte quaeso usum loquendi Calli-
1) I 46: apud Schneiderum, Frag. 113a.
2) Ibidem $113 \mathrm{~b}$.
3) Ibidem 104.
4) IV 1716 seqq.
5) c. 49 .
6) I 139 . 
macheum in hymno in Delum, ubi $\Delta$ ijios modo insula modo dea est ${ }^{1}$ ). Itaque quoniam poeta Aegleten et Anaphen consociavit et aequiperavit, non dubito quin Anaphe pro dea vel nympha insulae accipienda sit. Iam Strabo nos certiores facit in hoc versu memoriam exrorum Argonauticarum latere. Poeta autem historiam indicarit tantum ac perstrinxit, atque geographus quasi ad rem clarius declarandam illud distichum, unde appareret de quibus ageretur, statim addidit. Ergo neque versus ipse neque verborum contextus poetam hane historiam fabulosam multis verbis ornasse aut per singula persecutum esse patefacit ${ }^{2}$ ). Nunc alterum fragmentum quod est de Colchis inspiciendum est:

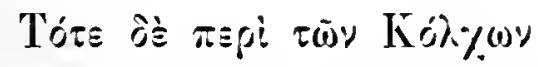

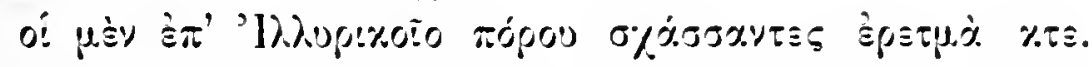
Iterum quidem Strabo ad Callimachum provocat (V 216), eisdem versibus allatis, ubi de Polis conditis agitur: жriø..

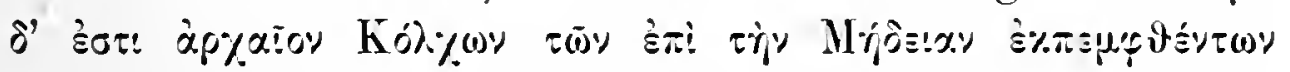

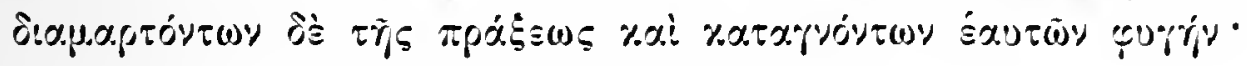

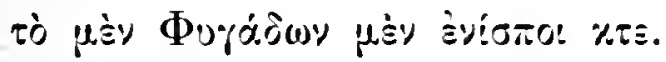

Itaque quas res hi versus illustrent, dubium non est. Vestigia enim Colchorum frustra Argonautas persequentium etiam in intimo Adriae sinu monstrantur.

Iam primo obtutu testimonium Strabonis Schneiderum qui contendit cum Callimachum tum Apollonium unam rationem in reditu enarrando secutos esse, valde adiuvare

1) Cf. vs. 4-6.

2) Quare disputatio Knaackii (Callimachea pagg. 1-5), qui narratiunculam Cononis Callimacho attribuit, admodum improbabilis mihi videtur. Nam illa nota e qua Callimachea cognosci poterant scil. mentio Anaphes nymphae, Cononi deest. Quod contra narratum est Anaphel prope Theram iacere, id tali modo premere non licet. Nam mentio apud Cononem, qua maxime Knaackius nititur, ex ipso locorum situ explanari potest. Vides etiam Strabonem ( $X$ 484) duas insulas una commemorasse. Nimis confisus est Knaackius silentio monumentorum neque ei concesserim ex Apollodori Bibliotheca argumentum carminis Callimachei tam facile erui posse. 
viderur. Nimn qummonlo tindem fit ut Colehi usque ad Hinllinn prontralint nisi viam per Histrum ingressi sunt? Sic ratiocinatur etiam (Aeffekenius ${ }^{1}$ ): Auch Kalli-

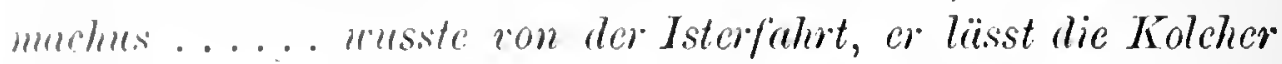
Jolni grimlen. lessenius ut concedat Argonautas apud Callimalum per crancas redisse, ita ex scholio Apolloniano in $11: 31: 3$ concludit alteram Colchorum partem per Histrum iter ferisse. Sed mili non persuaserunt argumenta doctorum virorum qui Callimachum ullo quidem modo his in rebus montionem Histri Huminis fecisse statuerunt.

Ac primum quidem isti conclusioni repugnat, ut milhi

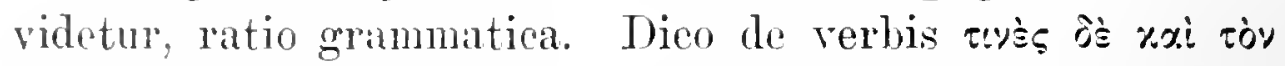
"lotpoy d.y. per totum locum monet, quam late monumenta Argonautarum dispersa sint, etiam in locis a via inter Pontum et 'Thessuliam remotissimis. Plane apparet virum illum, rerum geograplicarum peritum, revera credidisse talia monumenta exstare. Quam ad opinionem confirmandam doctum poetam testem arlrocat. Ergo opiniones Callimachi de Polis conditis probat iisque rim at anctoritatem tribuit. Pestimo-

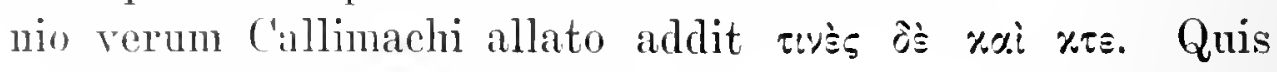
tandem qui rerba ingenue inspieit, non concesserit aliquid

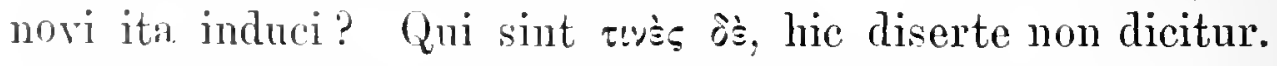
Id maxime quaerimus, num Callimachus qui modo laudatus est, simnl in numero eorum qui propter ignorantiam locorum reprehendantur, haberi possit. Profecto non potest. Ergo inter eos qui de itinere per Histrum facto fabulas proferebant, Strabone teste, non fuit Callimachus.

Tum operae pretium est etiam Strabonis opinionem considerare. Ille enim Colchos Polas condidisse credidit, neque tamen illam de Histro narratiunculam recipiendam esse putarit ${ }^{2}$ ). Cur non etiam (allimachus? Rationem

1) Timaios Georn. des Westens p. 93. Cfr. etiam Seeliger, in Roscheri Myth. Lex.

2) Cfr. I 46,57 . VIII 317. 
igitur Geffekenii Kallimachus wusste von der 1sterfalwt, er lässt die Kolcher Polai grïnden more novellorum potius quam veterum concludi vides.

$\mathrm{Si}$ enucleare volumns quae fuerit ratio consiliumque Callimachi in his versibus edendis, via longe alia ingredienda est. Nam practer Callimachum multi testes audiendi sunt, ac primus Apollonius. Libro IV 511 seq\%. fortunas eorum Colchorum exponit qui Apsyrto iam interfecto, omni spe opus susceptum conficiendi orbati essent: quorum alios quidem in iisdem insulis ubi Argonantae appulerant sedes collocasse, alios terram Illyricam Encheleensibus proximam petiisse, alios in montibus Cerauniis domicilia constituisse. Tum narrat ${ }^{1}$ ) Apollonius de ea Colchorum parte qui, via per Cyaneas facta, nsque ad Corcyram perrenissent, hos metu Aeetae commotos non rediisse sed inter Phaeacas ut socios exceptos esse, ibique diu habitasse donec gens Corinthia Bacchiadarum eos expelleret: tum sedes in terram continentem circa montes Ceramios transtulisse. Adiecit poeta doctus,

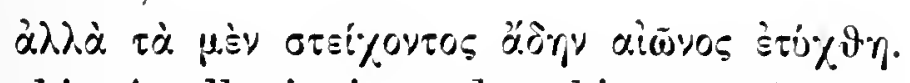

In his Apollonianis eadem bis narrata esse observas. Unus est historiae fons etiamsi poeta duos Colchorum exercitus introduxit. Mox enim videbimus primordia huius memoriae a Corintho Corcyraque petenda esse, ut etiam Apollonius IV 1209 seqq. monstrat. Ergo ista narratio de Colchis per Histrum ad has regiones pervenientibus recentior et a pristina historia derivata est.

Deinde non incredibile est Timaeum aliquid de Colchis has regiones incolentibus accepisse. Quod maxime apparet duobus scholiorum Apollonianorum locis ${ }^{2}$ ) inter se collatis:

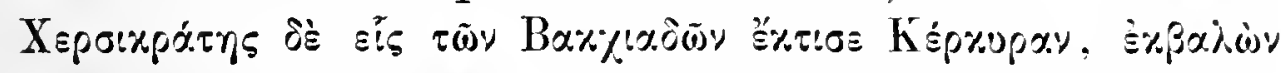

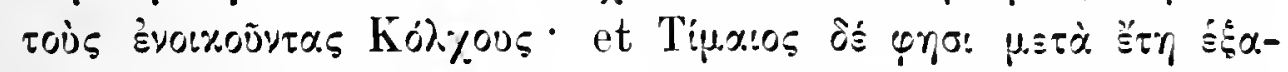

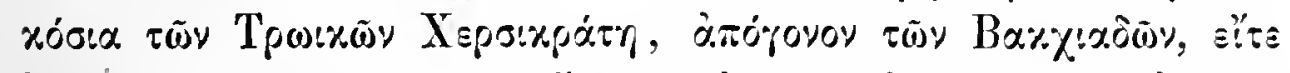

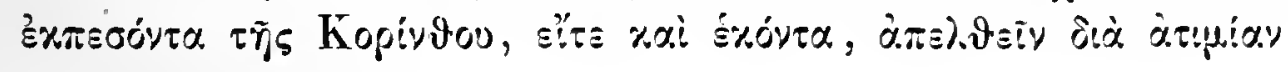

1) IV 1206 seqq.

2) in IV 1212, 1216. Memoriam pleniorem Florentinae editionis adhibui. 


\section{$-32-$}

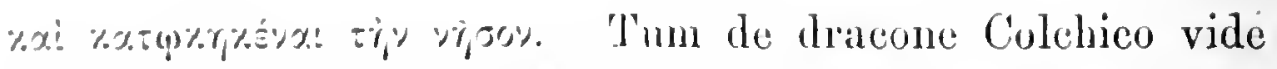
sctmlia in laycophonem 615. Deinde verisimile est etiam ("il quill in schul. lave. 6330 proferuntur Timaeo tribnenda asse. Areolit quod prima mentio terrae Kojyosos apud Eumehm puetan ('orinthium invenitur'). Denique Homeri textimmium. in $\bar{g}$. 2.5. Odysseae, ad rem pertinet:

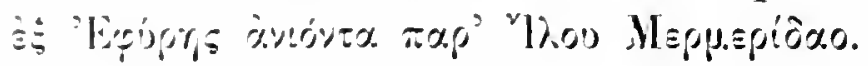

Mermerum, Medcae filium iam in carmine Naupactio commemoratum esse Pausanias II 3,9 tradidit. Stirps igitur Medeale venteficae ei qui Odysseam in formam qua nunc est redegit haud ignota erat. Haud parvi aestimandum

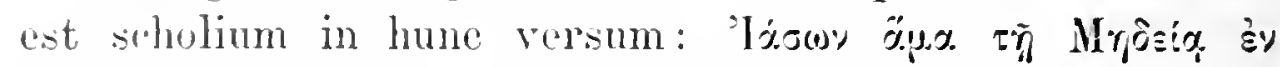

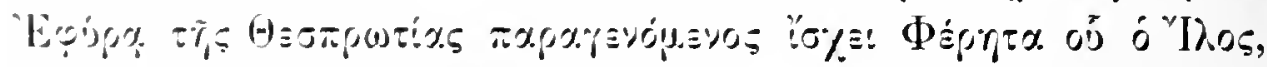

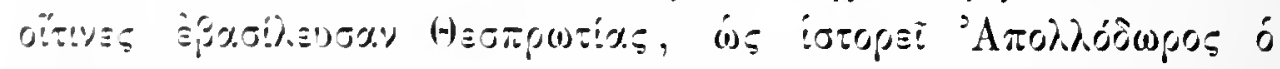

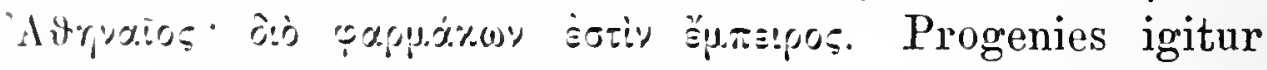
Nedeae Apollodoro Atheniensi teste in regionibus prope Corcyram regnabat.

Qnae cum ita sint, concludere licet Apollonium ea quae de dispersis circa Adriam Colehis narraverit, ex memoria uberiore desumpsisse. Neque Callimachus qui illud reriloquium nominis Polarum protulit hac in re solitarius fuit. Denique apparet quae inter tales historias et opinionem de Argonautis per Histrum navigantibus vera ratio sit. Hane enim multo recentiorem atque ab illa pervetusta memoria magnopere adiutam esse O. Muellerus iamdiu perspexit ${ }^{2}$.

His iam satis tractatis Callimachea quae in scholiis Apollonianis ad IV 1322 servata sunt paucis tangam. Poeta Rhodius nymphas Libycas Argonantis omni spe redeundi destitutis opem consiliumque tulisse narrat. Docet *choliasta, $\pi \approx 0$ i

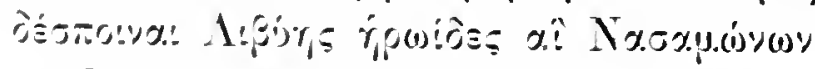

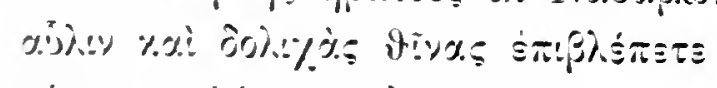

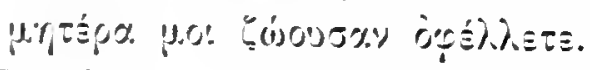

1) cf. Dion. Per. 488 seq., Plin. N. H. 3, 144, ubi de coloniis Colchorum in mari Adriatico sitis agitur.

2) Orchomenos p. 292. 
Unde concludunt Knatekius") et Iessenius") haee quoque verba ad reditum Argonantarum spectare et Apollonium his etiam in rebus Callimachum presse secutum esse. Facilis quidem est coniectura, praesertim cum Cyrenae, ubi natus est Callimachus, et Libya iam retustis temporibus ad errores Argonantarum pertinuerint. Nihilo minus certa ratione omnino non demonstratur. 'Tota enim quaestio pen-

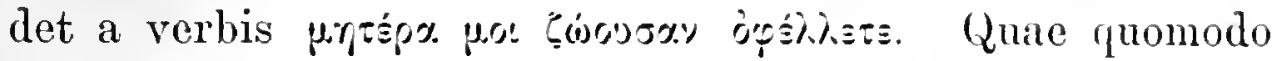
ad hanc fabulam pertinere possint, non apparet. Si enim Valckenario assentiamur qui verba de Callimachi matre dicta intellexit, aut cum Schneidero explicemus ${ }^{3}$ ), poeta nymphas precatur ut vigentem patriam suam etiam magis angeant, tamen nullum restigium errantium Argonantarum reperitur. Ne Knaackio quidem rem declarare contigit. Concedamus ei Apollonium docere quomodo fragmentum Callimacheum intellegendum sit, etiam tum non efficitur ista conclusio. Ambigunm enim illnd dearum dictum, quod recte interpretatus est Peleus (1370 seqq.), Iaso de sua matre intellegere non poterat, propterea quod deae formam verborum pluralem bis usurparerant ${ }^{4}$ ). In hoc sane Knaackius verum vidit quod versus Apolloniani 1309, 1322 illa Callimachea $\Lambda: P i r r_{5}$ ipowisss referunt. Quod etiam scholiasta cognovit et adnotarit. Sed neque scholiasta neque verba ipsa allata hanc similitudinem latius quam ad vocabulorum imitationem pertinere indicant. Sic plerumque A pollonius, teste scholiasta, Callimachum imitatus est $\left.{ }^{5}\right)$. Itaque nihil certi ex hac adnotatione erui potest nisi quod etiam Callinachus nymphas Libyae commemoravit.

Nunc disputationem Heckeri ${ }^{6}$ ) de navi Argo ad Phaeacum terram appulsa inspiciamus. Primum enim in scholiis ad Dion. Per. 49匚̃ et Ap. Rh. IV 983 servatum est illud
1) Callimachea p. 13.
2) Apud Pauly et Wiss. II 774 .
.3) Callimachea II 395.

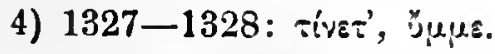
5) ad I'669, 1008, 1297, 1309.
6) Comment. Callim. p. 36 seqq. 


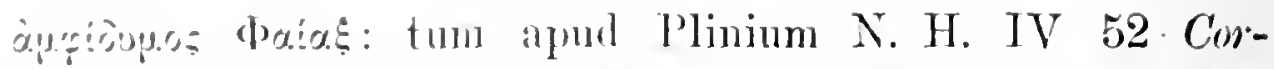

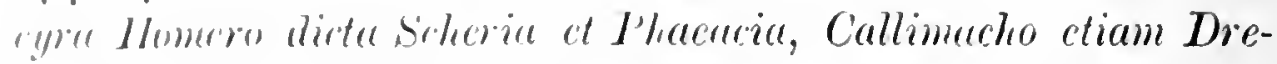
pune. Vir ductus, pustquin summa diligentia etiam alia testimunial pertractavit, has mentiones Coreyrae in carmine de Argonatis hue adrunientilus esse factas statuit. ('ni conclusioni nomnihil auxilii aliunde comparare posse milhi videor. Tam poeta Corcrram insulam etiam apposito

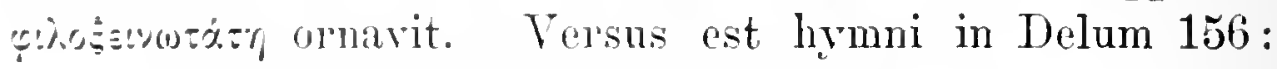

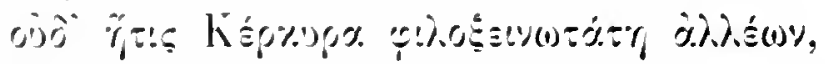

Sane illa laus eximiae liberalitatis primo loco ad Ulixem a Phaeacibus humaniter affectum attingit. Sed in illo superlativo haud iniuria famam etiam Medeae Iasonisque apul Phacaces commorantium agnosces. Tum opinione Heckeri recepta facile intellegitur cur Colchi persequentes in Adriam adrenerint'). Itaque summa probabilitate dici potest Callimachum sicut Timaeum. Philetam, Apollonium in numero corum qui nuptias Medeae in Corcyra collócaverint liabendum esse.

Restat ut singula perstringam in quibus poeta Rhodius in rocibus et ornamentis orationis magistrum suum secutus est. Cuins generis exempla pleraque Knaackius apud Panly et Wiss. s. v. Apollonius Rhodius congessit. Lnum afferam quo quale sit totum genus facile perspicias. Apollonius in libro altero. quomodo filii Phrixi Colchidem relinquentes in Graeciam cursum dirigerent, his verbis depingit: rss. 1093 seq.

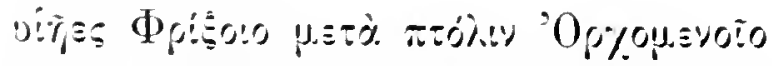

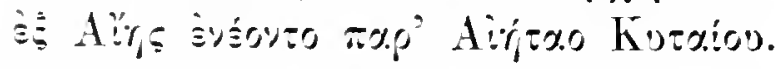

Quanta sit his cum Callimacheis (Frag. 113)

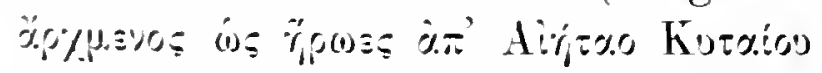

similitudo, riri dueti iam pridem sentiebant. Tamen similitudo in rerbis reddendis desinit neque ad eandem ratio-

1) Illis distichis quae sunt de Polis conditis subiecit Heckerus hoc

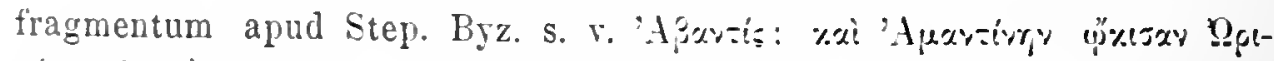
wrir. ita ut etiam in bis memoria Colchorum nova domicilia constituentium reperiatur. At veri similius est Callimachum sicut Lycophronem (1043) fabulam Elephencris in his respexisse. 
nem carminis instruendi pertinet. Ergo ut talia in genere loquendi Apolloniano exquirendo et in universo ingenio poetae illustrando magni momenti sunt, ita in hae quacstione quae ad rerum tractationem pertinet parvi aestimanda sunt.

Alia quaedam fragmenta quae ad Argonautarum historiam Schneiderus rettulit, num lne recte relata sint,

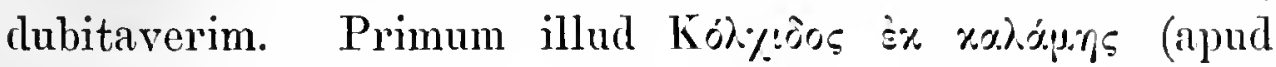
Schneiderum 265) sive affirmas sive denegas de pallio Iasonis accipiendum esse, tota quaestio in incertis versatur. Tum Callimachus, teste Etym. Mag. p. 72, 8 (est frag. 324) Halyn et Irin unum fluvium, Apollonius II 367, 963, duos esse statuit. Cum poeta Rhodius hoc loco res geographicas, non fabulares respiciat, neque in his quidem cum Callimacho consentiat ad propositum nihil adiuvat haec comparatio. Denique distichon illud apud Strabonem XVII 837 (est frag. 112) quod est de insula primum Calliste, postea Thera dicta, e carmine desumptum esse videtur quod Cyrenas conditas potius quam reditum Argonautarum celebravit.

Fragmentis Callimacheis, quae ad propositum pertinent, ex ordine percensitis, par est formam carminis rel carminum in quibus de reditu illo agebatur, designare. Et primum hae reliquiae opinionem redarguunt Callimachum velut poetam epicum reditum Iasonis fuse ac copiose narrasse. Nam illa caedes fratris, quam Medea domi fecit, apud Callimachum sicut apud Euripidem unum duosve versus postulat. Tum ad viam quam Argonautae per Propontidem tenuerunt definientam, nilil est cur magnnm carmen ponamus. Deinde cum illi versus de Anaphe insula ad rectam a Ponto in Thessaliam viam non pertineant, concludimus heroes apud Callimachum etiam per mare Aegaeum errasse. Omnia quidem adhue tractata in fines unius carminis facili negotio includas. Denique illam historiam de Polis conditis in duobus distichis absolutam esse vides. Omnia igitur indicia nos deterrent quominus Callimacho magnum carmen vel magna carmina attribuamus. 
Alterum quidem ex his reliquiis eum Apollonianis compraratis erni potest. Cavendum enim est ne in elegiis restituondis poetace epico nimis confidas. Cum enim alterum (1) alter" camine cum natura tum ex arte Alexandrina longissine distet, summma cantione opus est, si ab Apollonio purfoctus ad Callimachum ascendere vis. Scimus quihem quod ad unirersam reditus rationem attinet Cyrenacum ab insulsis illis fabulis geographicis se retinuisse. Apollonii enim narratio ex duabus partibus constat, quarum una ad regiones singulas iam vetustis temporibus cum hac fabula coniunctas pertinet, altera ad rationem quil hae regiones diversae in mum reditum rediguntur. Quod fecisse cum maxime intersit epici poetae, a Callimacho alienum omnino fuisse, consentaneum est. Itaque Apollonins si omnino in rebus Argonautarum narrandis ad Callimachum se applicuit, in singularum fabularum coloribus veluti in veriloquiis et maxime in ornamento orationis cohibuisse initationem existimandus est.

Conclusio igitur firma atque certa efficitur Callimachum in reditu enarrando rationem ab Apollonio plane diversam secutum esse. Quae ipsis Callimachi verbis examinatis enucleavimus, eadem etiam iudicio et auctoritate scholiastae freti dicimus. Par enim est, cum fides scholiorum non tam facile quam Schneiderus putaverit subverti possit, hoc quoque argumentum perpendere. Ratione enim satis certa concludendum est scholiastae, qui hae in adnotatione Callimachum bis testem adrocarit, carmina Callimachea satis nota fuisse. Qui igitur illa verba ojòsı

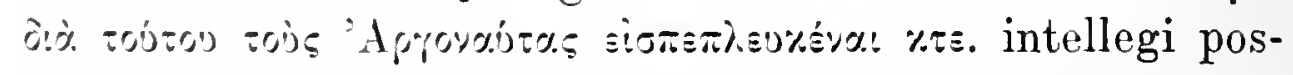
sunt? Profecto necesse esset, si Schneidero adstipularemur, illud ponere quod ne speciem quidem reritatis prae se fert, scholiastarum alterum illa Callimachea, alterum hane adnotationem de Timageto condidisse. Inest sane in scholio illud de Hecataco testimonium quod viros doctos diu rexavit, quod rero id tantum docet aut nomen esse corruptum aut nomulla intercidisse. Tali de causa ne suspicionem quidem de diversis scholii fontibus habere licet. 


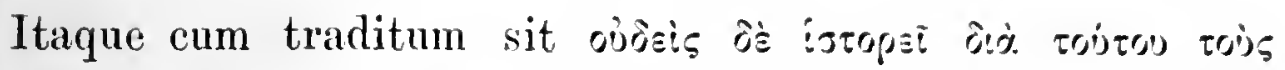

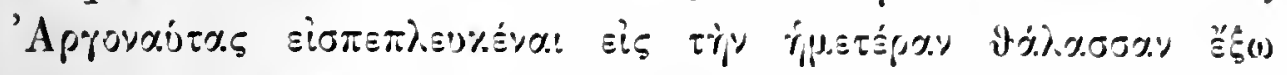

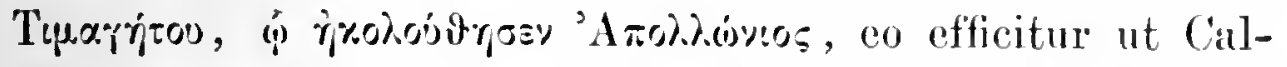
limachus qui commentatori haud ignotas erat per haec verba a numero eorum qui de reditu per Histrum narraverint excludatur.

\section{III.}

\section{DE MIRABILIVM AVSCVLTATIONVM LIBRI CAPITE CV.}

Supra ostendi fragmenta Callimachea nihil omnino praebere, cur fides scholiastae in dubium rocetur. Qnod ut concedas, tamen scriptoris alicuius testimonium in libro, qui auctorem ementitur Aristotelem, servatum sententiae interpretis veteris repugnare videtur. Caput enim CV. libri cui titulus $\pi \approx s i$ ingy.g.

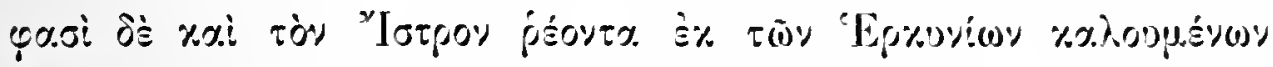

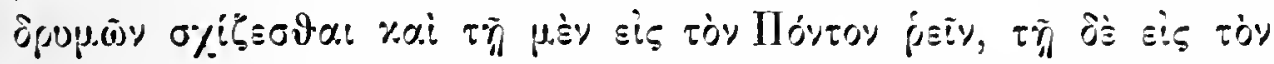

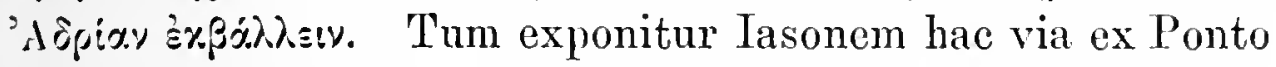
in Adriam rediisse. Cum totum caput in diversis illius fabulosi reditus rationibus exponendis et comparandis versetur, de eius indole fontibusque disserere opus est. Sed initio disputationis confiteor hanc quaestionem suscipcre longe aliud esse ac rem ad finem ducere. Via enim investigandi, ut statim apparebit, perdifficilis est neve me plus consecuturum esse quan quod veri simile sit exspectaveris.

Ac primum quidem caput ipsum $\mathrm{CV}$. inspiciamus, quale sit et quomodo cum ceteris quae in unum illum librum congesta sunt, cohaereat. Duo enim capita CIV. CV. ad regiones circa intimum Adriae sinum pertinent, sic quidem ut quodammodo singularia et a reliquis seiuncta videantur. Nam paulo ante de regionibus Italicis Siculisque agitur, eodemque oratio in capp. CVI. seqq. revertitur. Artior igitur est quasi nexus inter haec duo et firmior. Primum de monte quodam prope Adriam sito, unde etiam 
naves Pontun intrantes conspiei possint, tum de foro communi. uli merentones ah utroque mari sua coemant, andimus. Hactenus hoe capnt. ynod exeipit illud mirabile de Histro in duas partes diviso, quarum altera Pontum altera Arriam petit. Doincle in sequentilus practer opinionem divim cst (ut primum verba tradita respiciamus) istas peniones navigiis pervias non esse. Statim vero argumenta.) proferuntur quilus appareat naves per Histrum usque ad Adriam perrenire posse. Quae vero secuntur ${ }^{2}$ ), in argumentationem de Histro et Adria prorsus non quadrant. Quo enim pacto iter per Planctas factum, reditum per Histrum Adriamque demonstrare potest? Deinde de Argonautarum reliquiis mirabilibus in mari Tyrrheno re-

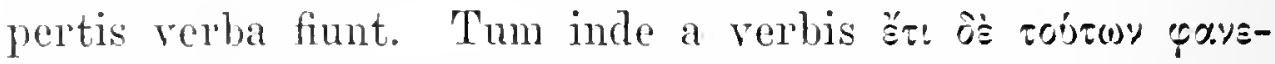

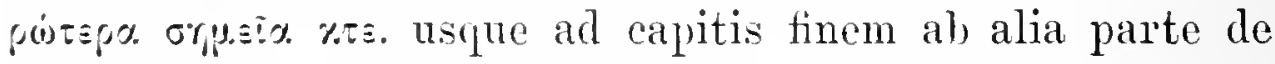
vir reditur disputatur. Inter se enim opponuntur iter per Srmplegadas vel (quod idem est) Cyaneas et reditus practer scopulos occidentales. Acriter quidem contendit horum scriptor Argonantas minime per Ponti ostium domum rediisse: rerba enim poetae, qui ignis procellas a scopulis emitti dieat; solum ad freta inter Siciliam et Italiam referri posse.

Itaque in hac orationis particula quam incongruentia in unum composita sint facile perspicis. Nam cum principio Hister in speeiem fureae dividi dictus sit, repente ad res longe alias neque cum propositis conexas transitur. Jnae quidem opiniones de Argonautarm erroribus permiscentur. quarum una his verbis exprimitur \%oi fò.p 'Í. उ

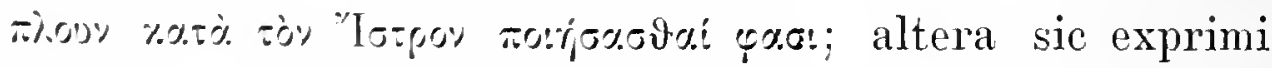

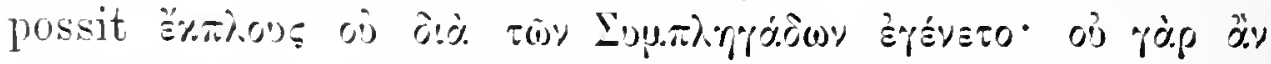

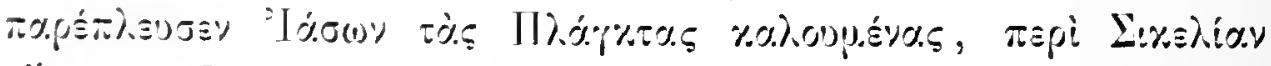
ởsos. Altera igitur sententia viam reditus per Histrum Adriamque exponit, altera, cum rem ab alia parte aggrediatur, potius in opinione vulgata oppugnanda et refu-

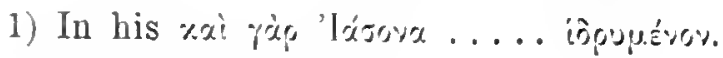

2) $气$ อง 
tanda versatur. Atque ad hane alteram arinumentationem referenda est etiam mentio signorum in Aethalia. maris Tyrrheni insula, repertorum. Ut ian rem paucis comprehendam, omnia quae in hae altera capitis particula contincutur huc spectant, ut demonstretur relitum per mare Tyrrhenum et fretum Siculum actum esse. Practerea apertum est haee argumenta ad aliquem yui in contrariam partem disputaverit vel fortasse ad opinionem fere omnibus notam ac acceptam respicere. Neque is qui demonstrare studeret Argonautas per-Histrum et Adriam cursum tenuisse ea ratione niti poterat; ut illa signa de Planctis et Acthalia afferret. Quod si mili concesseris hoc caput ex duabus partibus et dnobus ratiocinandi modis constare, inquirendum erit quo consilio quave cansa haec dissimilia in unum coniuneta sint.

Ordiamur igitur a parte altera, de enius fontibus haud pauca comperta habemus. Testimonium enim magnopere cum his consentiens, apud Diodorum Siculnm (IV 56) servatur, quod enm ad liane quaestionem disceptandam magnum auxilium ferat, diligentius tractare opus est. Diodorus quidem per libri quarti capp. XI--LVI de tota expeditione Argonautica fusius et continua oratione disseruit, ita ut primum de nave aedificanda, deinde de via usque ad Colchos et rebus ibi actis, tum de reditn per Hellespontum, denique de Medeae Iasonisque fortmis posterioribus rerba faceret. Quae narratio sub finem paragraphi alterins capitis LVI. desinit. Sed Diodorns nondum Argonantica enar-

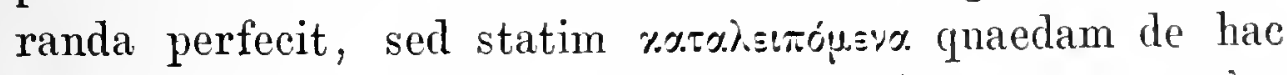

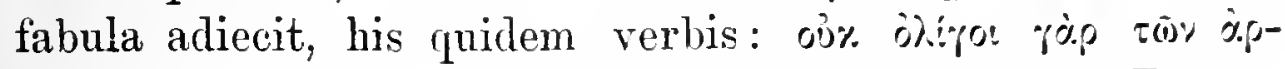

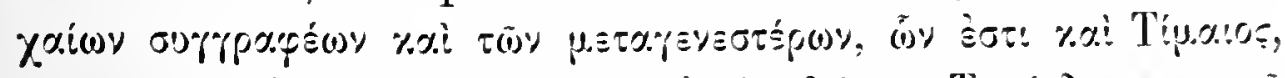

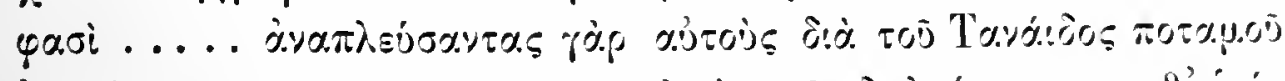

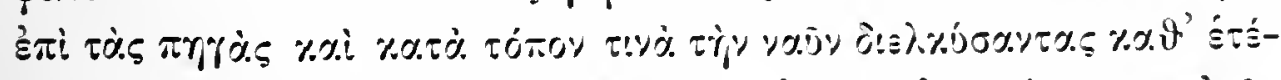

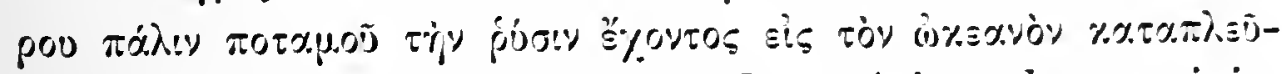

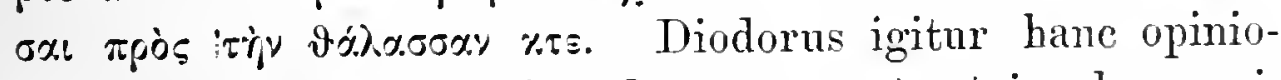
nem de cursu per Tanaim, Oceanum septemtrionalem occidentalemque, freta Gaditana facto quibusdam anctoribus ac praesertim Timaeo tribuit. Quare non dubium est quin 


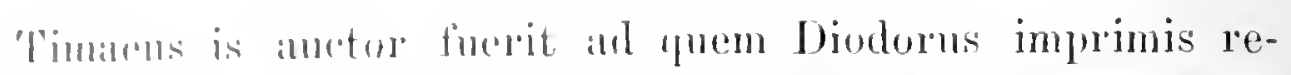

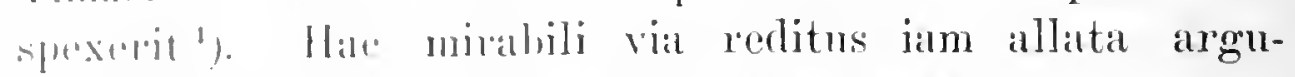

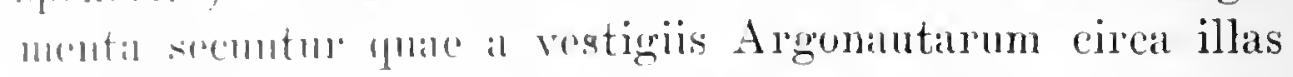

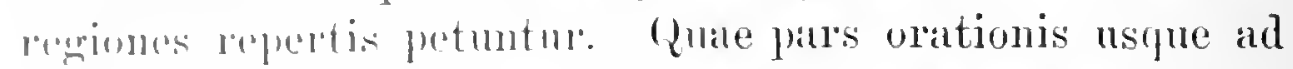

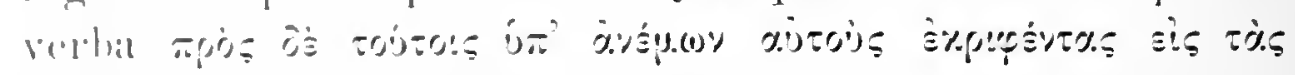

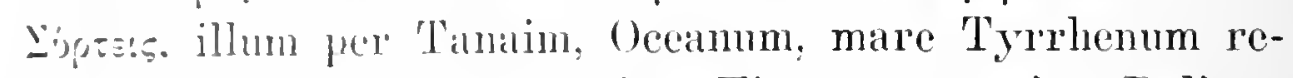
ditmm Ilefendit ot haud drbie a Timaeo manavit. Reliqua vero. yuare sunt de navi in Libyac oras delata, hand scio an al 'Timaco aliudicanda sint. Jeque enim alius testis cxitat qui 'Timace talia tribuat neque, quod maxime rem continet. vis allomenti quod ex rebus geographicis et situ locormm efficitur: etiam ad hatec pertinet ${ }^{2}$ ). Contra ommia quate antecedunt inter se bene congrument et unam integramyne quasi inaginem reddunt. Habemus igitur non solum 'Tinaei sententian de Argonantarum reditu, sed etiam lativnes quas in sententiam corruborandam ille contulit. Profecto hand levis momenti est aestimandum quod ex his Timaenm opinionem snam argumentis confirmasse demonstratur: ac talibus quidem argumentis quae a notitia illorum cilcal Italiam et Tyrrheniam locorum ducta sunt. Sed etiam aliis testibus utimur quorum ope in Timaè opinione enucleanda uonnihil proficimns. In scholiis Apollonii Rhodii ad IV 786 ubi de Argo per Planctas practervecta

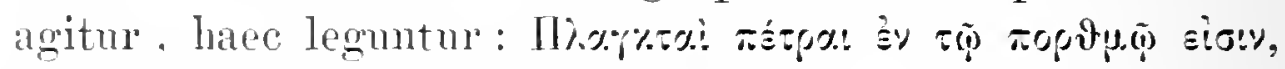

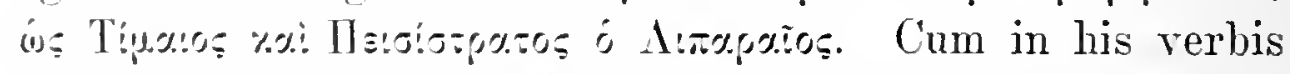

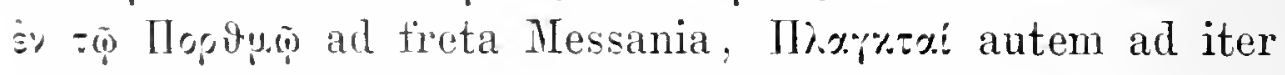
Algunautarum plane respiciat, satis constat Timaeum hunc reditum per freta inter Siciliam et Italiam esse factum cuntendisse. Quae conclusio cum illis Diodoreis omni parte concinit.

Idem Diodorus etiam alia quae hanc quaestionem

1) Sic Enmannnus Cutersuchungen über die Quellen des Pompeius Trogus. p. 195: Die dort stehenden Wrorte heissen für jeden, der Diodors Art zu citiven kenut, nichts anderes als: Timaios evählt, indem or sich dabei auf alte und neueve Schriftsteller beruft.

2) cf. Guentheri dissertationem De ea quae inter Timaeum et Lycophronem interceclit ratione p. 49. 
tangant praestat. Libri quinti capite VI regionem eirea

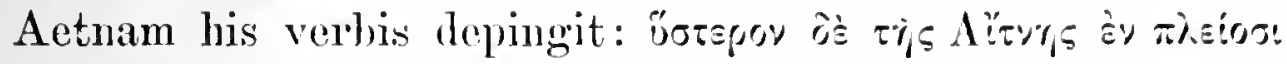

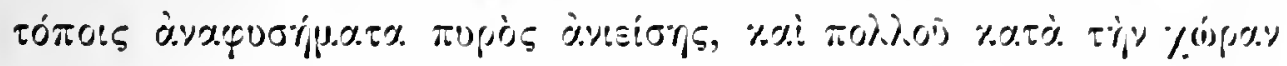

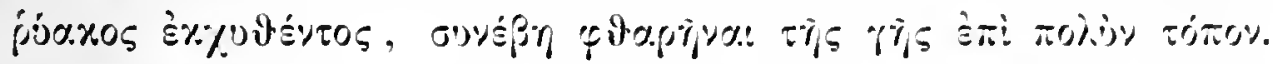
Iam exploratum est') et haec et multa quate initio huins libri Diodorns congessit, nihil esse nisi T'maei doctrinam. Tum Strabonem (V 223) Timaei verba oh oeulos habuisse, recte statnit Guentherus (p. 47) his potissimum comparatis :

Timaens ap. Diod. IV 56 Strabo V 224 $\pi$ epi p.èv qàps tìy Tupprivia. \%o-

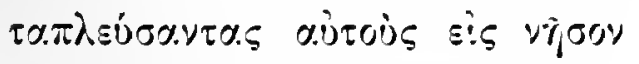

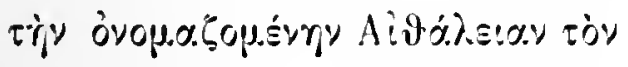

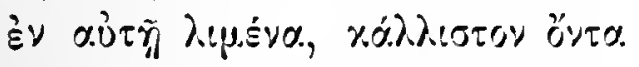

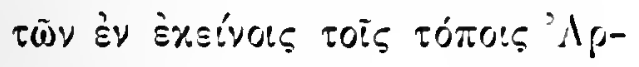

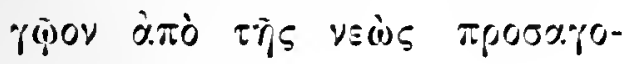

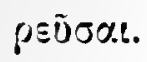

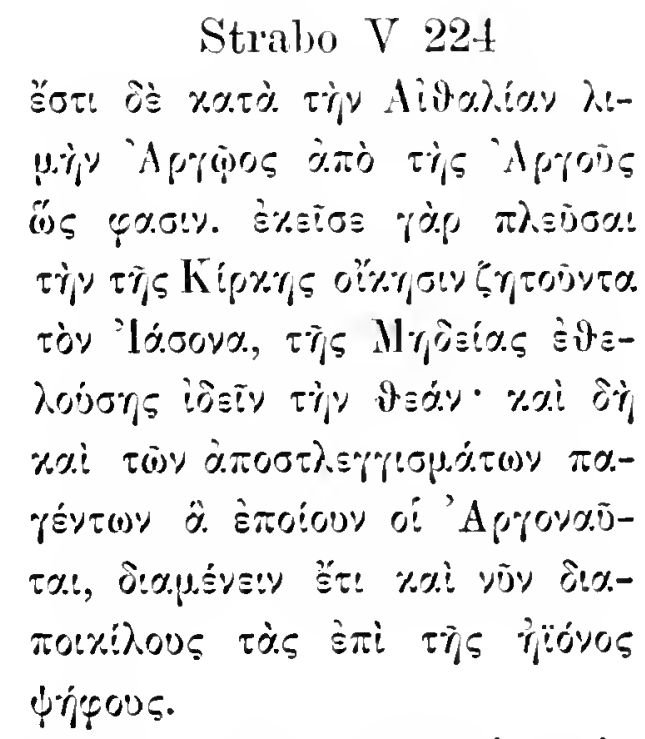

Si igitur omnia ad Argonautarum reditum pertinentia quae ant disertis verbis Timaeo tributa sunt aut ratiocinatione firma ei vindicari possunt, in unum comprehendimus, in aperto est quanta exstet similitudo cum his psendoaristotelicis quae iam tractamus. Quae tamen similitudo totum eaput non attingit. Immo illa pars prior narrationis, quae est de Histro diviso et in utrumque mare delato, tum de aris ab Iasone in Adriae insulis exstructis, plane aliena est ab illis quae omnium testium consensu Timaeo tribuenda sunt. Sed inde a verbis ह̌r:

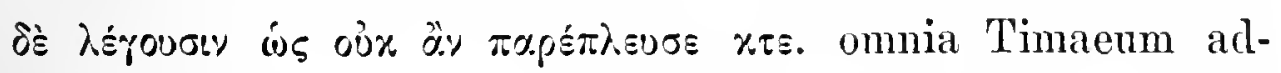
monent. Atque haec sententia manifeste ab eo enuntiata est qui contendit illos scopulos periculosos quos Argo praetervecta sit, in regionibus occidentalibus circa Italiam

1) cf.'Muellenhoffium, Deutsche Altertumshunde I 442 . Guenhterum 1. c. p. 28 adn. 1. Geffckenium, 1. c. pag. 62 . 
et Sirilian sitos esse; id quod Timaeus teste scholiasta an Ap. Rlod. IV TSti revera comntiavit. Tum quae Strabo 1 2.2.t he insula Acthalia narlarit sunt quasi nexus quo illar de cadem insula apud Jiod. IV 56 et haec psendoaristutelica conimgmer. Denique haec de Aetna ut paulo inte vidinus itcon 'Timareo vindicanda sunt.

(Quice cum ita sint, conchusio scriptorem in his conscribendis Timad rexha in sunm nsum convertisse evitari nom potest. Invat igitur ax lis nomulla quae rationem 'Timaei in hac fabula tractanda clarius illustrent colligere. Non solum enim monumenta Argus et ista mirabilia, sed ctiam Homeri verba puasi plurimum valentia, quae quidem demonstrent Planctas in ostio Ponti non esse positas sed circa Aetnam et Sieiliam, adrocata sunt. Item apparet Timaeum non satis habuisse vera vel verisimilia de hac pracelara expeditione narrasse, sed etiam falsa ac perrersa refintasse.

Consequitur ex his hactenus disputatis alteram partem huins capitis et mam simplicemque esse et Timaeo vindicandam. Restat ut locns ille quo oratio a prima in alteram partem quasi transit pancis tractetur. Haec enim

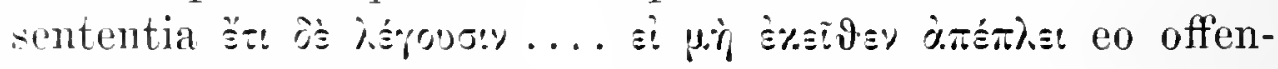
dit quod respicis, iis quae antecedunt minime accomodatum est. Quis enim tale ratiocinandi vitium in se admitteret ut asseveraret opus esse Argonantas, quia per Adriam iter fecerant, idcirco per Planctas navigasse? Quare in difficultate infringenda nihil proficeret qui illud $\Sigma \% \varepsilon$ ivev temptaret. Concedamus enim II.;\%\%rss ad freta Sicula spectare ${ }^{-}$) (id quod dubitari non debet) tum contextus

1) Enmannus quidem 1. c. pag. 193 seqq. ut magno acumine haec tractarit, ita hac in re mea sententia perperam indicavit. Cum enim sibi persuasisset totum caput a Timaeo repetendum esse, omnia quae sunt de Histro et Adria nilil esse credidit nisi argumenta scriptoris cuiusdam qui reditum ler Histrum factum esse contenderet; eidem scriptori quem Timaens impugıaret, etiam hanc sententiam हैa j̇̀ yous: … tribuendam esse. Verba ipsa habes (pag. 196) Die Cyaneischen Inscln lugen an der Mündung des Istros und wurden, und das 
sententiarum tali morlo restitui non potest. Iturne auxilinm alinnde petendum est. Apud Dioblorum rursus materiam ad ea quae desunt supplendal invenimus. Verbat

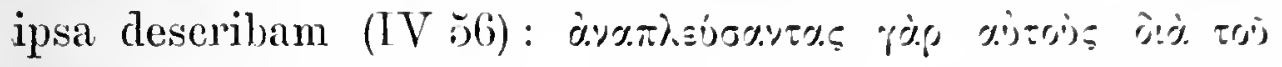

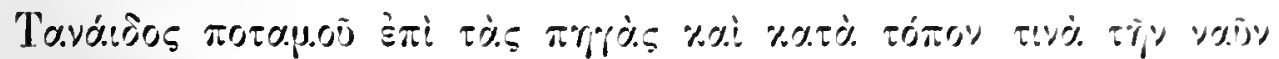

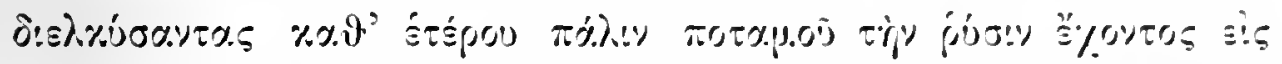

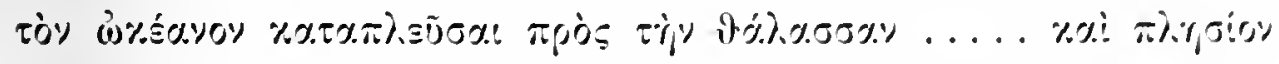

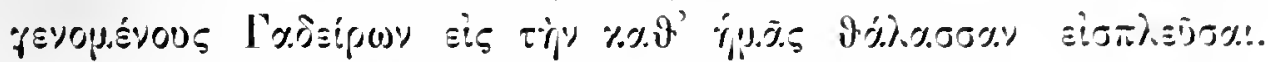

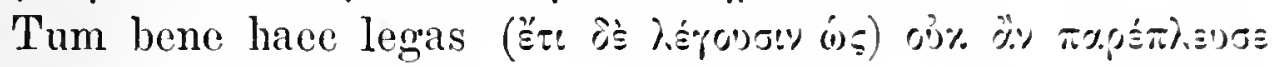

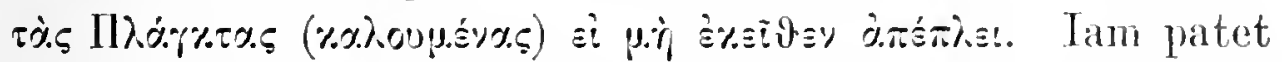

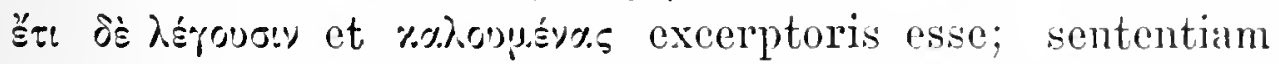
autem condicionalem in qua vis ommis argumenti continetur non excerptoris sed ipsius fontis esse. Imperfecta enim esset ratiocinatio nisi protasis quaepiam adderetur. Com igitur protasis pars integra ac necessaria totius sententiae,

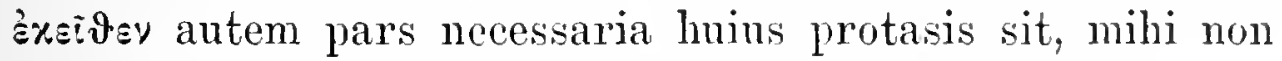

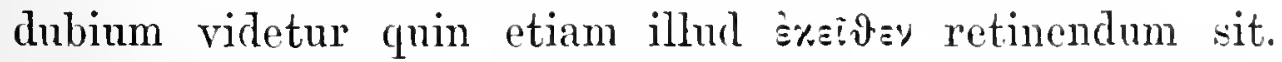

Tali igitur ratione haec altera pars orationis explicari potest. At mihi respondebis explicandum esse etiam totum caput: fieri enim posse ut scriptor aliquis qui sane Timaeo multa debuerit rem consulto narraverit ita ut nunc legimus: apud Strabonem enim V 224 traditum legi

ist das Hanptargument der Gegner des Timaios, idcntificirt mit den Symplegaden. Dieses Argument wird im Excerpt deutlich angeführt:

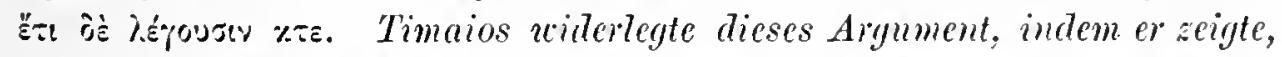

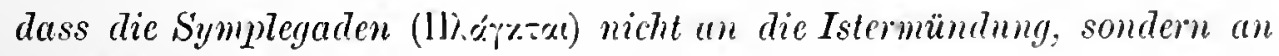
die Mecrenge von Messina zu verlegen scien. Sed baec ratio difficultatis sublevandae eo laborat quod ex se novam difficultatem procreat. Quis enim apud veteres putabat aut Cyaneas aut Symplegadas aut Planctas in Histri ostio esse collocatas? Ne obscurum quidem indicium exstat quemquam talia confinxisse, neque quae in hoc capite de Planctis dicta sunt vel speciem huius opinionis praebent. Nam illa verba

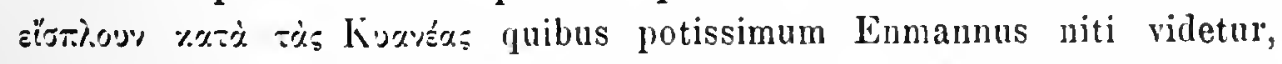

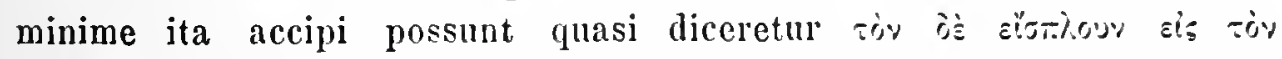

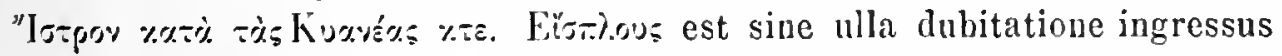
in Pontum per Cyaneas vel Symplegadas factus, qui cum illo egressu per Histrum comparatur. Quae clim ita sint, 'denegaverim talem adversarium Timaei cui Enmannus sententiam tam inauditam imponere voluerit, omnino exstitisse. 
Lasumm and C'ircesinsulam appulisse cum Medea deam visere

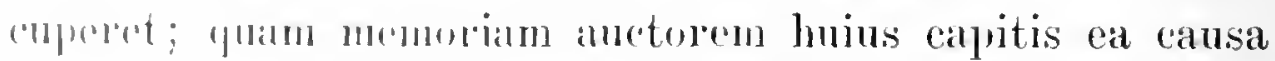
allhihusse nt "xplicaret cur Argonatae, Arlria relicta,

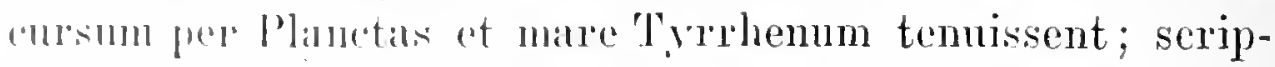
torem initur lunus capitis diversa in unum redegisse, cum Thimalei opininnem et iter per Adriam nova ratione coniunmerect.

Halle fore sententiam fert Geffekenius 1. c. pag. 92. Recte quidem illam difficultatem, quae initio capitis veram sententiam olsenrabat, Wilamowitrio snadente sic sub-

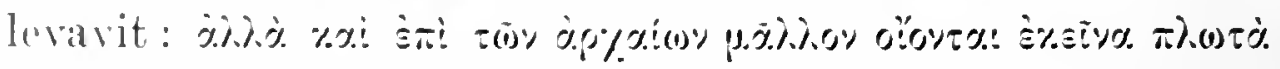

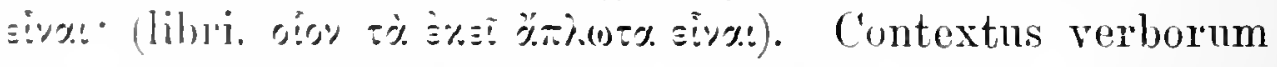
nun tim perturhatus est quam Enmannus existimavit, qui mistinam orationem in his corruptelis latere statmerit.

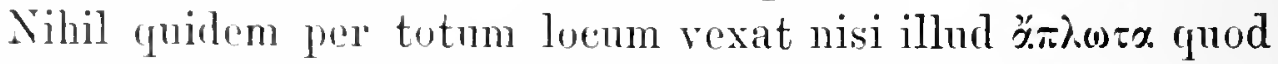
progeswm sententiae repente in contrariam partem conrertit. Sed ex verlis sic emendatis quam rationem Geffclienius conc.lusit, so ist innerhull des Capitels selbst eine richtige Gedunlienfolge hergestell, neglegenter conclusit. Nam hac ratione Circes insula quasi meta totius itineris per Planctas ot mare Tyrrhenum instituti fit, quo heroes cursum direxerunt undeque redierunt. Atque illa monumenta et praeternarigatio Planctarum tum ad propositum demonstrandum valent, si tota vis argnmentationis, nulla ratione situs locorum haljita, in hanc obseuram fabulam collocatur. At mittamus dubitationes et hanc explicationem cui ratio grammatica maxime favet, ponamus; tum mentionem reditus per Histrum seriptori alicui non tantum Timaeo sed etiam Apollonio posteriori tribuendam esse veri simillimum est. Nam talia quae hic composita invenimus consilium grammatici alicnius aperiunt, neque nllo modo geographo nobili reluti Timaeo digna sunt. Quod genus doctrinae Hrgini fibula XXIII, de qua mox agam, optime illustratur. Ob eam cansam ad partem Geffekenii accedere nequeo, qui in his Timaei genuinam sententiam latere statuit. Atque id maxime premendum est, Diodori testimonium (IV 56) qui nolic docet quae Timaeus de Iasonis erroribus protu- 
lerit, principatum obtinere, neque nostris ratiocinationibus infirmari posse.

Sed de his satis dictum est, nam apparet totam quatestionem de prima parte huius eapitis unde et quibus temporibus orta sit, obscuriorem esse quam nt in tanta penuria subsidiorum accuratius definiri possit.

Nunc ad scholium in Ap. Rh. IV 284 ojrès ìe iotopai

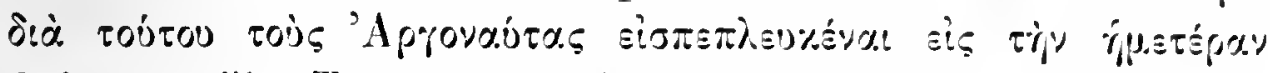

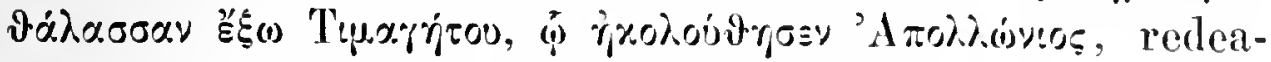
mus, unde tota commentatio profecta est.

Utcumque de his pseudoaristotelicis indicas, fides scholiastae eis non infringitur. Qui cum asseveraret neminem praeter Timagetum ducem Apollonii fuisse, plenam ac perfectam cognitionem totius litterarum memoriae nequaquam sibi arrogavit. Iicet suspieari ad illos anetores qui simul appellantur, potissimum respici, quae coniectura eo confirmatur quod ille reditus per Tanaim et Oceanum quem Diodorus apud Timaeum legebat, non Timaeo sed Scynmo tribuitur. Itaque scriptores omnes quieumque de re exposuerunt enumerare interpres non studuit, sed id tantum contendit Apollonium ab uno pendere Timageto, differre autem ab ea sententia quae Argonautas per Phasim nec minime ab altera quae eosdem per Tanaim in Oceanum pervenisse ferebat, huius poetas, illius Scymnum tamquam auctores gravissimos excitavit. At Schneiderus hisce verbis in eum invehitur ${ }^{1}$ ): manifesto crravit ut docent scriptorum loci a Bectmarmo ad Arist. de Mirabil. Auscult. p. 230 collecti: credebant cnim Istrum fluvium in duas partes scindi, quarum altera flucret in Pontum, altera in Adriam. Quibuscum confer Plinii locum (N. H. 3, 128) ubi hic er'ror quomodo ortus sit sie explicatur: Nullus ex Danuvio amnis effunditur. Deceptos credo quoniam Argo navis flumine in mare Adriaticum descendit non mocul Tergeste, nec iam constat quo flumine. Profecto duas res quae inter se distinguenda sunt, Schneiderus omnino non distinxit, quas res

1) Call. II 81. 


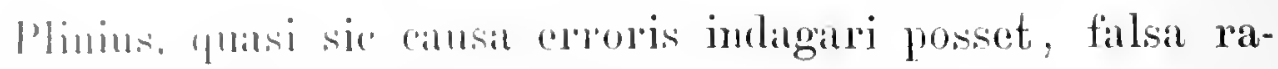
fiomo ropmlavit. Inquiremdmu enim est, quando et quibus ransis hace opinio de Histro etiam in Adriam decurente orta sit, deimele utrum reditus Argonautarum per flumen sir divismm rrorem geographicum progenuerit an potius "x gumiono goograplica pristinus Argonautarum reditus nututus sit.

lit primum quidem dubitari non potest quin lic error do Histri (ursu post Herodotum demum initium ecperit'). Ticit enim Herodotus (II 33) ubi comparationem inter Nilum ot Histrum instituit. Histrum totam Europam permeantem in Pontum Euximum decurere. Tum addit, ó p.غे

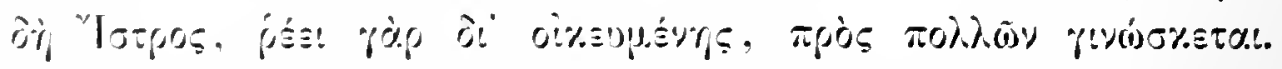
benique fluvios pelecenset ( $\mathrm{I}$ t9) qui per totam regionem "Thracia usque ad Italiam (yoprys 'Op.sp:z(i)v) aquas ad septentriomes in Histrum mittunt. Sine dubio Herodotus cursum Huminis sic non depinxisset, si quidquam de Histro aquas etian in mare Adriaticum mittente audivisset, neque de tali fama tacuisset. Cum probabile sit Herodotum, qui notitiam illis temporibus cximiam labuit, ea quae de hoc flumine tradit mercatoribus qui in Ponto Euximo et Histri ostio versabantur debere fons huius arroris aliunde petendus est. Primum enim testimonium et optimum et vetus. tissimum exstat in libro qui Periplus Scylacis Caryandensis

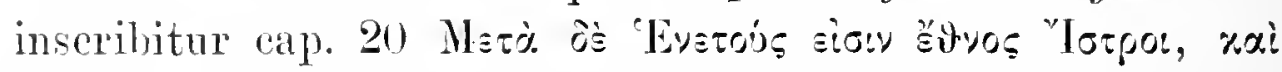

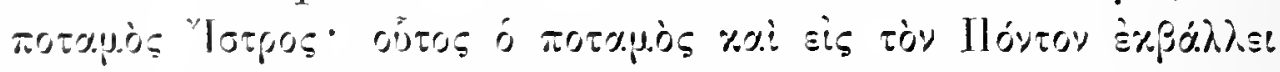
\%๘. \%). Statim movetur suspicio similitudinem nominis eam opinionem quae inter recentiores sacpissime repetita est, erncasse. (Zuod etiam seriptor aliquis vetustus apud Dio-

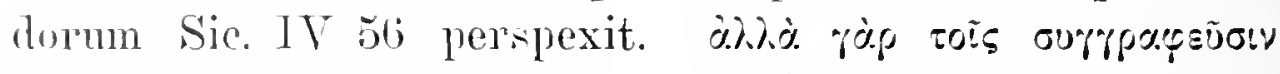

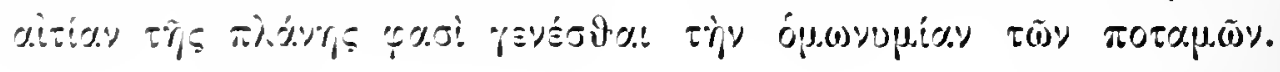

1) Cf. H. Bergerum, Geschichte der wissenschaftichen Erdlunde der Griechen I ST.

2) Etiam Hecataeus gentem Histrorum commemorarit, cf. Steph.

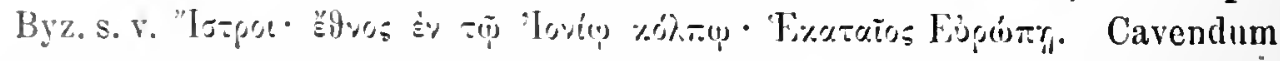
antem est ne Scylacis opinionem ei tribuas. Talia enim neque tradita sunt reque si Hecataeus ea scripsisset Herodotum fugissent. 


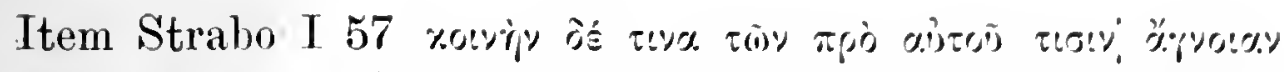

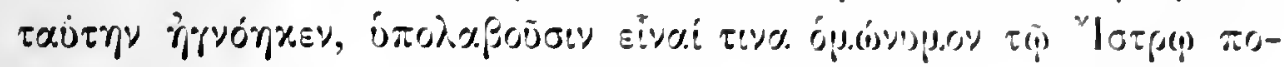

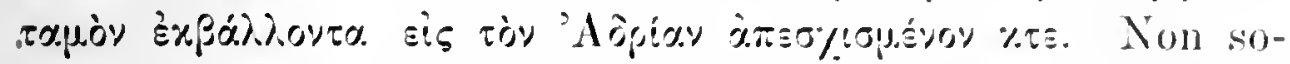
lum Hipparchus quem Strabo in his reprehendit, serl etiam Theopompus ${ }^{1}$ ) sic deceptus est. Hanc opinionem de cursu Histri viris doctis tunc temporis acceptam esse docet locus maxime nobilis apud Aristotelem Hist. Animal. VIII 13:

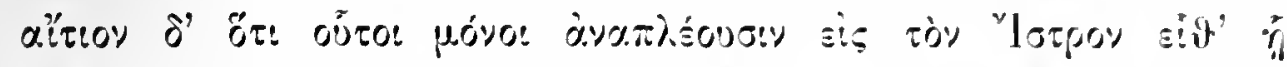

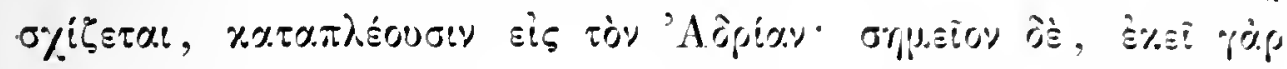

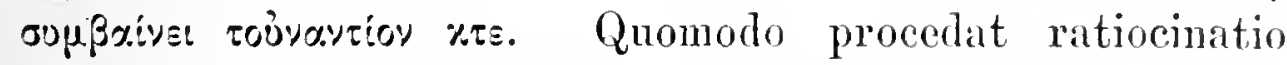
dignum est quod inspiciatur. Exposuit vir magnus de piscibus quibusdam qui Pontum intrantes non amplius egredientes videantur; cuius rei causam esse quod pisces Pontum per Propontidem revera non relinquunt sed per Histrum in Adriam egrediuntur; rem sic se habere hoe indicio (orjusioy) probatum esse, pisces illis regionibus a flumine in mare descendentes capi; contra antem cirea Pontum fieri. Iam perspicies rationem: sciebat Aristoteles cansuetudines thynnorum Pontum intrantium: sciebat quoque consuetudines eorum qui circa Adriam capiebantur: atque credebat Histrum in utrumque mare influere. Quam opinionem quasi fundamentum firmum ac certum posuit. Nam duas res bene notas, quae explicatione carebant, illo tertio de Histri cursu quasi vineulo conimnit et explanarit. Etiamsi ex his enucleari non potest, quomodo haee opinio primo facta sit, tamen plane apparet cur error qui nobis mirificus videtur, tam diu vigere et florere potuerit. Talibus enim fidem dedit vir inter veteres acumine ingenii princeps.

Sed ab alia quidem parte ad rem accedere possumus. In libra de Mirabil. Auscult. cap. CIV. fori commmis mentio fit ubi mercatores a Ponto cum illis ab Adria profectis convenirent ${ }^{2}$ ). Sine dubio in his memoria obscura neque satis intellecta latet commercii mercatorum inter has re-

1) Cf. Strab. VII 317.

2) Cf. Bergerum, Die Geogr. Frag. d. Erat. pag. 347 adn. 1. 
gumes habiti'). (2nan fanna si vulgo circunferebatur nefur conta lurom viarmmue cognitione nitebatur, facillime ppininnm te his regronibus Hurio percursis confirmabat. lam ridimus sacreulo ante Christum quarto teste Seylan nomen gentis et flurii intimo Adriae sinu cum nomine Histri Huvii ingentis congruens exstitisse. Procul dubio neutrum primo ab altero pendebat sed utrumque suo iure usurpabatur. Qui primus flumen per Histrorum fines in Adriam influens pro bracchio magni amnis Pontum Enxinum petentis habnerit, traditum non est. Sed vidimus quihus causis Aristoteles hune errorem receperit: seimms Theopompun quoque haec eredidisse"). Mox alius scriptur nescio quibus temporibus exstitit qui rem ea ratione novarit ut illum fabulosum Iasonis reditum hue collocalet. Magni est quod Apollonius qui totam fabulam versibus expressit, idem narravit. Quo factum est ut haec narratiuncula de Histro apud posteriores fere semper ${ }^{3}$ ) cum hac fabula coniuneta cireumferretur. Cum igitur haee duo quasi inseparabilia et individua fierent, sic quidem ut unum rarissime ab altero seiunctum commemoraretur, profecto non miramur quod Plinius rem sie declarare voluit: deceptos credo, quoniam Argo naris flumine in mare Adriciticum descendit non procul Tergeste. Sed haec conclusio more reterum facta haud probanda est. Causa enim errol'is de Danurio etiam in Adriam descendente per fabulam Argonautican minime explicanda est, sed contra potius. Nam prior est hic error de locorum natura: quo iam accepto mox orta est opinio de Argonautarum reditu per hanc riam effecto.

Tt iam hace de Histro in Adriam influente per similitudinem nominis evocata sunt et per inscientiam regrionm diu forebantur, sic error tum primum sublatus est

1) Cf. Brehmerum, Entleckungen im Alterthum I 2, 406 seqq. qui rem diligeuter exploravit.

2) Cf. Bergerum pag. 347 qui iure dubitat, num Eratosthenes in numero istorum fuerit.

3) Vide antem Hipparchum apud Strabonem I 57. 
cum Romani multis annis post bellum contra Histros gerentes fontes fluminis in proximis montilus invenerunt ${ }^{1}$ ). Itaque, ut rem pancis dicam, haec opinio de Histro quod ad ortum et interitum attinet, ex rationilus geographicis explicanda est, quod antem tam late disseminata ac divulgata est; id Apollonii anctoritate effectum esse dixeris.

\section{IV.}

\section{DE TIMAEO.}

Initio huius commentationis versus libri IV $552-556$ attuli qui mihi monstrare videbantur poetam ad novum caput transire. Quae secuntur ex duabus partibus constant, quarum prima de cursu per Eridanum et Rhodanum in mare internum, altera de via itineris illine usque ad Corcyram est. De hac parte quoniam res magis in aperto est primum paucis agam. Scholiasta enim in universum

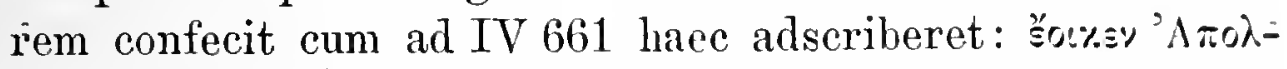

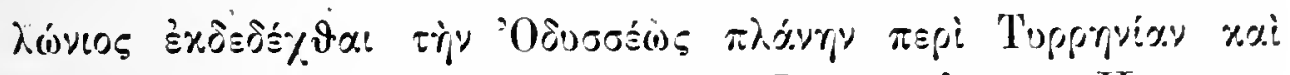

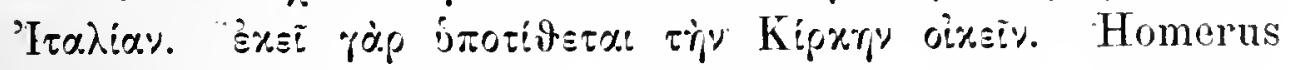
igitur omnium princeps est, .cuins in verba Timaens illustris ille rerum geographicarum scriptor iuravit. Qui quomodo Argonautica narraverit,. partim certo scimus partim rationibus satis validis eruere possumus. Cum autem pleraque diligènter iam tractata sint "), summam rerum breviter proponam.

Et primum fundamentum firmissimum Diodorus Siculus

1) Cf. Iiod. Sic. IV 56. Hoc bellum quibus temporibus gestum sit, non accurate scimus. Anno a. Chr. 17 Hlistri nondum subacti erant. Vid. Zippel die römische Herrschaft in Illyrien p. 175. Tum confer Suet. Caes. 22: et initio quidem Galliam Cisalpinam, Illyrico adiecto, lege Vatinia accepit. Unde concludendum est anno a. Ch. 59 totam regionem circa Adriam ad imperium populi Romani iam adiunctam esse. Rem propius definire nequeo.

2) Cf. 'Guentherus l. c. 27 seqq., 47 seqq., tum quae supra de Pseudoaristotelicis exposui. 
Harebet (IV 56), qui Timaeum Argo navem per Oceanum septemtrionalem et freta Gaditana practer 'Tyrrheniam et oram Italiac redenntem fecisse tradit. 'T'nm scholiat Apolloniana (ad IV 1153, 1217) docent Timacum de nuptiis Medeac Coreyrae offectis et de aris in nuptiarum memoriam prope urbem exstructis egisse. Itaque hos duos quasi tines terminosque habemus in quibus pars reditus cum magna tum per se absoluta includitur. Nam Argonautae ex partibus occidentalibus venientes et praeter Italiam navigantes sine dubio apud limaeum ad Corcyram appulerunt, quem cursum nantae reteres ab occidente Graeciam petentes tenere solebant ${ }^{1}$ ). Sic etiam apud Apollonium procedunt Argonautae. Ergo in hac reditus parte a mari Tyrrheno usque ad Corcyram Timaeus Apollonio praeivit. Sed etiam in singulis consentiunt. Ac primum quidem quod poeta fingit Argonautas ad Circes insulam advenisse aliquatenus ex geographo pendet. Strabo enim

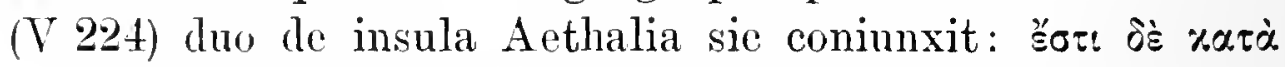

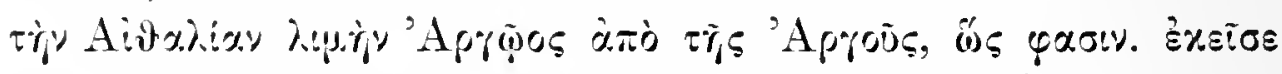

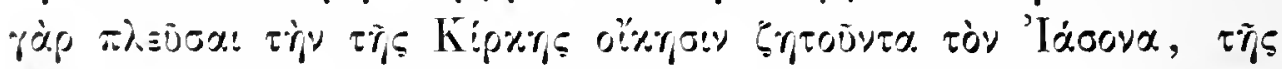

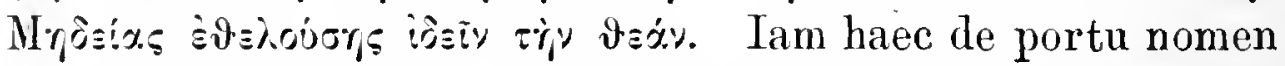
ab Argo recipiente e Timaeo profluxisse locus Diodori passim a me citatus demonstrat. Unde concludas ") Timaeum etiam adventum Argonautarum ad Circen narrasse. Tum magni momenti est quod Apollonius in versibus saepenumero allatis (IV 552-556) se insulas Stoechades et monumenta Argus insignia in mari Ausonio inventa laudaturum esse pronuntiat. Quos versus ut recte aestimemus, mox comperimus (IV 651-652) in insulis Stoechadibus aras et sacra exstare quibus filii Iovis semper colantur. Infra commemoratur Aethalia insula, cuius in litore calculi varii iaceant: ibique discos armaque, denique portum ab Argo dictum Argonautarum vestigia notare. Denique versus 912 seqq. enarrant Buten, Teleontis filium, in mare insiluisse, cum

1) Cf. Thuc. I 36 et 44. Xen. Hell. VI 2, 9. Diod. Sic. XII 54.

2) Quod explicavit Guentherus, 1. c. pag. 47. 
voces Sirenum andiret: eum autem per Venerem Erycis montis deam ex molis servatum esse, ut lilybaeum incoleret.

In his heroum monumentis enumerandis poetit ommino e Timaeo pendet. De Aethalia iam verha feei neque me opus est rem actam agere. T'um de versibus 1549-1553 Geffekenius statuit aras in insulis Stoechadilus an imitationem cultus Tyndaridarum exstructas asse (quem 'limaeus ${ }^{1}$ ) memorat: quae recte sensisse Geftekenius mihi vituetur. Quoniam enim haee mentio sacrorum in 'Tyndaridas obiter tantum cum ceteris coniuncta est, non dubium est quin hic etiam poeta, ut numerum monumentormm augeret. copias Timaei adhibuerit. Denique fabulan de Eryce (9)12 seciq.) Veneris et Butae filio quae etiam apud Diodorum (IV 203, 83) reperitur apud Timaeum fuisse pro explorato haberi potest ${ }^{2}$.

Quae cum ita sint, lucide apparet, quod etiam verba

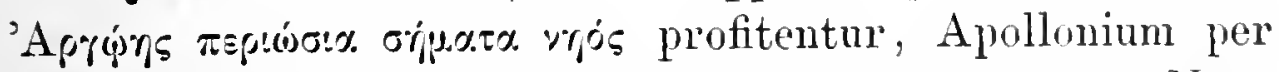
hanc carminis partem T'imaeum presse secutum esse. Nune quidem multo magis patet, cur Apollonius in erroribus Argonautarum depingendis haec de mari occidentali omittere non potuerit. Ibi enim scriptores Homerus et Timaeus, qui auctoritate multum valebant, praeclarissima Argonautarum monumenta monstrabant.

\section{V.}

\section{DE TRIPLICI FLVVIO.}

Quoniam de universa ratione quae in rebus geographicis inter Timaeum et Apollonium intercedit actum est, ad quaestionem paulo reconditiorem transeamus. Primum autem quo consilio ductus poeta iter per Eridanum et Rhodanmm sibi finxerit, summa probabilitate enucleari potest. Scimus

1) Apud Diod. Sic. IV 56.

2) Rem excussit Bethins Quaest. Diod. mythographae pag. 35. 
cnim Timacum talia non protulisse neque ille qui Argo: nantis per Histrum in Adriam navigasse putavit talia necessario fingere debebat. Immo in his plane apparet consilium eins qui se nulla pracelara heroum restigia silentio practermissurum esse profitetur. Habemus igitur in hac de Eridano et Rhodano fabula nequaquam veterem obscmamve rerum Argonanticarum memoriam, quae nisi a poeta retineretur, oblivione obruta esset. Immo nihil quidem sunt hace nisi artificia poetae, qui ita quasi vinculum inter duas carminis partes nectit. De fontibus horum tacent scholia, tacet etiam memoria litterarum, atque recentiores ${ }^{1}$ ) quicumque haec tangunt ab Apollonio pendent. Qui multa novarit, sed ita tantum, ut in suum usum quaedam antea nullo pacto ad fabulam Argonauticam pertinentia cunverteret. Haec paucis examinabo.

Tota narratio in versibus 592-658 continetur, quorum pars maxima fabulam de Phaethonte refert. His expositis, iter per Eridanum non amplius describitur. Tum Argo ad flumen Rhodanum pervenit qui cum Eridano iungitur. Rhodamus ab extremis terris, ubi portus et sedes Noctis sunt, ortum ducens, hic triplicem riam ingreditur aquasque in Oceanum et in mare Ionium et in sinum Sardoum mittit. Heroes huc progressi lacus Celtarum intrant qui exitum in Oceanum habent. Quam viam periculosam iniissent, nisi Iuno a scopulo Hercynio magna voce eos arcuisset. Quare viam repetentes per Celtas et Ligures usque ad mare Tyrrhenum cursum tenent. Sic fere Apollonius.

Ut iam videas qualis sit regionum species quam Apollonius animo conceperit initimm a versu 630 capiendum est. Cum dixit fontes ab extremis terris prope portus et sedes Noctis esse, rem sibi ita finxit quasi Rhodanus ab ultimo occidente profectus, circá eam regionem ubi lacus Celtici siti sunt, in tres partes dividatur quarum una mare Tyrrhenum (est igitur Rhodanus) altera mare Ionium (id est

1) A pollodori Bibl., Tzetzes ad Lycophronem 175. 
Eridanus vel Padus), tertia Occanum petat. How tertium bracchium, si Rhodanus ab occidente Huit, in ()ceanum septemtrionalem descendere necessario eonchulimus. Atque lacus illi, in quos primo heroes cursum dirigunt, sunt quasi pars brachii tertii, nt etiam ex versibus 634 seq. patct.

Iam talis regionum facies quae nobis quidem mirifica et vana videtur, tamen pro somnio poetae minime est habenda. Vossius recte cum rei naturam tum poetac ingenium perspexit, cum negaret ${ }^{1}$ ) Apollonium rationem rerum geographicarum sui propriam, aequalibus antem inauditam ac ignotam propositurum fuisse. Immo latet notitia quatedam lacuum Helveticorum et Rheni fluminis ${ }^{2}$ ), obscura quidem et falsis permixta, attamen ad opiniones explorandas quae tum temporis de illis regionibus ferebantur, haud spernenda.

Ac primum quidem interdum etiam apud recentiores testimonia de locorum situ parum accurata invenimus, quae ad haec Apolloniana prope accedunt. Haec exempli gratia

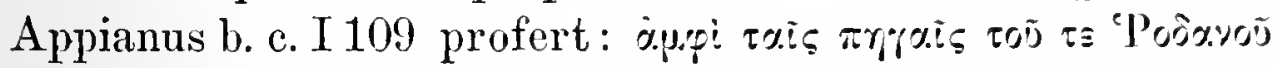

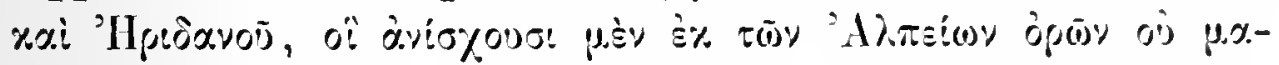

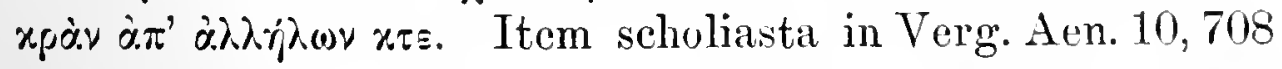
dicit utrumque fluvium in uno monte fontes habere: sane de hoc Vesulo quidam duo flumina Rhodanum et Palum nasci dicunt, quorum unus, id est Rhodanus, in Tyrrhenum mare alter, id est Padus, in Adrialicum fluit. Haec igitur medium locum obtinere videntur inter Apollonium qui fontes communes accepit et Strabonem ${ }^{3}$ ) qui veram fluviorum rationem cognovit.

Tum de fontibus Rhodani et Rheni etiam inter Romanos diu remanebat ignorantia. De qua re Mommsenus in Hermac vol. XVI pag. 445 seqq. disseruit, demonstrans ipsum Iulium Caesarem eam Rhodani partem quae in lacum Lemannum influit pro Rheni initio habuisse. Nisus

1) J. H. Vossius Kritische Blätter II 390.

2) Cf. Bergerus Gesch. der wiss. Erdkunde der Griechen I 21.

3) IV 204. 
(sit vir duetus his locis Commentin'iorum de Bello Gallico 18, III I. IV 10. Xam cum C'aesar Rhenum per fines Nantuatium ferri dixerit (IV 10), plane ad eam gentem respieit yui regiones inter lacum I emannum et summas Alpes ineulit (111 1): videtur igitur ille hoc flumen quod in lacum influit, Rhodamum non appellasse (I 8) neque hoe ullo modu respexisse cum de Rhodano ageret: atque plane "plaret Cacsarem ipsum has regiones numquam visisse ${ }^{1}$ ). Denique ipse Strabo IV 207 ex uno lacu aquam in $\mathrm{Hi}$ strum et in Arliam profluere tradidit. Quis sit lacus et qui fhrii propter memoriam verborum imperfectam inter viros doctus dissensio quaedam est. De sententia dubitare non licet. Vides ergo cum etiam Strabo in hoc genere peccaverit, quantum valuerit vetus error.

Iam certa mentio Rheni apud scriptorem ullum ante Apollonium non exstat. Eratosthenes enim utrum Rhenum commenorarit necne, non constat. Inter fragmenta geographica unum tantum quod ad hanc regionem spectat (apud Cacsarem de Bello Gall. VI 24) est de Hercynia vel Oreynia silva. Tum descriptionem Rheni quam Ammianus Marcellinus XV 4, 3 serr. luabet ad Eratosthenem esse referendam recte Bergerus denegavit ${ }^{2}$ ). Nihil igitur superest quod certa ratione principi geographorum tribui possit. Itaque in tanta reliquiarum paucitate poetae gratiam habemus qui memoriam de his regionibus ut falsis permixtam ita reterem atque singularem prodiderit. Klausenus quidem ctiam Hecataeo similia vindicare studet (Frag. 22): testimonio Arieni in rss. 680 seqq. ${ }^{3}$ ) Orae maritimae nisus. Quamobrem quam tabulam orbis terrarum ad opiniones Hecataei descripsit, sic conformavit. Tum Vossius ${ }^{4}$ ), item hos Avieni rersus tractans, Aeschylo,

1) Cf. Mommsenum ibidem.

2) Erat. Frag. 361 seqq. Sic etiam Mommsenus Hermae vol. XVI pag. 621 .

3) Apud Holderum.

4) Krit. Blätter II 390, 417. 
Euripidi ${ }^{1}$ ), potissimum antem 'Timateo hane opinionem do triplici fluvio tribuit.

Sed verba Avieni nihil ad rem. In his enim

$$
\text { „rursum efflums }
$$

Arctansque sese fluminum ad formam, dehinc

Atlanticos in gurgites, nostrum in mare

Et occidentem contuens, evolvitur",

haeremus in particula ct ${ }^{2}$. Iam si te triplici vel quidem de duplici fluminis cursu ageretur, particulam post gurgites flagitares. Etiamtum res nondum in aperto esset. Muellenhoffius ${ }^{3}$ ) enim, versus Orae Maritimate 55 sey. $83 \mathrm{seq}$. 393 seqq. conferens, Avienum mare internum pro sinn Atlantici habere statuit. Denegat igitur rir doctus ullam omnino memoriam de Rholano in duo maria aquas cvolvente hic exstare. Rem amplins illustrare nequeo. Sed infirmius hoc esse fundamentum apparet quam quo freti ad Hecataeum Rheni et triplicis fluvii cognitionem referamus.

\section{VI.}

\section{DE APSYYRTO.}

Quomodo Apollonius hanc primam reditus particulam composuerit et depinxerit, quod ad res geographicas attinet, iam satis tractatum est. Restat autem antequam ad norum procedimus, ut aliam quaestionem quac etiam huc pertinet, de Apsyrto Medeae fratre qui Argonantas persecutus ac denique dolo occisus est. instituamus. Ac primum quidem par est inquirere, quomodo Apollonius hane fabulam in contextum suae narrationis inseruerit, tum quo consilio ductus hac in parte rem norarerit. Primum igitur quae de Apsyrto narrata sunt paucis percensebo.

1) Ne talia de Aeschylo et Euripide credas, adeas quacso Knaackii Quaest. Phaeth. pag. 17.

2) Cf. A. Sonny de Massiliensium rebus quaestiones p. 61.

3) 1. c. 196 seq., 194. 
Prima mentio huius Aretae filii libro tertio rss. 241 sqq. fircta est. Poeta lasonem filiis Phrixi doobusque sociis comitatum ad domicilinm regis Colchorum aceedentem faeit; andes mas multo splendidiores Aectem eiusque coniugem habitare, alteras vero filium Apsyrtum quem ex Asterodia nympha Caneasia progenuerit, prinsquam Idyiam Tethyos et Oecani filiam, uxorem duxisset ${ }^{3}$ ): eundem a Colchis Phathontem appellari, quia omnibus praestiterit. Altero loco Apollonius tilio Aeetae hoe nomen ipse indidit, sub finem libri tertii v. 1236 ubi splendor armaturae Colehorum regis depingitur. Rex armis fulgentibus indutus in currum escendit: escendit etiam Phaethon equorum rector. Tum in versibus 223 seqq. libri quarti legimus, aureo vellere iam rapto, Aeetan, quem Apsyrtus auriga comitetur: fugientes Argonantas persequi. Cum antem Argo, fluvio iam diu relieto; in mare eursum dirigeret, Aeetes Colchos statim navibus consectari iubet neque prius domum redire quam Iledeam prehenderint. Horum Colehorum persequentium alteram partem ducit Apsyrtus, et Histro per Ostium Pulchrum intrato (303 seqq.) ante Argonautas in mare Ionium penetrat ostiumque loe valida manu oceupat. Argonantae antem qui sie Medeae causa in magno perieulo versantur, istam Colchis dari iubent. Quod consilium ubi Medea comperit, ut a se casum tam miserabilem avertat, Iasoni lacrimis precibusque persundet ut Apsyrtus fraude vecidatur. Quae igitur Medeae mente ae consilio exeogitata sunt, Apsyrto in insulam

1) Scholiasta qui versum 244 sic interpretatus est quasi de genere Asterodiae dictum esset, procul dubio erravit. Statim enim apparet in calce scholii, ut saepissime fit, opiuionibus scriptorum quorundam de uxore et matre Aectae iam allatis, explicationem versuum ipsorum esse additam. Quid vero Apollonius velit, nou solum ratio grammacica sed etiam alia indicia docent. Quoniam enim Asterodia nympha Caucasia est, non est Oceani filia, neque poeta hac in re ab illustri Hesiodi genealogia distare voluerit, qui in Theog. vss. 352, 959 Idyiam filiam Oceani Tethyosque uxorem Aeetae Medeaeque matrem iam novit. Ergo non dubito quin scholiasta parum accurate procedens res diversas confuderit. 
Dianae sacram allecto Iasonis manu conficiuntur. De sepultura ibidem facta poeta haec addit: $480 \mathrm{sel}$.

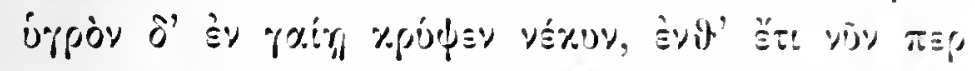

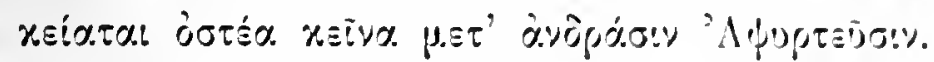

Colchi antem duce amisso metuentes sine Medea an Aeetem redire, in proximis insulis et oris 1llyriac nova domicilia constitumt. Attendas quaeso poctae ipsa verlan qui incolas insularum nomen Apsyrti accepisse monet: 514 seq.

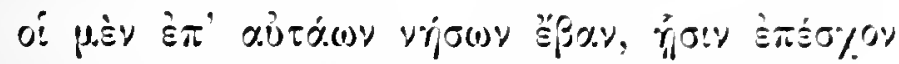

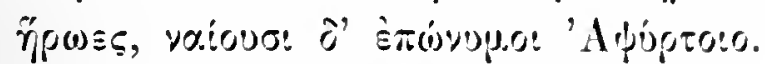

Denique (ut nihil omittam) hoc nefas Jasonis et Medeac, in Apsyrtum commissum, in causa est cur Argonatue late vagantes ad insulam Circes, quae una paricidio obstrictos expiare possit, appellant.

Iam ante oculos habes quae Apollonius de Apsyrto protulit. Quae si in universum inspexeris, in hace duo maxime animum advertes. Nam quod Apsyrtus iam adultus Medeaeque maior natu est et in recessu septemtrionali Adriae occiditur, haec apnd superiores, quoad saltem memoria litterarum nobis iudicium permittit, non reperiuntur. Primum est ad consilium poetae in his enucleandum, ut inquiramus quomodo poeta de Apsyrto fabulam ceteris intexuerit. Mea quidem sententia, quae Apollonio propria sunt minime ab hac parte intellegi possunt quod heroes ad paricidium expiandum Circen petunt. Nam pari iure poeta haec fingere poterat, si sicut superiores Apsyrtum infantem vel puerum in Colchide necatum narrasset. Neque quod Apsyrtus auriga comesque patris indneitur rem declarat et explicat. Hoc munere sane functus est Aeetae filius: tamen ita rem non attingimus. Quid tandem sibi vult iste anriga qui tantum commemoratur neque in rebus conficiendis quidquam valet? Immo poeta ipse in illis verbis supra citatis nos monet quo oculos intendamus. Nam Apsyrtus Apollonianus nihil omnino efficit misi quod moriens et in insula sepultus causam nominis (quod Graeci a.trcov . vocabant) explicat. Ne dubium quidem est quin 
poetac docto tale veriloquium maxime placuerit, atque hine etiam apparet cur Apollonius reditum Argonantarum sic conformaverit ut via per Histrum in Adriam peteretur.

Nunc fortasse exspectas me station longius progressurum et de Ajollonii fontibus esse acturnm. Quae via ut recta ita difficilis et obsenra est. Mihi igitur persuasi neque a proposito alienum neque inntile esse eam viam ingredi ut totam litterarum memoriam quae huc pertinet percenseam ale disponam. Unde spero me quam maxime ad verum in tota causa examinanda accessurum esse.

Ae primum quidem etiam retustis temporibus de Medeae fratre a sorore cruleliter necato fabula circumferebatur. Quare procul dubio a juo tempore homines fugam Medeae a patre patriaque enarrabant etiam foeda fratris caedes est pervulgata. Hesiodus sane quo vetustior auctor Medeam non commemoravit, in iis quae aetatem tulerunt, nihil de fratre habet. Hic autem in tantis reliquiis a conclusione ex silentio effecta nos contineamus. Inter auctores qui et Medeae fugam et fratris mortem rettulerunt, princeps est Pherecydes, qui, teste scholiasta in Ap. Rh. IV 223, 228 Medeam Iasone iubente parvum fratrem e lecto rapuisse et ad Argonantas tulisse tradidit: quos cum Colchi persequerentur, membra occisi et dispertiti pueri in flumen iecisse. Ex lis efficitur facinus in Colchide esse factum et eo quidem consilio nt persecutio Aeetae retardaretur. Snspicor ex his Pherecydeis priscam et genuinam fabulae formam elncere. Frater enim in fabula vix suo iure exstabat, sed ea cansa ut caedes eius moribus Medeae veneficae scelestae convenienter narrata hos mores maxime illustraret.

Tum scholiasta eodem loco quae fnerint apud Sopho-

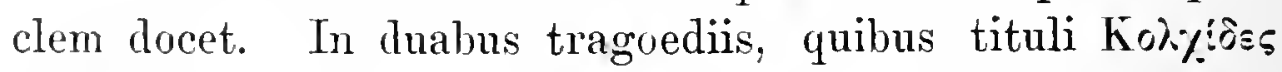
et Lisos: erant, rem tetigit poeta; puerum qui alia matre ac Medea natus esset, domi Aeetae periisse. Quae in universum ab illis Pherecydeis non distant. Hactenus autem Sophocles diversa habet quod puer qui ex alia matre susceptus est domi navi nondum conscensa trucidatur. 
Euripides rem obiter commemoravit, ter quidem nt nos certiores faciunt versus Medeae 167, 13334-1335) 'um scholin

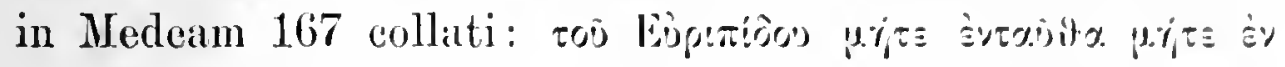

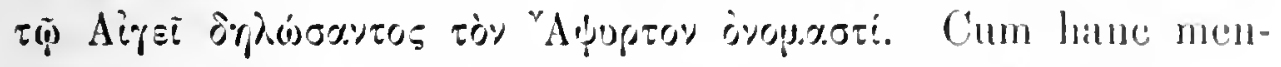
tionem in fabula Airsós scholiasta ad versus Medeac

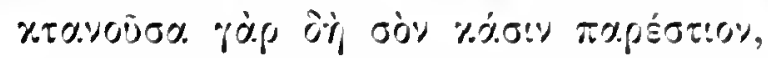

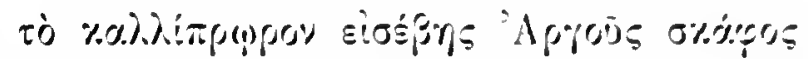

conferret, quam leviter Euripides rem perstrinxerit fiucile

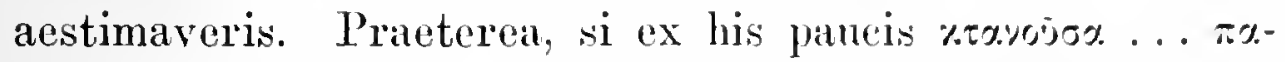

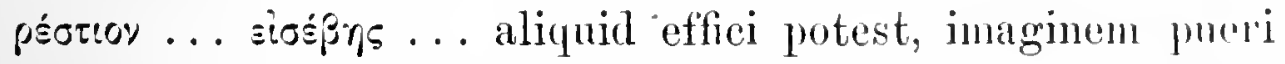
domi Aectae interfecti, sicut Sophocles sibi finxit, ctiam Euripides ante oculos habuit. 'Tres igitm testes nobiles interrogarimus, qui etiamsi in singulis paulo distant, tamen in his consentiunt Medeam fratrem in Colehide interfeeisse. Sed restat aliud magni quidem momenti, de yno hactenus tacui.

Si enim in his rebus investigandis omnia ex scholiis Apollonianis solis haurire necesse esset, conclusio de nomine huius fratris faeillime pracmatura et inperfecta fieret. In scholiis enim ubicumque de Phereeyde ct Sophocle agitur puer semper Apsyrtus vocatus est. Quod mirum non videtur, quoniam Apollonius, a quo in universum memoria vulgata pendet, hoc nomen praeoptavit. Apud posteriores igitur nomen Apsyrti adeo valebat, ut appellationes ceterae fere oblivioni darentur. Ad verum autem nos revocat adnotatio scholiastae in Eur. Med. 167, quam cum ad hane disputationem valde pertineat, hic describam: T:p.oyica...

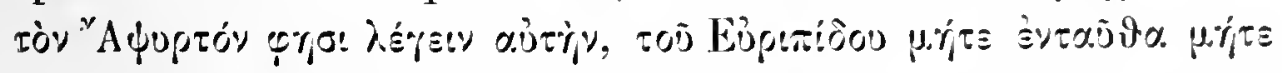

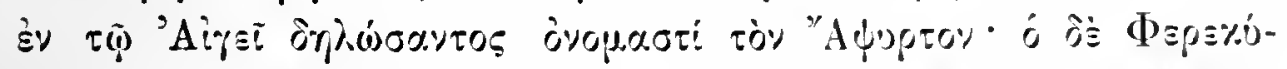

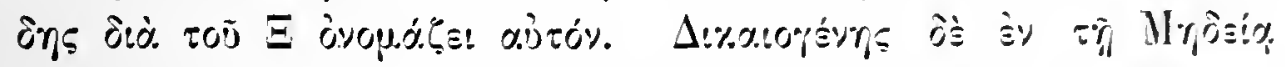

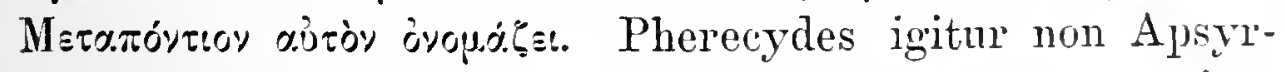
tum sed Axyrtum novit: Euripides puero nomen proprium omnino non imposuit: Dicaeogenes, poeta tragicus saeculi ante Chr. quarti, qui fabulam Medeae eondidit: puerum Metapontium appellavit.

Quae cum ita sint, res digna est quae accuratius investigetur, ut quae diversa diversi auctores habent distin- 
muantur. Et primum Apollonius iis locis quos panlo ante cummoravi nomen Phacthontem retinuit (III 245, 1236). Explanat same Colchos hoc cognomen addidisse quia Apsyrtus inter invenes praestantissimus fuerit. Revera autem musfuam per totum carmen praestantia ista elucet neque ulla causa ac ratio numinis apparet practer studinm illud doctrinate ostentandac, quod Apollonius semper et ubique prae se fert. Itapue non audax est conclusio hane appellationem ea cansa servatam esse quod superiores tradiderant. Accedit quod scholiasta aliud testimonium de hoc nomine

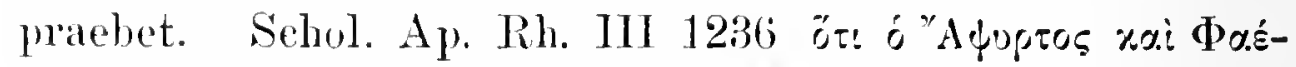

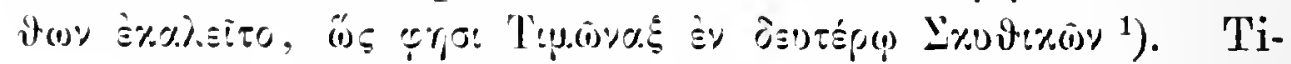
monax qui fucrit et quando floruerit, eerto non constat neque ulla memoria nisi in his scholiis ad nos pervenit. Hace autem pauca docent Timonactem duos saltem libros (cf. schol. III 1236) de rebus Seythicis edidisse et fabulam Argonanticam tetigisse (cf. schol. IV 1217). Ita quidem procedit (cuod fragmentum nobile scholio ad IV 1217 intextum docet), ut ad terras describendas et nomina explicanda fabulas adhibeat. Et in fabula Argonantica tractanda viam propriam ingressus est, ut Iasonem Aeeta spondente Medeam in matrimonium duxisse referret. Quare memoria apud T'imonactem in his quae ad res in Colchide gestas pertinent, a ratione non solum Apollonii sed etiam Phereeydis Sophoclis Euripidis plane distabat. Iam quae Timonax de hoc filio Aeetae protulerit, cum neque adulescentem fugientes Argonautas insectantem neque puerum crudeliter interfectum depingere potuerit, nescimus. Tantum dubio obnoxium non est, scriptorem rerum geographicarum qui ex Apollonio pendere vix potest nomen Phaethontem usurpasse.

1) Haec non significare Timonactem utrumqne nomen usurpasse ex genere dicendi in scholiis usitato satis apparet. In his enim $\delta \pi:$

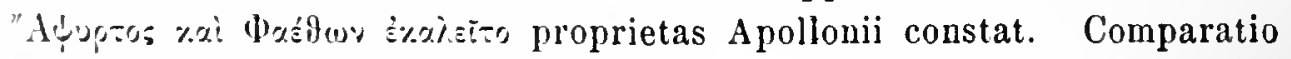

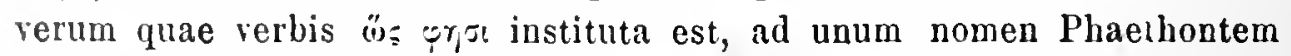
spectat. Cur igitur Timonacti etiam nomen "A uporos tribuatur causa non exstat. 
Quo nomine filius Aeetae apud Sophoclem vocatus sit, num nomen omnino tulerit, sane nescimus. Nam denego certo affirmari posse soli tide scholiorum in IV 22:3, 2.28 nomen Apsyrtum apud Sophoclem exstitisse. Contra mihi veri videtur simile Sophoclem filium Aectae Phacthontem appellasse. Puerum enim ex Solis gente prognatum tale nomen tulisse aptissimun est. Atque testimonium Apollonii, qui hane appellationem praeterire non vilt, demonstrat etiam antea filium Aeetae esse Phaethontem vocatum. Maxime autem confirmant hane coniecturam scholia Apolloniana in III 242, IV 223 cum Homeri Odyssea p. 132 seq. collata:

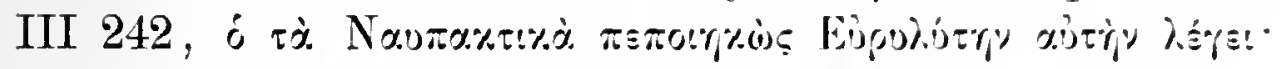

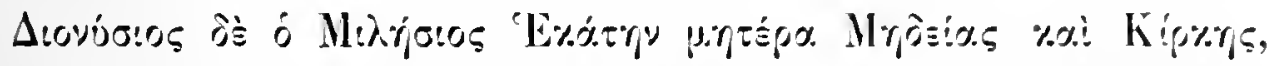

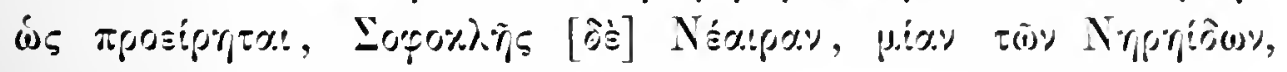

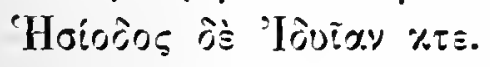

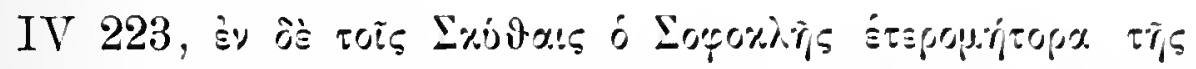

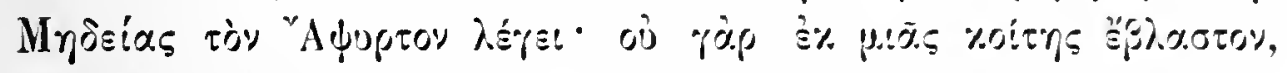

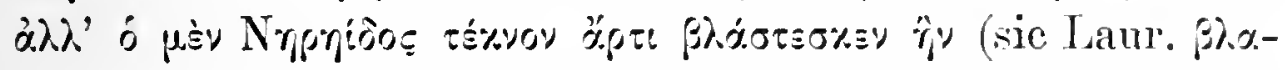

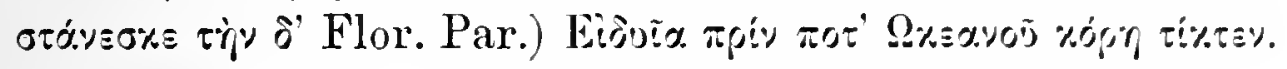
Od. « 132 seq.

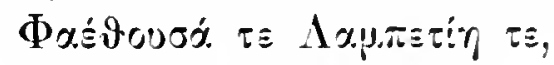

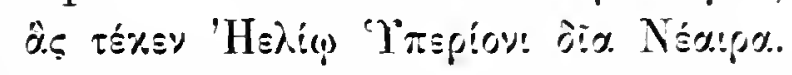

Plane confusum est primum scholium (III 242). Nam cum poeta in versibus qui explicantur duas Aeetae uxores commemoraverit, exspectamus commentatorem eandem distinctionem ante oculos habere. l'ergit ille quasi de nympha

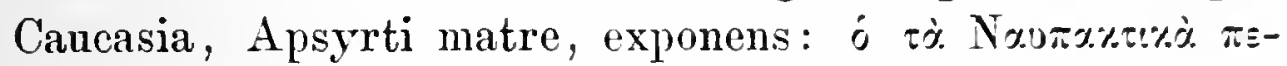

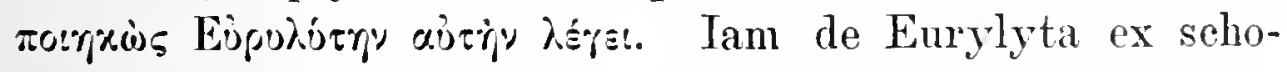
liis IV 86 plura comperimus, unde patet eam, quo tempore expeditio Argonantica fiebat, Aeetae uxorem fuisse. De altera coniuge in Naupacticis commemorata nihil omnino scimus. Ergo hoe scholium, quod primo docere videbatur Eurylytam carmine Naupactio isti Asterodene respondere, minime ad talia comprobanda valere potest. Sed station in sequentibus dilucide apparet in quo scholiorum

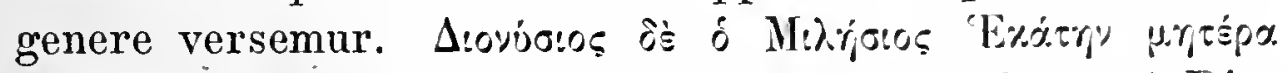

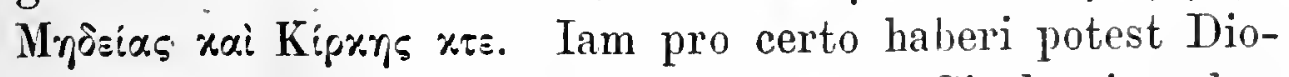
nysium Milesium illum fuisse cui Diodorus Siculus in rebus 
Arenatuticis enaramblis multa debet $\left.{ }^{1}\right)$. Confer igitur

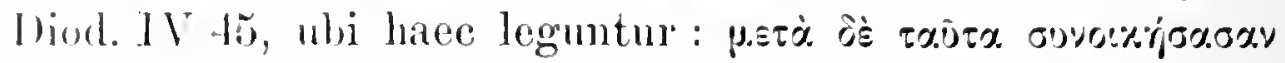

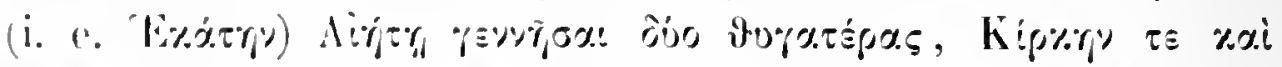

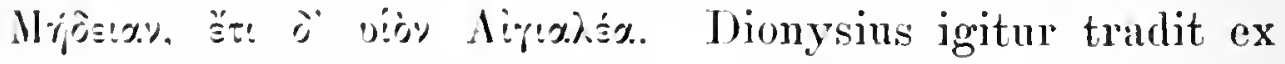
una matre Herate ommes esse susceptos. Quid igitur? Nune comeludere licet quod iam ex his de carmine Nanpactio elucehat, scholiastam rem neglegenter tractasse neque ommino id respexisse quod primo obtutu maxime respicere videtur. Revera de duabus Acetae uxoribus ne cogitavit quidem, neque vestigia Apollonii pressit qui alia matre Apsyrtum, alia Medeam natum esse dicit. Immo varias ex dirersis fontibus sententias de nomine Aeetae coniugis composuit et ad hune versum illustrandum adscripsit.

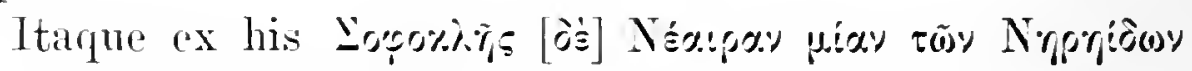
nihil praeter nomen Neacram comperimus: ntrum autem illa Apsyrti an Medeae mater fuerit, adhuc incertum est ${ }^{2}$ ). 'Tollit autem ut mihi videtur hanc dubitationem scholium in IV 223. Sed primum pedem sistamus et locum difficultatum plenum propius inspiciamus. Numerorum ratio quomodo restituenda sit, quaerere nolo. Ad propositum enim satis erit, si recensionem verborum pau-

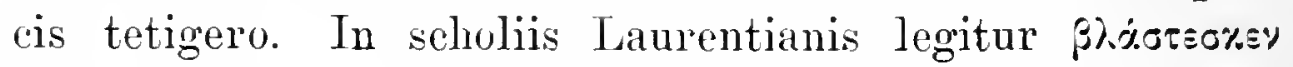

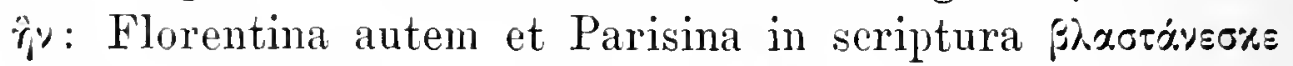
rivy o' proferenda consentiunt. Mittamus iudicium inter

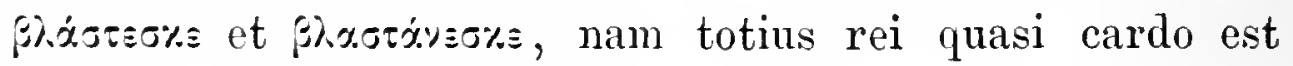
quaestio inter $\hat{r}_{y}$ et $\tau \dot{r_{y}} \bar{\partial}$.

Iam quod ad fundamentum criticum in scholiis recensendis attinet, alio loco demonstrare conatus sum hos qui vulgo deteriores fontes appellantur haud spernendos esse. Disceptandum igitur est inter has duas scripturas utra melior sit. In universum sententia minime incerta est, natos Aeetae eadem matre non susceptos, filium quidem

1) Cf. Bethium Quaest. Diodoreae mythographae pag. 13.

2) Sic Nauckius Trag. Gr. Frag.: Quae dubitari potest utrum de Apsyrti an Medeae matre intellegenda sint. 
ex Nereide procreatum esse. Si scripturam Lamrentiman $(\hat{r}, y)$ ponimus, tum poeta in sequentibus unde nata sit illa Nereis explicat. Si contra alteram verbormu memoriam

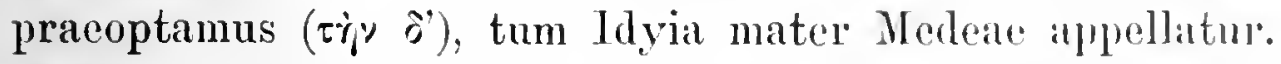

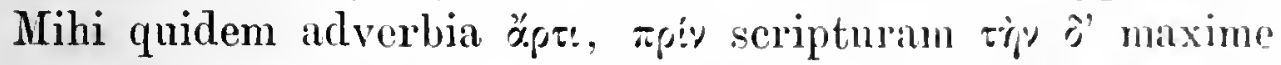
confirmare videntur ${ }^{1}$ ). Particulae enim quamman vim habeant nisi quod distinctionem et quasi oppositionem temporum indicent, hand perspicio. Sic optime poeta pucrum natu minorem, Medeam adultam esse, monstrat. Contra, parum apte adiuncta essent temporalia atque otiosa, si in verbis nihil est nisi una sententia filium ex Nereide, Nereidem antem ex Idyia procreatam esse.

Iam ad illam inter scholia et Homerum comparationem

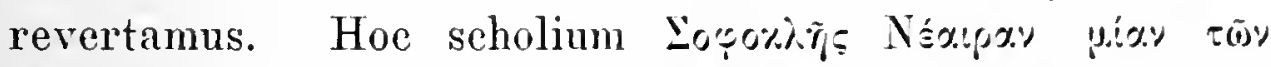

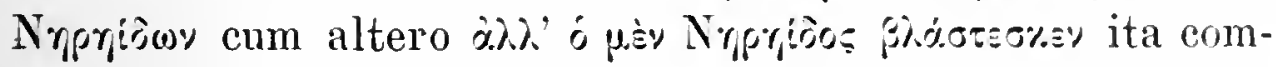
ponere licet ut in dubio esse non possit quin apud Sophoclem Neaera mater Aeetae filii fuerit. At apud Homerum Neaera Phaethusam peperit. Si mater Phaethusae est, cur non etiam Phaethontis? Vis argumenti in eo potissimum inest quod Neaera aut ex Sole aut ex Solis filio liberos peperit. Sed de Sophocle satis.

Nunc ad istam nominis differentiam unde hue digressi sumus, revertamur. Vidimus filium Aeetae modo nomen Apsyrtum aut Axyrtum, modo Phaethontem, tum Metapontium, denique nomen nullum tulisse. Sed alia memoria eaque satis vetusta, exstat. Primum Diodorus, loco paulo ante citato (IV 45), non solum Circen Medeamque sed etiam filium Aeetae, qui nomen Aegialeum tulerit, Hecaten peperisse tradit. Tum Cicero in libro de Natura Deorum $(3,48)$ sic seripsit: quid Medeae respondcbis, quae duobus aris, Sole et Oceano, Aeeta patre, matrc Idyia procreata est? Quid hu-

1) Th. Bergkius, qui verba in versus iambicos redigere conatus est, Index lect. Marb. 1843, iry 'o' recepit, quod aliter fieri non potuit, quoniam scholia Laurentiaua nondum divulgata erant. Nauckius in fragmentis recenseudis Laurentiani auctoritati oboediens, $i_{y}$ posuit, ita tamen ut alteram scripturam commemoraret et secunda cura haud spernere videretur. 
ius: Absyrti fratri; qui est ayud Pacuvium Acgialcus? Sca illud nomen veterum literis usitatius. Itaque unum nomen Aegialeum proferelant Diony sius Milesius vel Scytobrachion et Pacurius. Tertius est Iustinus, Trogi Pompei historiae epitomator, qui de Iasone haee tradidit $(42,3,1)$ : ct filiom cius abluxerut et filium Aegialeum interfecerat.

Hac tanta nominum varictate iam ante oculos posita multo magis liquet quod paulo ante de iis enuntiavi. Nam nomen pueri qui crudeliter a sorore dilaniatur, primo minoris momenti fuisse, vix denegaveris. Atque cum prisca et retusta fabula aut hoc aut illud nomen admitteret aut nomen omnino tacere posset, non mirum est quod scriptores inter se differebant, neque quod nomen, quando additum est, cum appellatione regionis cuiuspiam coniungebatur. Optima enim occasio nominis barbari explicandi ita dabatur. Et primum urbs Tomi in oris Ponti Euxini occidentalibus sita, vulgi sermone eo loco collocata est ubi Aectes disiecta filii membra sepelivit $\left.{ }^{1}\right)$. Hic habes narratiunculam, in qua puer et nomine caret atque causam nominis praebet. Cetera quidem nomina, quamquam hanc opinionem exemplis confirmare nequeo, non dubito quin eodem studio veriloquia excogitandi explicari possint. De Metapontio iam egit Welckerus Gr. Trag. pag. 1045. Etiam Aegialeus qui est litorulis huc spectat"). Sed in hoc genere princeps est Apollonius qui Apsyrti mortem in sinnm Adriaticum transtulit. Antequam autem ad quaestionem de fontibus aggredior, restat illud de nomine Apsyrto unde natum sit. Nam supra vidimus nulla certa ratione hoc scriptoribns vetustioribus tribui posse.

Knaackins quidem Quacst. Phact. pagg. 15-16 "dyporos a nomine barbaro "A'vopos formatum esse statuit, auctori-

1) cf. Apollodori Bibl. I 132 (Wag.). Stepl. Byz. s. v. 'Touźs. Ovidii Trist. III $9,33$.

2) Quod nomen neque Pacuvium neque poetam tragicum quem se-

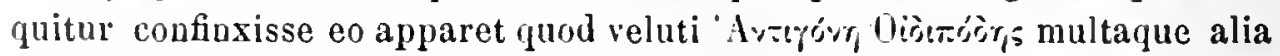
parun in trimetrum, optime in hexametrum convenit. Fieri igitur potest ut haec appellatio ad carmen epicum redeat et perretusta sit. 
tate Arriani Peripl. Pont. Eux. c. 7 potissimum ut videtur

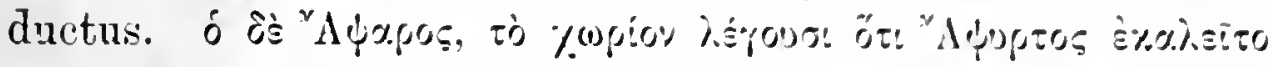

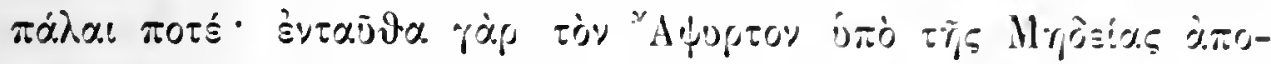

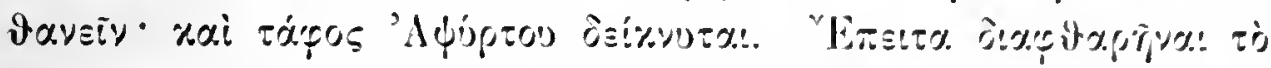

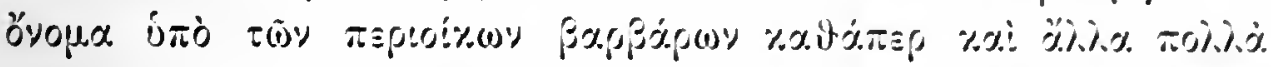

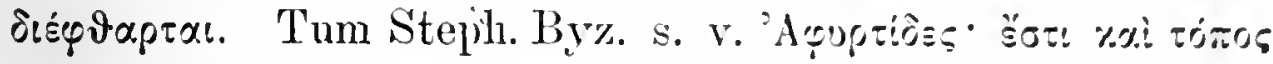

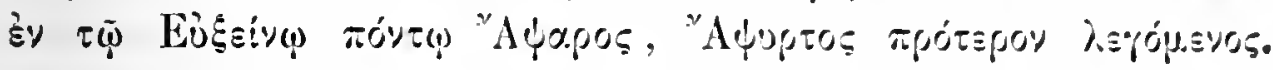
Quibus testimoniis si fidem damus, nomen Apsyrtum et vetustum et in regionibus Ponticis urtum esse efficitur. Sed vereor ut haec explicatio defendi possit. Nam Arrianus res duas valde dissimiles composuit. Multo quidem graviora sunt haec de nomine quam illa appellationis causa. Nune quod ad Apsari vocem attinet, hand paulum adiuvat Scylax, qui in regionibus circa Phasin percensendis idem

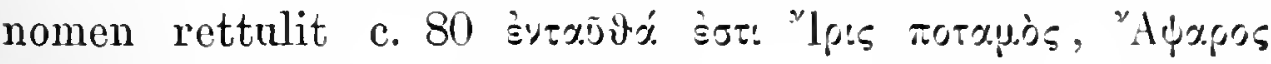
rozquós. Exstabat igitur nomen Apsarus iam saeculo ante Christum quarto fluvio non procul a Colchide tributum. Quae cum ita sint, opinio vel Arriani vel geographi quem sequitur, qui Apsyrtum appellationem priscam postea a barbaris in Apsarum corruptam esse assererat, haud probabilis videtur. Ut concedamus incolas sepulcrum Apsyrti ostendisse, ita ratio rei explicandae quae apud reteres in talibus nimis credulos valebat minime probatur. Censeo igitur pristinum ac vetustum nomen Apsarum fuisse, quod temporibus recentibus cum fabula de Apsyrti morte coniungebatur. Itaque haec mentio nominis ad rem declarandam nihil proficit, neque ullum omnino exemplum ante Apollonii aetatem nisi apud Lycophronem inveni, rs. 811

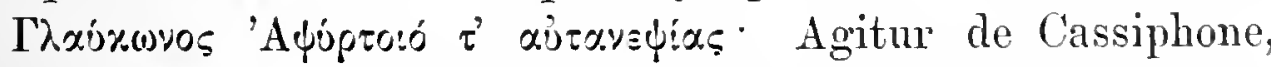
Ulixis et Circes filia, quae fratrem 'l'elemachum occidit. Cassiphone quae Solem arum habuit, est Apsyrti et Glauconis, qui item genus ex Sole ducunt, consobrina. Hac brevi mentione facta poeta tacet. Sed consensus inter Lycophronem et Apollonium suspicionem hane nominis formam in mari Adria ortam esse movet. Quanta enim Lycophro Timaeo et aliis scriptoribus qui potissimum de rebus et fabulis ad Italiam Adriam mare Tyrrhenum per- 
tinentibus egerunt deberet, Guentherns acumine et diligentia exposuit.

In fontibus Apollonii exquirendis haud scio an longius procedere non possimus. Rem vero si non in singulis depingere, at quasi lineis extremis designare posse mili videor. Nam primum nulla memória nominis Apsyrti Apollonio multo retustior suppeditat; tum insulae Apsyrtides, quae causam nominis pracbuerunt, in intima Adria revera exstiterunt, neque probabilis ea ratio videtur ut insularum appellatio recentior habeatur, sed contraria potius. Quamobrem haee narratiuncula de Apsyrto non ex illa fabularum copia quae in Ponto et circa Propontidem orta sunt sed ex his parum notis et dirulgatis profluxit, quae ad regiones occidentales spectant.

\section{VII.}

\section{DE APOLLODORI BIBLIOTHECAE LIBRO I 132-138 ET HYGINI FABVLA XXIII.}

Quorum auctoritatem Apollonius in iis quae sunt de Argonautis et Colchis in Adria errantibus amplexus sit, nondum satis compertum est neque in tanta subsidiorum inopia aut incitamentum ad judustriam aut spem fructus laboris capiendi inveneris. Fieri sane potest ut recentiores qui de Argonauticis egerint, memoriam aliquam Apollonio vetustiorem et fortasse ab illo in suos libros receptam praebeant. Atque revera ab hac parte rem aggreditur Wernicke ${ }^{1}$ ) cum contendat harum rerum versiones exstitisse duas, quarum unam Apullonius in universum secutus sit, altera in Hygini fabula XXIII reperiatur; Apollonium autem etiam hanc respexisse.

Iam quaestio statim se offert quatenus Apollonius memoriam litterarum apud posteriores quasi definierit ac constituerit, quatenus alia praevaluerint. Quibus de rebus in

1) Pauly et Wissowa Real.-Enc. s. v. Apsyrtus. 
universum ne verbo quidem opus est. Sed in singulis quaestio versatur, praesertim cum Wernicke in faluula $\mathrm{Hy}$ gini XXIII memoriam Apollonio rel retustiorem exstare statuerit.

Primum autem totam materiam ante oculos proponam. Habemus nonnulla in Apollodori Bibliotleca, tum $\mathrm{Hyg}_{\text {yini }}$ fabulam unam, deinde Orphei (quem vocamus) Argonatica, denique apud diversos singula. Et primm quae Plinius N. H. III 151, Strabo VU 315, Steph. By\%. s. v. 'A'spt'$\delta \lesssim \varsigma$ habent, ex Apollonio plane pendent, neque aliter de Orphicis indicandum est. Quomodo Valerius Flaccus rem formaverit, ex illis quae supersunt non satis apparet. Sed de fonte Apollonio retustiore in eis quae de Apsyorto protulit, ne cogitare quidem licet. Paulo aliter in Bibliotheca res se habet. Quamquam plurima quae de Argomautis smont ex Apollonio profluxerunt ${ }^{1}$ ), tamen etiam alia memoria hic subest.' Sub finem enim cap. 132 novum incipit al, his

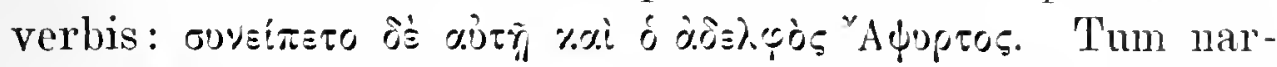
ratur Medeam ut patrem persequentem retardaret, fratrem trucidasse et membra dissipasse; quo factum esse ut Acetes a persecutione desistens membris filii collectis et in sepulcro conditis regionem Tomos appellaret. Enuntiatio quae

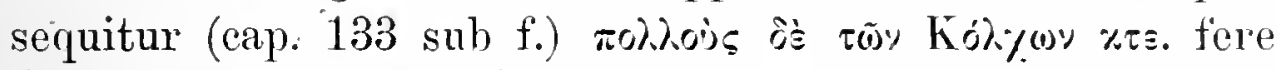
ipsa Apollonii verba (IV 231 seqq.) reddit. Tum pancis (capp. 134-136) congesta sunt ea quae Apollonius versibus pluribus quam quingentis expressit. Mentio itineris per. Histrum ominino non fit neque amisso carmine Apolloniano quomodo via in mare Sardoum facta esset intellegeremus. Ubique quidem apparent restigia alicuius qui in rebus maxime geographicis narrationem nberiorem dedita opera contraxit. Sed ne opineris hacc aliunde desumpta esse, observes quanta diligentia ordo ac progressus rerum retineantur, cum deinceps de ira Iovis, de Celtis et Lignribus, de Circe, de reliquo usque ad Phaeaciam itinere agatur. Accedit quod morte Apsyrti alio modo narrata

1) Quod iamdiu perspexit et demonstravit Robertus. 
omnia quac Apollonius de caede eius in insula profert necessario omittuntur. Atque cum illa de Colchis in insulis circa Illyrian et Ceramios montes domicilia collocantibus compilator practermittere nollet, rem tam breviter comprehendit') ut oratio parum accurate verbis Apollonianis respondeat. Sunt igitnr in his quae de reditu heroum afferuntur.sane varia ac dissimilia, sed adeo in unum redacta ut totius narrationis fundamentum carmen Apollonianum fuerit. Illud alterum de Apsyrto Tomis sepulto haud probabile est poetae nobili vel tragico vel elegiaco tribui posse, cum solum veriloquium oppidi respiciat. De quibus utut indicas, nihil ad Apollonii fontes aperiendos efficitur.

Iam ad Hygini fabulam 23 aggrediamur, in qua multis in rebus mirus cum Apollonianis consensus est. Appellunt enim naves cum fugientium tum persequentium ad Alcinoi urbem, qui arbiter litis constituitur. Tum Aretae calliditate nuptiis Iasonis et Medeae occulte effectis, Alcinous proximo die Medeam Colchis non esse tradendam diudicat. Sed narratio Hygini eo discrepat quod Apsyrtus dux Colchorum arbitrio regis neglecto Argonantas usque ad Minervae insulam insectatur ibique interficitur. Deinde cum Apollonius duos Cochorum exercitus, quorum alterius dux Apsyrtus est, et iter per Histrum factum habeat, compilator fabulae unum exercitum, cui Apsyrtus praeest, novit neque quidquam de reditus ratione profert. Quaerimus igitur utrum in his forma fabulae ceteroquin ignota lateat, vel fortasse ut Welckerus coniecit ${ }^{2}$ ) argumentum tragoediae cuiuspiam, utique memoria Apollonio quidem vetustior, an contra excerpta a grammatico facta quae nullum alium fontem atque carmen Apollonianum habeant. Sed res non tam recondita est ut nos diu vexet, quoniam ex indiciis quae verba ipsa suppeditant, compilatorem praeter

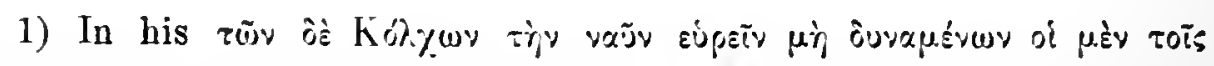

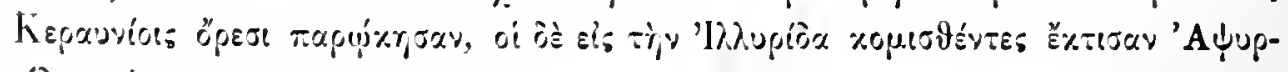
тíjas v'rjous xte.

2) Gr. Trag. 339 seq. 
Apollonium seriptorem ullum adhibuisse iure denegari potest. Primum autem monendum est phurima quate in his fabulis de Argonantis tradita sunt proeul dubio, ita ut in Bibliotheca Apollodori, ex carmine Apollonii manasse. Cuius rei exemplo sunt quate de Hyla rapto, de Tiphye et Idmone apud Lycum, Eribote et Cantho in Libya morientibus (fab. 14) relata sunt, tum potissimum fab. 16, 17, 18, $20,21,22$. Deinde fab. 23 ctiam in singulis vestigia poctae aperit. Conferas ibidem se iudicem sumptum a duchus diversis civilatilus, inter Colchos et Argivos cun Argonauticis IV 1074 seqq. Sed fortasse interrogabis qui explicandum sit quod in nonuullis distent compilator et poeta. Credo etiam hoc non esse inexplicabile. Nam animadvertimus compilatorem historiam de itinere per Histrum facto prorsus neglexisse: eandem conditor Bibliothecae silentio practermisit, tamen vestigia pristinae narrationis non penitus delevit. Opinionem diu pervulgatam de Histro ctiam Adriam petente his recentibus temporibus quibus Hygini fabulate ortae sunt, esse abiectam, satis constat. Si igitur animo informanus grammaticum discipulis historiam narrare rolnisse ita ut et Apollonium sequeretur et veritati tunc temporis vel pueris notae satis faceret, aliter vix poterat rem instituere atque factum ridemus in fabula Hygini. Itaque mirifica eorum opinione supersedemus qui scriptorem aliquem Apollonio superiorem ea quae Hygini propria sunt protulisse contendunt. Nam quod Argonantae Corcyra relicta ad septemtriones cursum dirigunt prorsus mirabile est, neque alibi reperitur neque causam ac rationem ullam habet. Qualia cum apud Hyginum revera tradantur, iudicandum est ingenio magis compilatoris quam poetae nobilis deberi. Vides igitur nos ne ex his quidem de Apollonii fontibus quidquam comperiri posse. 


\section{VIII.}

\section{DE SCHOLIIS RECENSENDIS.}

Cum disputatio mea haud raro in scholiis interpretandis rersata sịt, quaestio saepins se obtulit quid verum recensionis findamentum esset. Gravis quidem est quilestio necque sperare andeo me rem statim and finem perducere posse. Sed tamen nomnulla exempla composui quae ostendant rem aliter se habere ac viri docti Keiliana editione confidentes fere credunt. Ut primum manifestum fiat qualis sit quaestio, pancis de scholiorum memoria agam. Amo saeculi XV. nonagesimo sexto Florentiae primum typis expressa sunt Argonautica Apollonii cum scholiis, quam editionem curarit Ioannes Lascaris. Saeculo sequenti Henricus Stephanus editionem scholiis ex hoc fonte adiectis protulit. Hace igitur scholia din circumferebantur neque alius fons cognitus erat. Tum Ruhnkenius e codice Parisino 2727 varias quastam lectiones enotarit tota huius codicis memoria nondum edita. Apographum integrum scholiorum Parisinorum primus Schaeferus in nova cura editionis Brunckianae publici iuris fecit ${ }^{1}$ ). A quo tempore viri docti duabus scholiorum recensionibus utebantur. Denique anno huius saeculi LIV. Henricus Keil codice Laurentiano XXXII 9 diligenter collato scholia denuo edidit, ea autem ratione usus ut testimonio editionis Florentinae et codicis Parisini prorsus abiecto, fundamentum unum recensionis codicem Laurentianum poneret. Sibi enim persuasit unum omnium fontem exstare Laurentianum codicem XXXII 9 neque alio praterea libro horum scholiorum memoriam ad nostram aetatem propregatum esse ${ }^{2}$ ); Florentina quidem et Parisina communem fontem habere, qui vero non sit ipse Laurentianus sed apographum quoddam valde interpolatum ${ }^{3}$ ); nihil
1) Lipsiae 1813.
2) Praefationis pag. 299.
3) cf. ibidem p. 300. 
igitur novi in Florentinis et Parisinis exstare praeter recentia nullaque omnino fide digna.

Ex his igitur quae Keilius in pratefatione editionis uberius exposuit stemma sic constituas:

\section{Laur.}

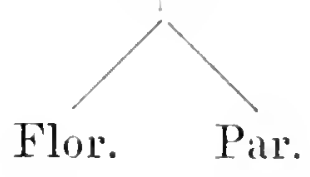

Et tanta quidem fuit eins auctoritas vel potins tinta est codicis Laurentiani praestantia, ut ceteris posthabitis viri docti hune solum librum in seholiis usurpandis evolvere soleant.

Sed tamen Keilii sententia fundamentem recensionis in uno Laurentiano positum esse interdum oppugnabatur, ut videbis si Bergkii adnotationes velut ad Pindari fgm. 167, Wilamowitzii Heraclem² II 132 adn., Lnetkii Phere.

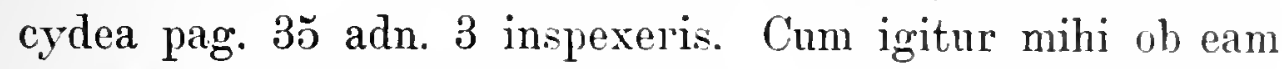
cansam plerumque Laurentiana cum Parisinis et Florentimis conferenti, eadem dubitatio se obtulerit, par est ut Laurentianum non esse solum fontem scholiorum pancis exemplis confirmem.

Ac primum quidem in multis reddendis quae in Lanrentiano desunt Florentina et Parisina consentire, Keilinm minime fugit. Denegarit autem talia ullius momenti esse aut ex memoria scholiorum vetere profluxisse. Illa exempla (praef. pag. 300) quibus opinionem corroborare studebat, sane ad persuasionem aptissima sunt. Sed rana est argumentatio viri docti eo quod ista exempla nequaquam ad veram rei imaginem animo reddendam sufficiunt. Sunt enim diversitates hand paucae quae notam neque interpolatoris neque aetatis recentioris prae se ferunt. Cum igitur Keilins Laurentianum memoriae reliquorum scholiorum esse parentem posuerit, locos aliquot ubi Florentina et Parisina recensionem ostendunt et pleniorem et meliorem afferam. Primum memoriam duplicem scholiorum ad IV 308 inspiciamus: 
I. a a r r.

Flor.

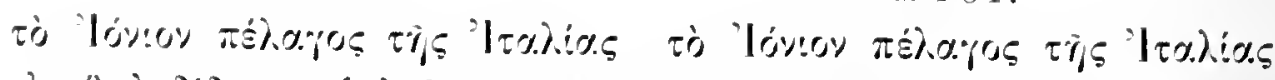

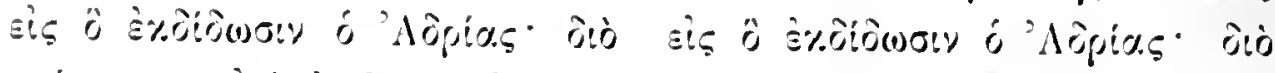

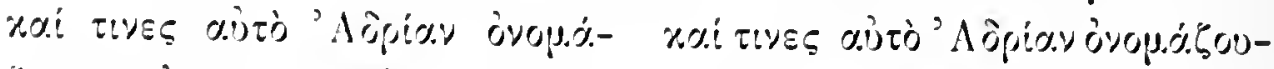

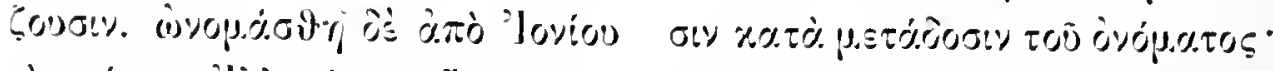

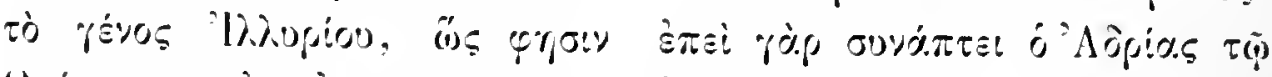

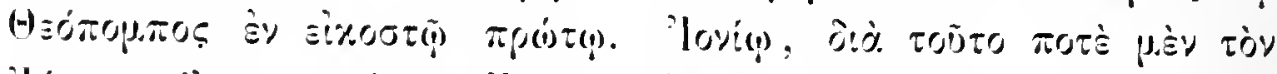

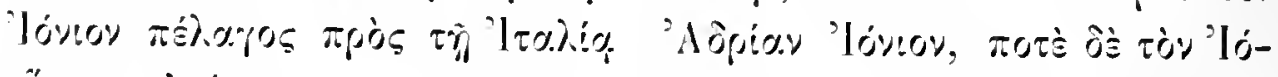

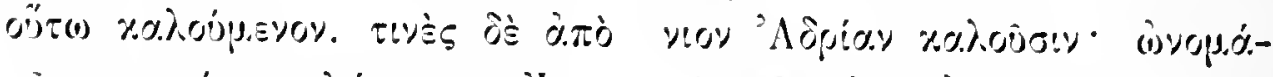

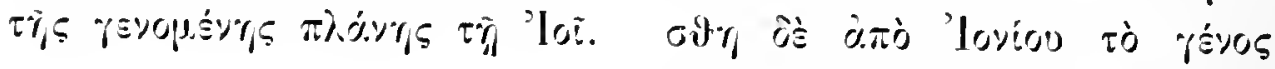

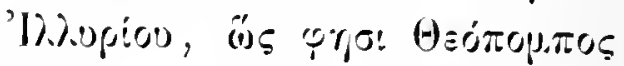

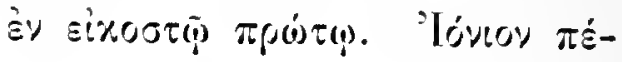

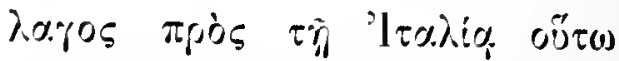

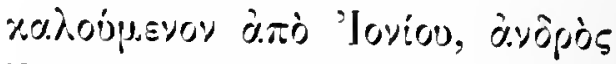

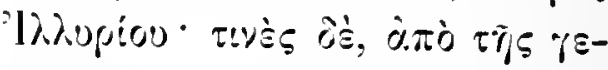

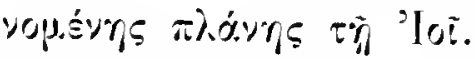

Utrumeumque testem audis, duas adnotationes in unum coniunetas habes. Bis enim de mari Ionio agitur, ubi situm sit, eur hanc appellationem ferat. Unde a verbis

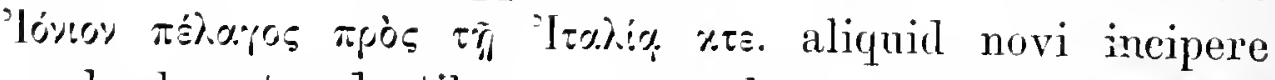
quod ab antecedentibus non pendeat, ex ipsa verbortim sententia concludere licet, atque illud 'lóvoov $\pi \dot{\varepsilon} \lambda$ aros, sine ulla particula positum, eadem denuntiat. Quae cum ita sint, mili facile concedes integram memoriam in Florentinis servari. Nam haee altera scholii pars duo veriloquia

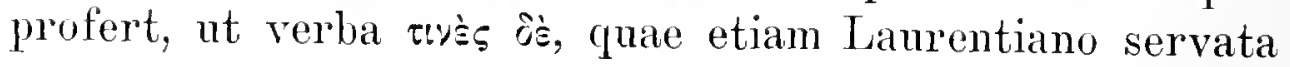
sunt, maxime deelarant. Is qui scholia Laurentiana confecit, eum paulo ante primam nominis explicationem legeret, verborum contextum adeo decurtavit ut sine ope libri Florentini pristinam orationem vix quisquam cogniturus fuerit.

Tum confer scholia ad IV 611.

Laur.

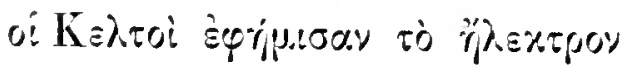

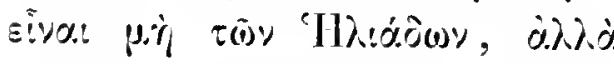

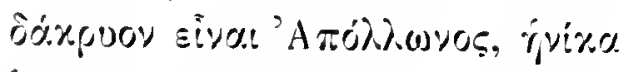

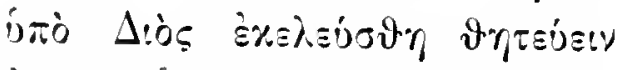

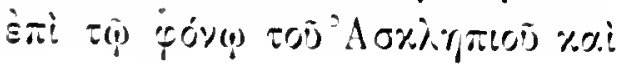

Flor.

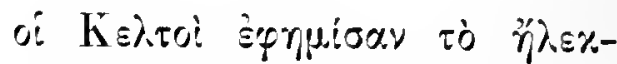

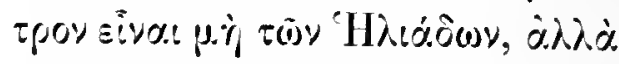

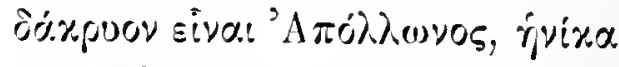

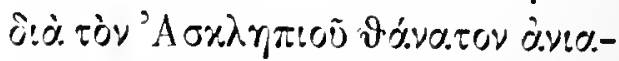
V)is sis tojs 'Tipepopécous àpi- 
$\tau(\bar{\varphi}) \tau(\tilde{)}) \mathrm{K} v \gamma_{\lambda}(\dot{\omega} \pi(\omega) \%$

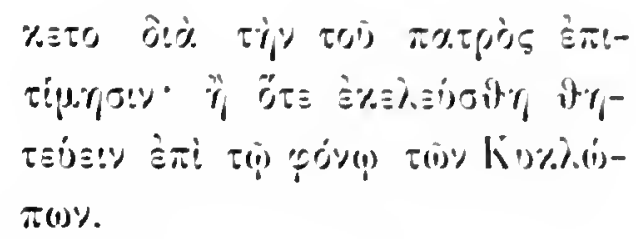

Parisinus quoque uberius seholium habet, in singulis vocibus discrepans.

Iam plane confusum est scholium Lanpentianum. Ne verba quidem poetae aceurate exprimuntur neque res duae quae inter se differunt recte distingumntur. Unum enim est fabulosa Celtarum historia quam Apollonius nescio e quo fonte petierit: alterum autem est istud de Apolline propter Cyelopas interfectos apud Admetum serviente (cs: schol. in Enr. Alc. 1). Enucleate et aptissine Florentina rem exprimunt, quae praestantia interpolatori haud probabiliter tribui potest.

Sub finem scholii in IV 280 Flor. et Par. haec ha-

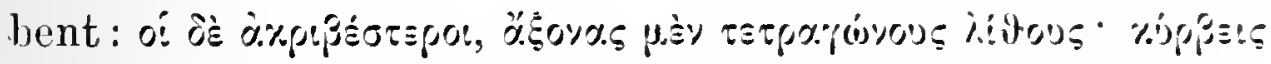

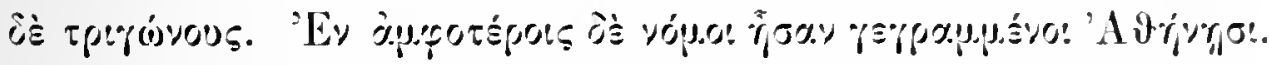

Ad finem scholii in IV 627 Flor. et Par. addunt $\tau$

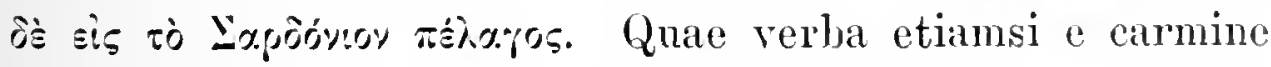
orta esse possunt; tamen necessaria et procul dubio pristini verborum contextus sunt.

IV 984. Complura declarant scholia Florentina hie praestare. Et primum vides in Laurentiano nonnulla post nomen Scheriae explieatum intercidisse (apud Keilium pag. 512, 26). Quae enim secuntur in causa nominis Drepanae exponenda versantur. Sic igitur ex Florentinis la-

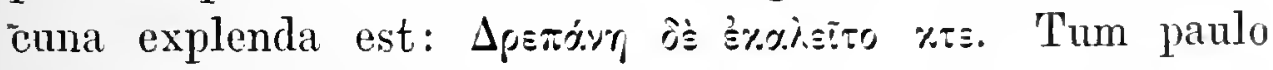

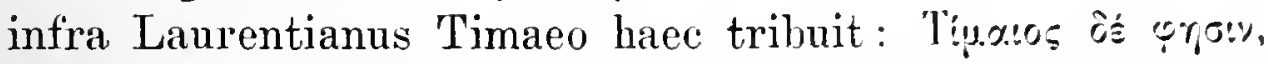

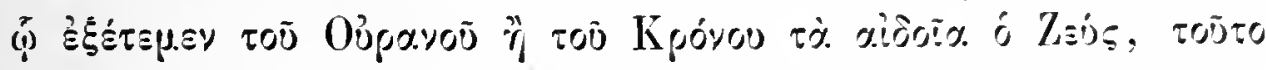
xहxpóp̧qa. Hesiodus primus (Theog. 164 seqq.) Caelum a Saturno exsectum esse narravit. Ecquis autem tradidit Caelo vim adhibuisse Iovem? Mrulto meliora in Floren-

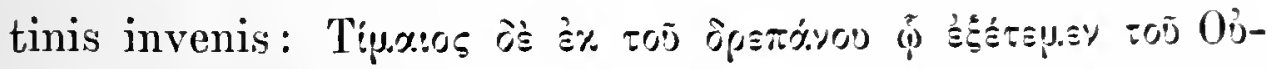

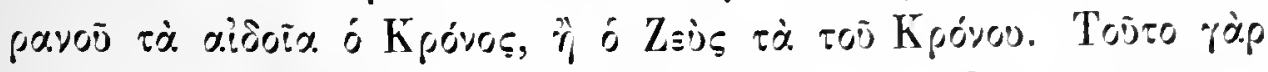

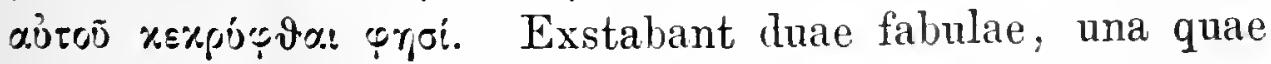
est apud Hesiodum et bene nota, altera multo obscurior. 
Porphrins de Antro N!mmliarum Cap. XVI ipsis verbis Thengoniae Orphicae allatis Iovem Saturnum ope Terrae consopitum exsecuisse tradidit. Adde etiam Aristidis testimonium I 35 Dind. Lobeckius Aglaopl\%. I 516 qui una scholia Florentina ante oculos habuit, Timaeum utramque fabulam respexisse recte iudicavit. Sub finem haec in Flo-

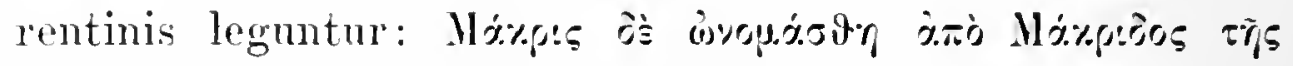

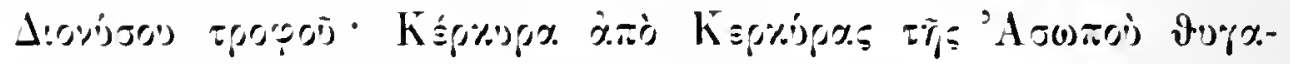

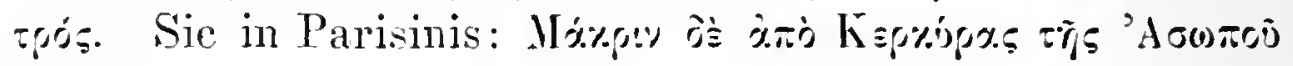
intropos

Haee ex Apollonio non esse repetita eo apparet quod ipse in versu huins libri 566 hanc causam nominis insulae Corcyrae Nigrae protulit. Vide antem Hellanici testimo-

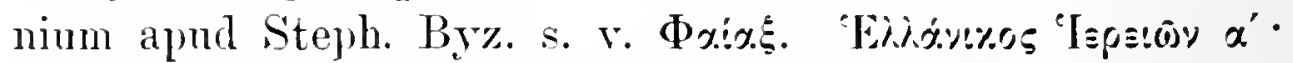

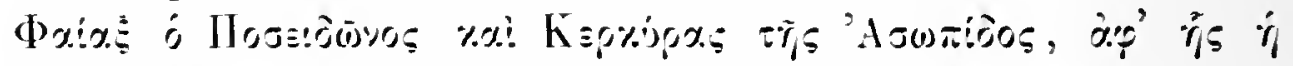

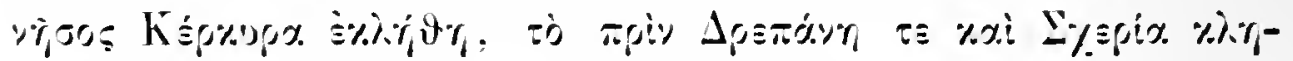

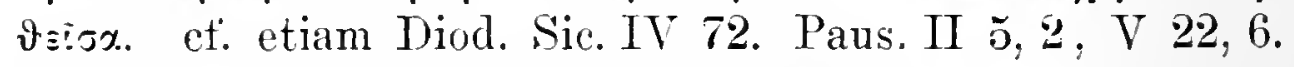
Haec igitur pristinis scholiis vindicaverim.

IV 1216.

$\mathrm{L}$ a $\mathrm{r}$.

Flor.

... j.

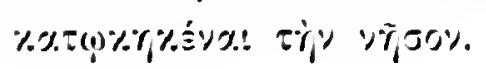

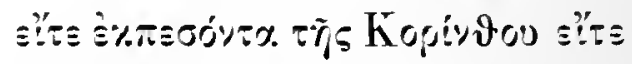

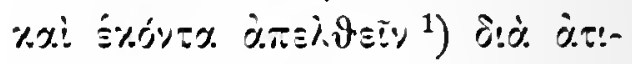

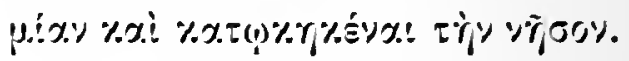

Quaestio quidem gravis est cum ad Timaei sententiam pertineat. Vides Florentina et Parisina ut verbis discrepare ita Laurentianum non esse fontem communem monstrare. Tum observes quaeso sententiam quam Laurentia-

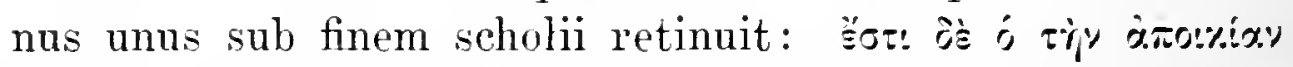
$\% \tau \Sigma^{2}$ ). Elncet igitur neque Laurentianum neque ceteros

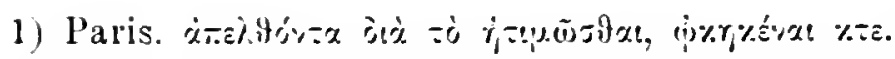

2) Quae sententia non intellego quo iure ad Timaeum referri pos-

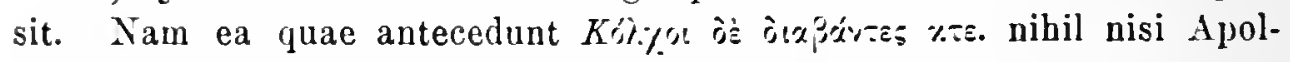
lonii sententiam reddere videntur. Keilius tamen omnia quasi arte coniungenda et ipsius Timaei rerba signis inclusit: sed perperam. Neque credo Muellerum iure haec inter Timaei verba recepisse. (Fr. Hist. Graec. I frag. 53). 


\section{- T⿱宀八}

ubique integram memoriam pracbere, sed modo illum modo hos fide digniores esse.

\section{1217.}

Is a ur.

Flor.

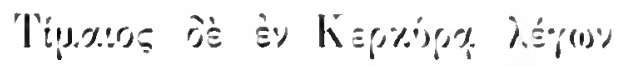

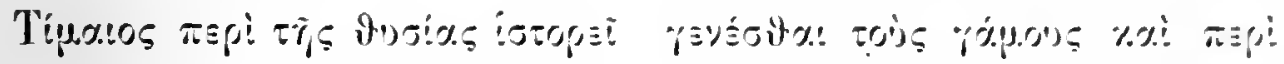

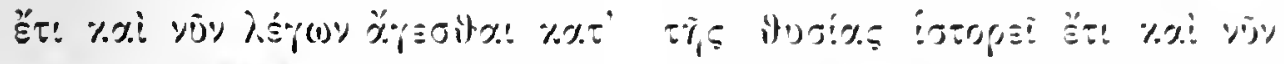

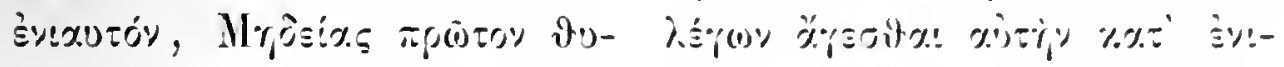

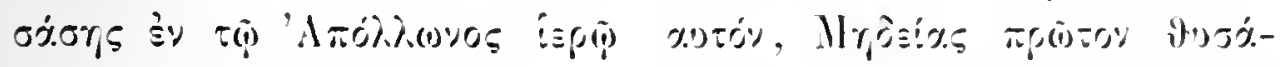

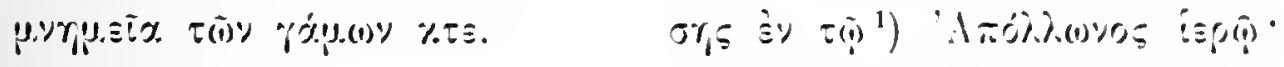

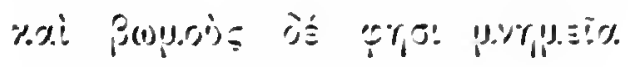

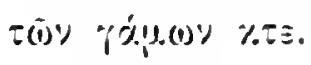

Iterum Flor. et Par. memoriam uberiorem atyue nnea sententia integram praebent. Talis enim ratio inter testes intercedit ut in his pristinus verborum contextus, in Laurentiano contra contractus ae mutilatus inveniatur. Nam generis dicendi scholiorum proprium est, sententia nori auctoris allata, particulam $\partial \dot{s}$ nomini subiungere. Integra

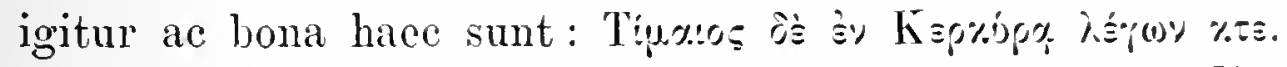
Scriptor autem Laurentiani brevitatis ut ridetur studiosus, cum fere eadem de Timaeo panlu ante ad versum 1153 adscripsisset, hic orationem nimis contraxit. Etiam rerlua

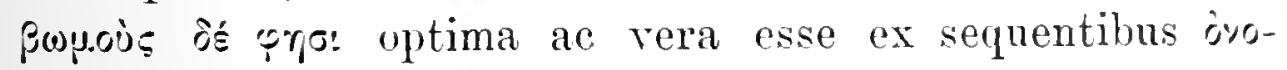

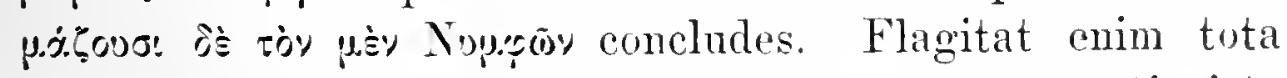
oratio nomen pousos, ut putissimnm docet comparatio ista cum Apollonio, qui etiam has aras commemoravit ${ }^{2}$ ).

IV 1515. Legimus in Laur. (apud Keilium pag. 526,

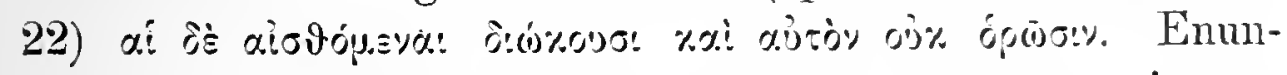
tiatio quidem, quod ad sensum attinet, obscura ac imper-

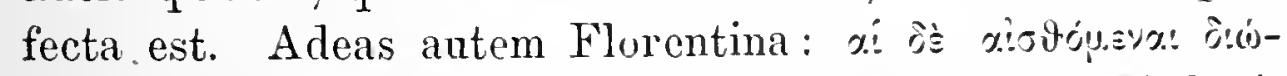

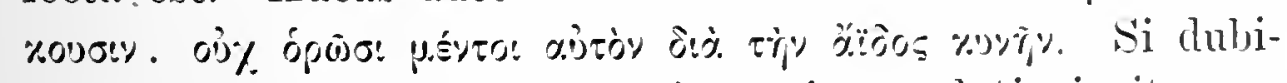
tes utrum in his pristina oratio an interpolatio insit, confer universum scholium cum Apollod. Bibl. Il 36-42, haec maxime verba respiciens: (c. 42 sub finem) di $z$ Iop-

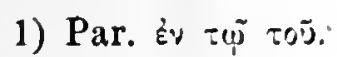

2). IV 1219 . 
ชơ

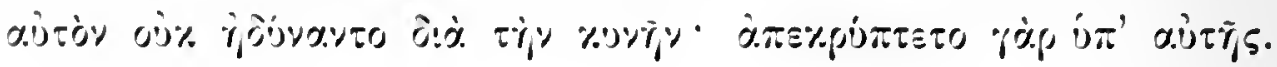
IV 1780.

La $11 \mathrm{r}$. Flor.

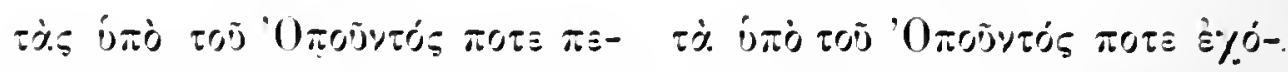

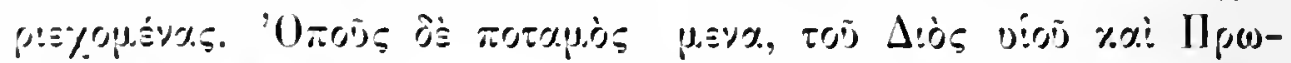

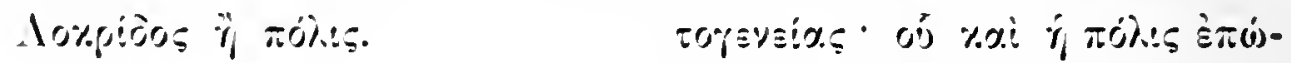

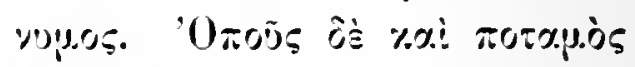
Ioxpioses.

In Parisinis eadem menoria atque in Flor. exstat, verbis mutatis.

Haec exempla melioris memoriae in Florentinis et Parisinis habeo quae dubio vix obnoxia esse censeam. Quaestionem cum gravem tum intricatam quod longius persequi nequeo aegre fero. Etiam scholia ad libros I-III adscripta, quamquam eadem diligentia atque haec nondum pervestigavi, tamen memoriam habere duplicem asseverare andeo. Quare in calce huius commentationis Bergkii sententiam quasi summam rei et conclusionem repetam: scholia in Apollonium non possunt solius Leurentiani auctoritate in integrum restitui.

\section{AD CALLIMACHEA ADDENDVN.}

Dum typis exprimuntur ea quae sunt de Callimacho, commentationem Eugenii Dittrich in supplemento XXIlI. Annalium philologicorum modo editam inspexi. Qui cum Callimachi Aetiorum libro I tractato etiam scholia Apolloniana in IV 284, 303 emendare conatus sit (pag. 191 seq.), par est pauca addere. Suspicor eum qui haec scripsit (pag. 192) putet dilucidissime cosdem qui Apollonio auctore (IV 303) per Cyaneas petras navigaverant frustra quaerentes domum redierunt, Callimacho contraria testato Argonautus in Scheria occurrisse, Apollonii librum quartum nimis neglegenter legisse. Nam neque Apollonio neque Callimacho 
anctore Colchi domum redierunt. Cum igitur summa totius rei Dittrichium fugeret, perspicere non poterat quibus de rebus poetae contraria testati essent. Do seholii IV 284 distinguendo et intellegendo, non video cur plura dieam. Videant periti uter nostrum propius ad veritatem accesscrit. 


\section{Vita.}

Nitus sum Edvardus Fitch Waltoniae in oppido Novi Eboraci civitatis Americanae ante diem VI. kal. Jun. a. h. s. LXIV. patre Georgio, matre Harriet e gente Sinclair. Rudimentis litterarum in seholis Waltonianis instructus per quattuor ammos Collegium Hamiltonense frequentavi, et curriculo disciplinarum permenso ante diem VI. non. Iul. a. h. s. LXXXVI. baccalanreum artium liberalium curatores Hamiltonenses me renuntiaverunt. Deinde per annos tres discipulos Collegii Parcensis Missouriensis elementis litterarum Graecarum Romanarumque et historiae Anglicae ipse tiro pro viribus imbui. Tum in Collegium Hamiltonense reversus Edvardum North, olim pracceptorem meum maxime renerandum et professores Hopkins et Brandt in docendi munere fungendo adiuri. Mense Iulio a. h. s. XCIII ut artem ac disciplinam philologicam diligentius colerem me in Germaniam contuli, ubi ineunte semestri hiberno inter cives academicos Georgiae Angustae receptus sum.

Docuerunt me viri docti Bechtel (nune Halensis), Dilthey, Kielhorn, Leo, Schulze, Volquardsen, WilamowitzMoellendorff. Ad exercitationes archaeologicas Dilthey, historicas Volquardsen, Indicas Kielhorn, grammaticas Bechtel benigne aditum mihi permiserunt. Per bis sex menses regii philologorum proseminarii, regii seminarii per ter sex menses moderantibus Wilamowitzio et Leone sodalis ordinarius fui.

Quanta benevolentia eum professores tum sodales me peregrinum atque hospitem receperint et in sacra philologiae admiserint, semper grata memoria tenebo. Imprimis Udalrico de Wilamowitz-Moellendorff qui me ad hanc dissertatiunculam conficiendam incitavit et semper consilio suo adiuvit, tum Carolo Dilthey et Friderico Leo, egregiis monumentorum antiquorum interpretibus, gratias ago pio gratoque animo quam maximas. 

BL

820

A3F5
Fitch, Eduardus

De Argonautamum reditu quaestiones selectre

PLEASE DO NOT REMOVE SLIPS FROM THIS POCKET

\section{UNIVERSITY OF TORONTO}

\section{LIBRARY}


